\title{
Westland petrel (Procellaria westlandica) foraging behaviour: Patterns and drivers of individual variation
}

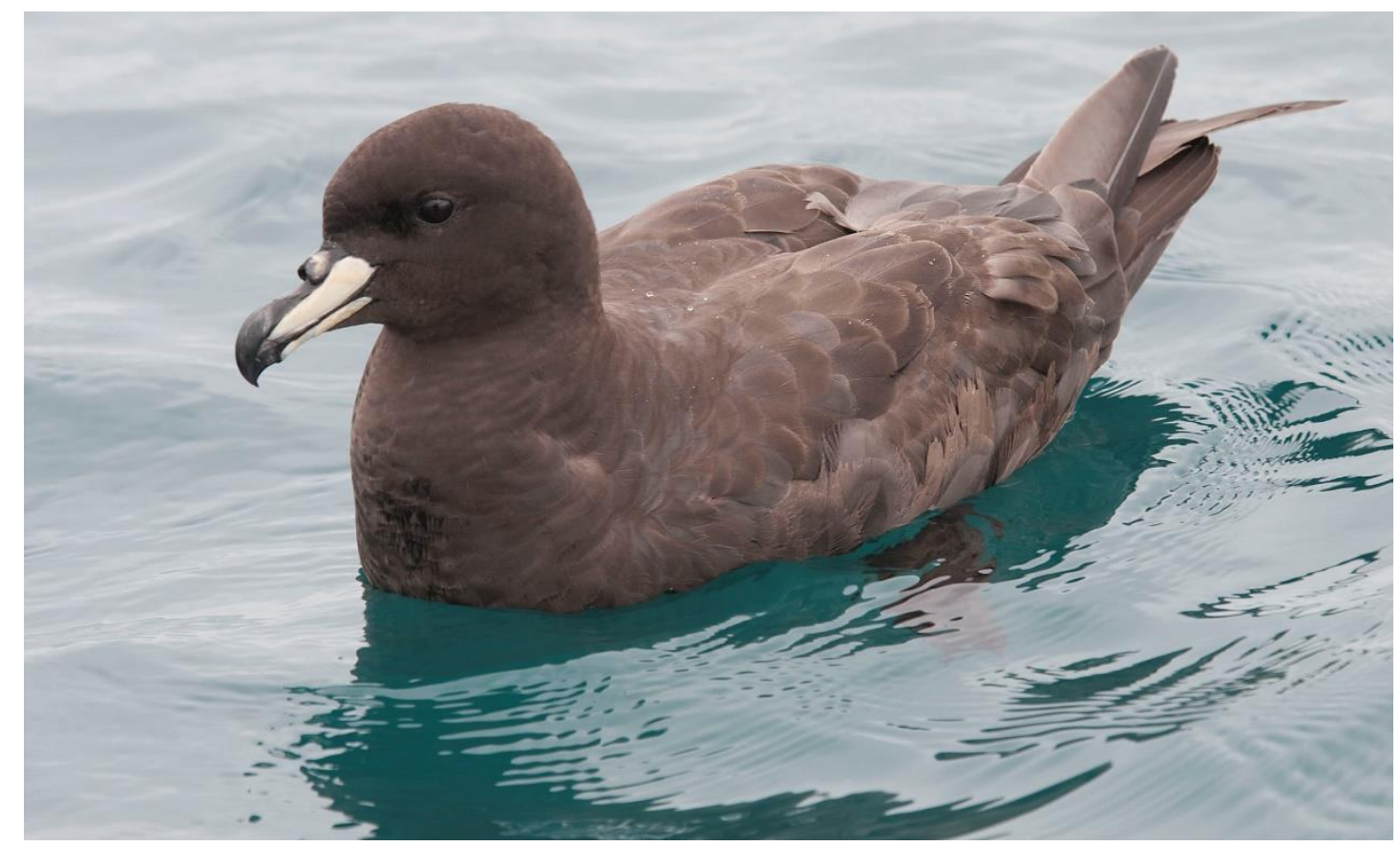

Westland petrel (Procellaria westlandica) sitting on the water, Kaikoura 2013. Photo credit: (C Philip Griffin

\section{Douglas Richard Dott Rands}

\author{
A thesis submitted to Victoria University of Wellington \\ in partial fulfilment of the requirements for the degree of \\ Master of Science in Ecology and Biodiversity
}





\begin{abstract}
Foraging behaviour can have a major influence on the survival and reproduction of individuals which can ultimately impact the viability of a population. Foraging is particularly challenging for procellariiformes (tube nosed seabirds) who feed on patchily distributed prey in the highly dynamic marine environment. During the breeding season procellariiformes must also increase their foraging effort to raise their chick whilst having a reduced foraging range. As a result, procellariiformes have adopted various foraging strategies, such as dual foraging and sexual foraging dimorphism, to cope with this energy demanding lifestyle. Westland petrels (Procellaria westlandica) are an endangered winter breeding procellariform endemic to the West Coast of New Zealand's South Island. Unlike other procellariiformes, previous studies have found little evidence of Westland petrels using sexually dimorphic or dual foraging strategies. Furthermore, Westland petrels also display a high level of individual variation in foraging behaviour. To understand why there is so much variation and what factors are driving it, I first examined variation at the population, individual and within individual level to describe and categorise different foraging strategies. I then investigated how factors such as year, sex and foraging site influenced variation. Finally, I examined how oceanic variables influenced habitat selection and foraging characteristics to understand how the environment drives variation in foraging behaviour.
\end{abstract}

Considerable variation was found at all levels. Most of the variation was explained by year with individuals taking shorter foraging trips in 2011 and longer trips in 2015. Females foraged further than males suggesting that there is some degree of sexual foraging segregation occurring in Westland petrels. I also found that the highest variation in foraging behaviour was exhibited by individuals within their core foraging site on the West Coast. Sea surface temperatures were highest at the West Coast foraging site and individuals within this site showed differences in habitat selection among years. Habitat selection at the West Coast site also differed between sexes suggesting that males are outcompeting females for prime foraging spots.

Overall, my results indicate that foraging conditions on the West Coast are highly variable likely due to rising sea surface temperatures, marine heatwaves, and the effects of the El Nino-Southern Oscillation. As a result, it is likely that prey availability on the West Coast is unpredictable causing high variation in foraging behaviour and sexual foraging segregation. With climate change, foraging conditions on the West Coast are predicted to get more unpredictable as sea surface temperatures continue to rise and extreme weather events become more frequent. These factors will make foraging increasingly difficult for Westland petrels and could see them rely more on fishery discards as a source of food, increasing their risk of incidental mortality. Conservation management should focus on protecting the petrels core foraging area around the Hokitika canyon to help limit the effects of climate 
change. Fishery management should also focus on limiting or prohibiting offal discards to prevent the incidental mortality of Westland petrels. 


\section{Acknowledgments}

First and foremost, I would like to give a huge thanks to my supervisors, Nicky Nelson, and Susan Waugh, for their amazing support and guidance through the highs and lows of this thesis. I could not have asked for better supervisors to help me produce a thesis whilst the world battles with a global pandemic. Even in times when I thought all hope was lost, your determination and wise words always made my stress melt away and helped drive me to achieve my best.

I was also like to give big thanks to Nicky's lab group (Fixit) for all the support and encouragement they have given throughout my time at Victoria University. I have loved getting to know such awesome people and helping out with some amazing projects. Thanks to Brittany Florence-Bennett, Chris Woolley, Diane Ormsby, Florence Kelly, Kerstin Thornton, Liam McAuliffe, Laura Ryan, Lily Tidwell, Lin Lin Liu, Logan McPherson, Michelle Goh, Ox Lennon, Sarah Herbert, Sarah Lamar, Sue Keall and Sydney Dean. I would also like to give thanks to Neville Higgison for the awesome modifications made to the burrowscope that, although was not needed in the end (due to Covid-19), was still very much appreciated. I would also like to thank Johannes Fischer for giving me inspiration for my analysis in chapter 3. Also, a big thanks to Danyl McLauchlan for the Excel code which saved me literally months of time processing my data.

This thesis was done in collaboration with Te Papa and would like to thank for all the work they have put into researching the Westland petrels over the years with assistance from the Department of Conservation (DOC) for which I also extend a huge thanks. A special thanks to Tim Poupart (DOC) and John Arnould for collecting the telemetry data used in this study. Also, a big thanks to James Griffiths for the use of his data loggers. I would also like to give thanks to Kate Simister (DOC) and Jess Calcutt who helped me in the field leading up to my thesis. While this work was unable to continue due to Covid-19, I am very grateful to have worked alongside you.

I would also like to give a massive thanks to my friends: Dan Torres, Georgia Yee, Islay Simpson, Jacob Lippman, Jaimy Monteiro, Lochie Freear, Michael Gardiner, Nick Bell, Paddy O’Sullivan, Petra Panchavinin, Sammy Macher and Tomas Fuge. Thanks for being there during my highs and lows, fantastic banter, and just general nonsense. Literally could not ask for better friends.

Finally, a huge thanks to my family for all the love and support throughout this endeavour and future endeavours to come. Thanks for feeding me, telling me to clean all my muddy fieldwork cloths and installing a heater in my room so I don't freeze to death while writing my thesis in lockdown. 


\section{Table of Contents}

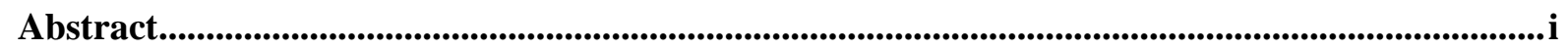

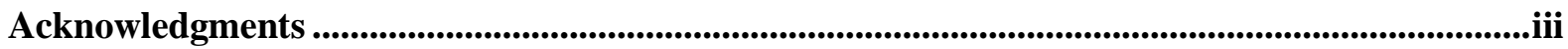

Chapter 1: General Introduction.......................................................................................................1

1.1 Optimal foraging .......................................................................................................................................2

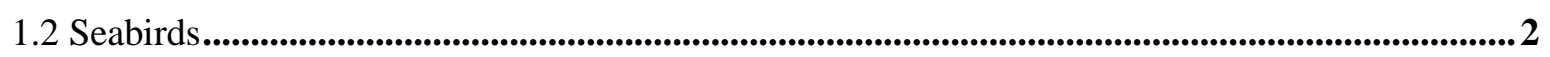

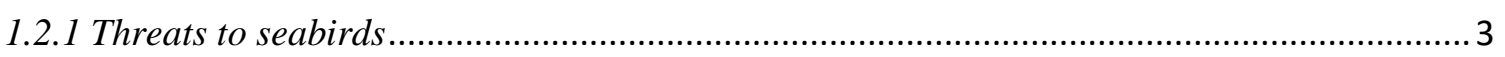

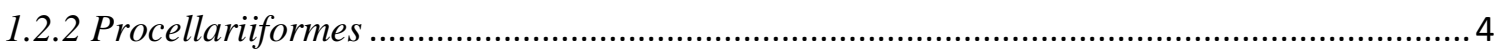

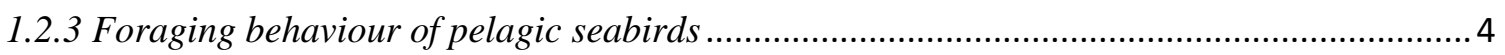

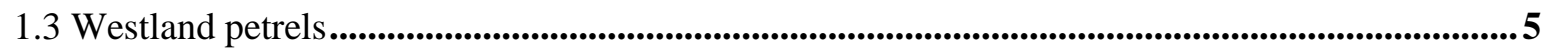

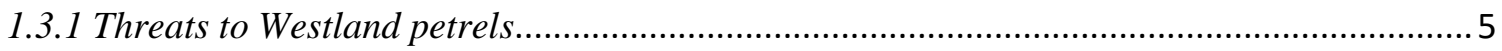

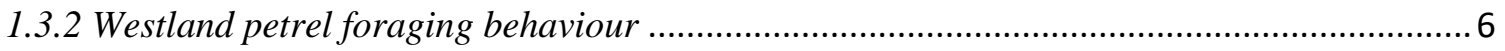

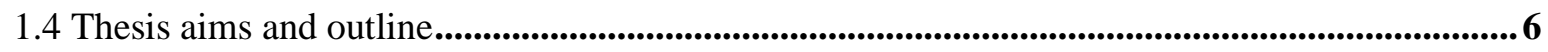

Chapter 2: Variation in Westland Petrel (Procellaria westlandica) foraging behaviour .................8

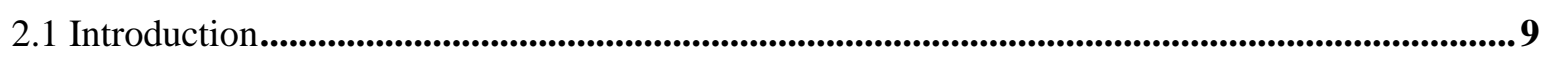

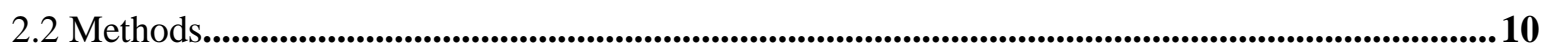

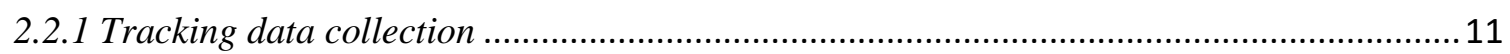

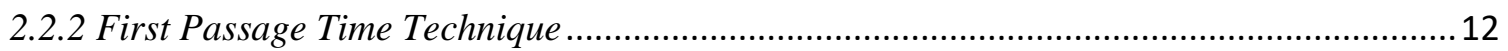

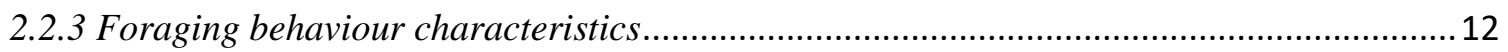

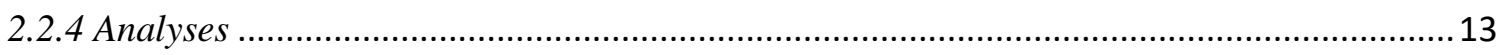

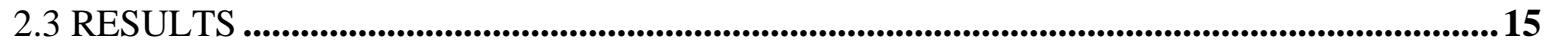

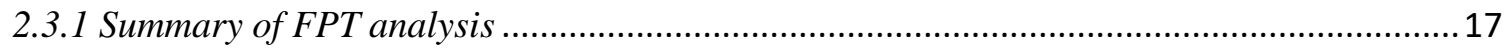

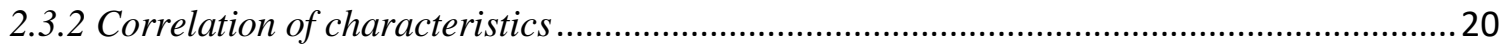

2.3.3 Factors explaining variation in Westland petrel foraging behaviour..................................2 20

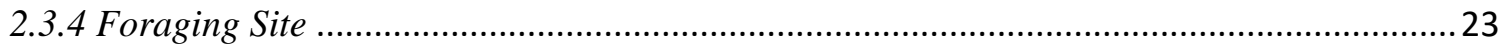

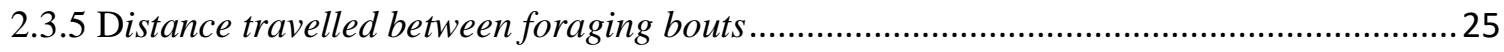

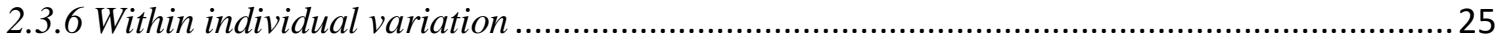

2.4 Discussion ...................................................................................................................................................227

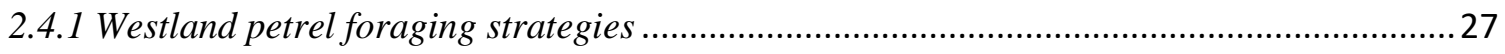

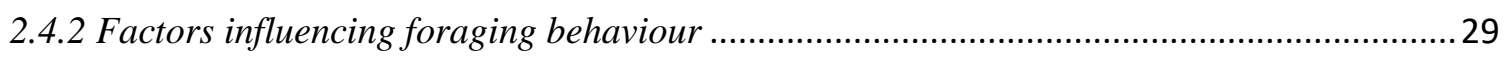

2.4.3 Implications for population viability and conservation .................................................... 32

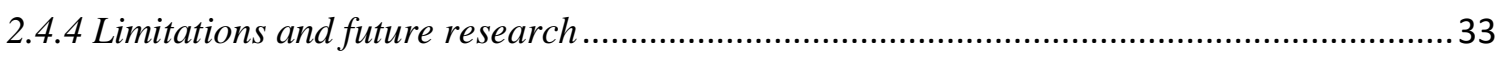

Chapter 3: Environmental drivers of Westland petrel (Procellaria westlandica) foraging

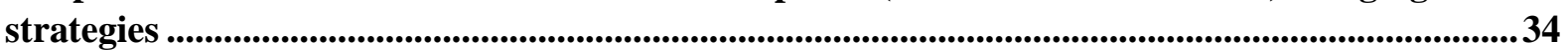

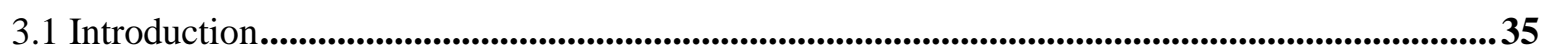

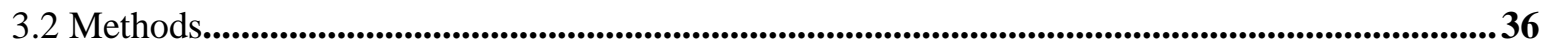

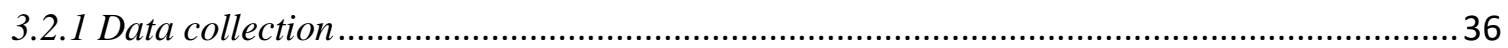




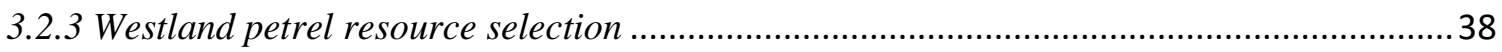

3.2.4 Environmental influence on foraging characteristics ....................................................... 40

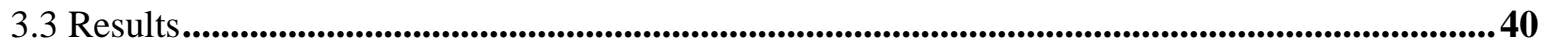

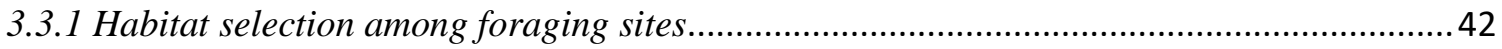

3.3.2 Habitat selection within sites at the individual level ......................................................... 43

3.3.3 Habitat selection within the West Coast foraging site by year ............................................. 45

3.3.4 Habitat selection within the West Coast foraging site by sex .............................................. 47

3.3.5 Environmental influence on foraging characteristics ........................................................ 48

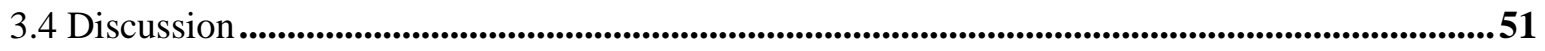

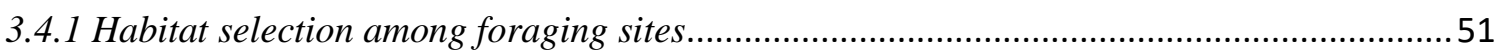

3.4.2 Habitat selection within the West Coast foraging site by year and sex ................................52

3.4.3 The influence of wind on Westland petrel foraging behaviour ........................................... 54

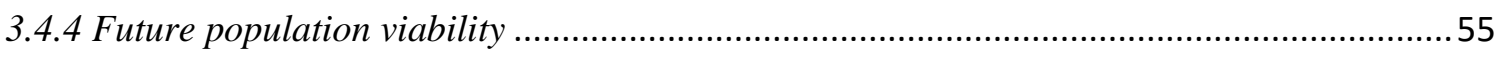

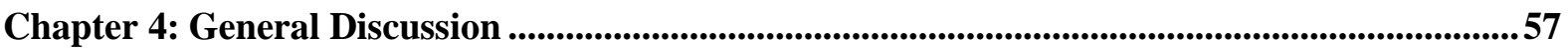

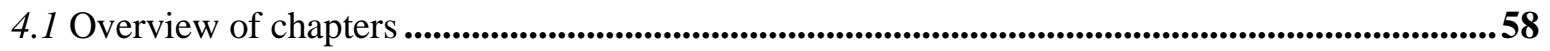

4.1.1 Chapter 2: Variation in Westland Petrel (Procellaria westlandica) foraging behaviour:

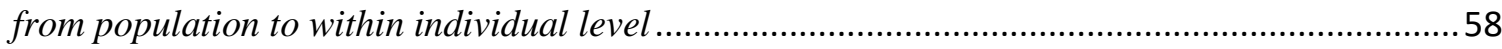

4.1.2 Chapter 3: Environmental drivers of Westland petrel (Procellaria westlandica) foraging

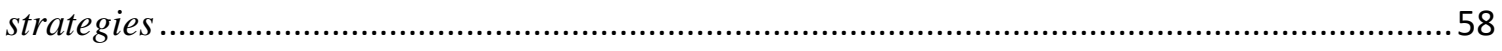

4.2 Discussion .......................................................................................................................................................59

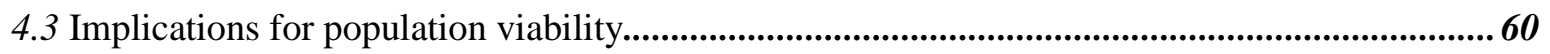

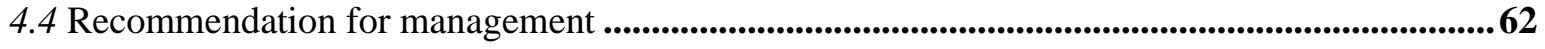

4.5 Limitations and Future Research ............................................................................................63

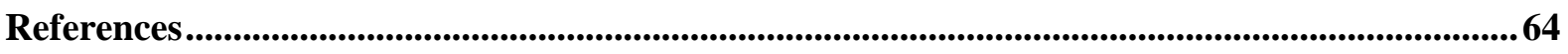

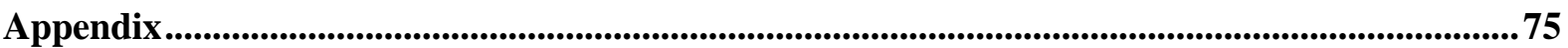




\section{Chapter 1}

\section{General Introduction}

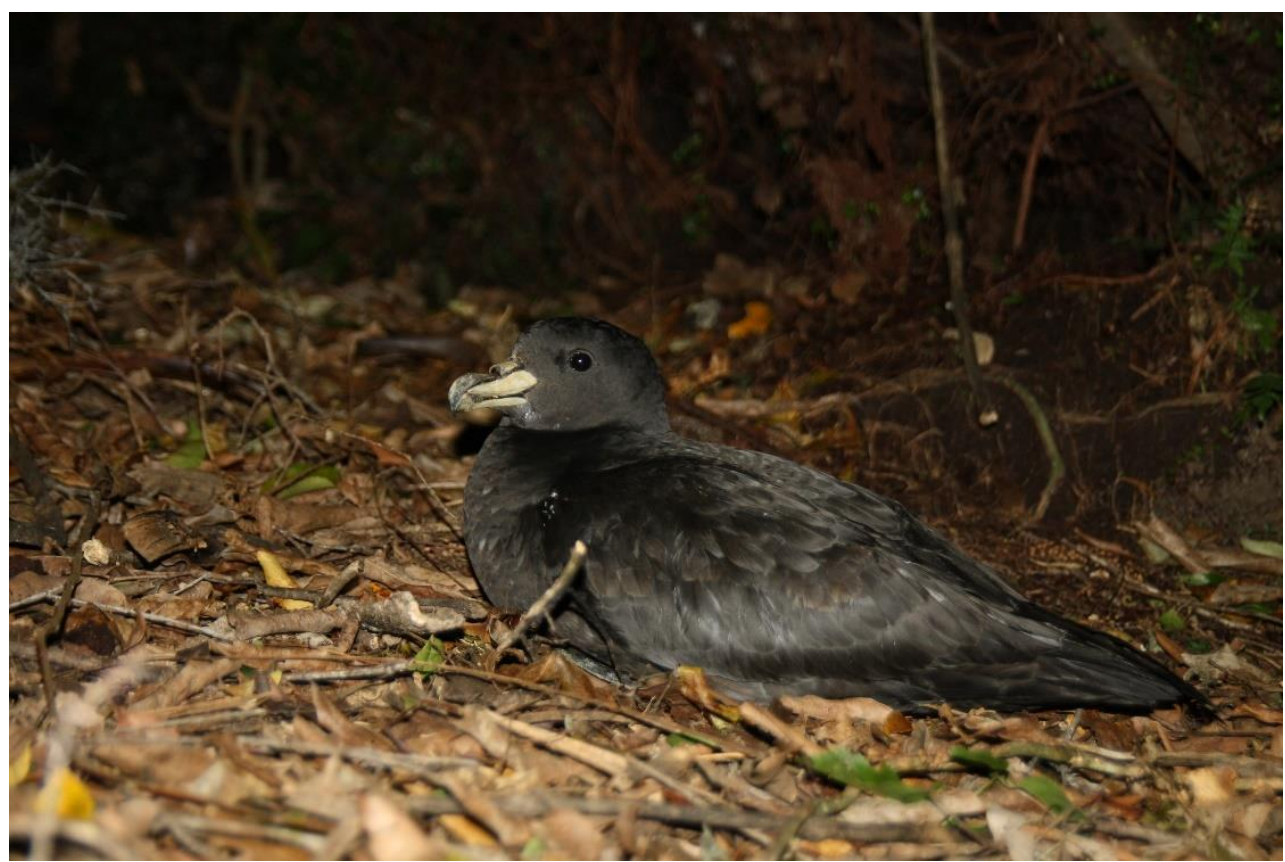

Westland petrel sitting on the ground, Punakaiki, 2011. Photo credit: Susan Waugh

The earth is currently experiencing its sixth mass extinction with over 37000 species threatened with extinction (Barnosky et al., 2011; IUCN, 2021). With 15-37\% of species predicted to go extinct by 2050 , understanding factors influencing the viability of population is a high priority for the conservation and management of species (Pimm et al., 2014).

Population viability can be defined as a population's ability to avoid extinction. There are many factors that can influence a populations viability such as genetic diversity, population demographics, environmental variability, natural catastrophes, and anthropogenic factors (Lande, 1998; Pierson et al., 2015; Shaffer, 1981). While all these factors can influence a population, it is the combination and level of exposure of these that determines a population's risk of extinction (Shaffer, 1981). Ultimately the viability of a population comes down to the survivability and reproductive success of individuals. For many species these are often mediated through foraging success (Pinaud et al., 2005). 


\subsection{Optimal foraging}

In order for an animal to forage optimally and meet survival and reproductive requirements, the energy gained from foraging must exceed the energy lost (MacArthur \& Pianka, 1966; Schoener, 1971). Whether an animal is successful or not is influenced by both intrinsic and extrinsic factors (Louzao et al., 2014). Intrinsic factors relate to the physiology of the animal and govern decision making on where and when to forage, what food to consume and when to stop feeding and move on (Nathan et al., 2008; Owen-Smith et al., 2010). Extrinsic factors include food availability, predator presence and environmental conditions which constrain the foraging decisions of an animal (Nathan et al., 2008).

As species occur in different habitats and have different life histories, a variety of foraging strategies have developed to maximise foraging success. Group foraging offers many advantages such as the improved ability of locating prey patches and increased protection against predators (Clark \& Mangel, 1986). In some cases, groups foraging can also increase the efficiency of catching prey or help defend a food supply (Clark \& Mangel, 1986; McInnes et al., 2017). On the other hand, solitary foraging has the advantage of reducing competition with conspecifics and making the animal less conspicuous to predators (Le Roux et al., 2009). In some cases an animal can switch from group foraging to solitary foraging when food is abundant (Le Roux et al., 2009).

Animals have also developed various generalist and specialist foraging strategies. Generalists exploit a wide range of resources and offers an advantage in areas where environmental conditions and food supply changes (Terraube et al., 2011). A generalist foraging strategy also uses less energy as an animal can feed on what is locally abundant (Gormezano \& Rockwell, 2013). Specialists on the other hand exploit a narrow range of resources (Terraube et al., 2011). While this strategy often costs more energy, it also reduces competition with other species and allows the animal to focus on exploiting high energy food (Stewart \& Dudash, 2018). However, as the world changes from human activity and climate change, it is becoming increasingly harder for animals to forage successfully, raising concerns about their future population viability (Beever et al., 2017; Evans \& Moustakas, 2018; Terraube et al., 2015). One group of animals particularly at risk are seabirds.

\subsection{Seabirds}

Seabirds can be characterised as birds that rely on the marine environment for at least part of their lifecycle (Votier \& Sherley, 2017). They are important marine top predators, consuming as much fish biomass as global fishery landings (70 million tonnes), which helps regulate species composition and ecosystem function (Brooke, 2004; Parsons et al., 2008; Spatz et al., 2014). Being important top predators also make seabirds useful indicators of marine health, commercial fishing pressure and climate change, as changes in prey availability can have a large influence on seabird populations (Parsons et al., 2008; Piatt et al., 2008). Seabirds are also important for terrestrial ecosystems as they transport essential nutrients such as phosphorus, from the marine environment to terrestrial ecosystems 
(Adame et al., 2015). There are around 350 species of seabird making up nine orders. They range from coastal species, such as, gulls and pelicans to pelagic species, such as, gannets and penguins (Votier \& Sherley, 2017). Unlike coastal species, pelagic seabirds spend most of their life out at sea, only returning to land to breed (Weimerskirch, 2007).

\subsubsection{Threats to seabirds}

Despite their ecological importance, seabird populations are declining around the world (Dias et al., 2019). According to the IUCN 'Red List of Threatened Species' (2021), 47\% of all seabirds are declining with $31 \%$ threatened with extinction. Because seabirds are exposed to terrestrial and marine threats, they are now considered one of the most threatened group of birds (Dias et al., 2019). The biggest threat to seabirds is from invasive mammalian species such as rats, cats, dogs, and feral pigs (Dias et al., 2019). These species predominantly impact seabirds at their breeding colony by killing and eating adults and their offspring, as well as destroying important nesting sites (Carr et al., 2021; Sarmento et al., 2014).

The second biggest threat to seabirds is incidental mortality from commercial fishing industries (Dias et al., 2019). Seabirds are often drawn to fishing vessels as they offer an easy source of prey, but often get entangled in fishing nets or hooked on longlines resulting in the drowning of individuals (Da Rocha et al., 2021). In longline fisheries alone, an estimated 160,000 to 320,000 seabirds are killed each year (Anderson et al., 2011).

Climate change is the third biggest threat to seabirds although this may rise as it is predicted to impact all seabird populations in the future (Dias et al., 2019). Currently, climate change is predominantly impacting seabirds through changes in prey availability (Dias et al., 2019). For Cape cormorants, rising sea surface temperatures in South Africa has shifted prey distributions to cooler waters (Hamann et al., 2012). As a result, individuals are having to travel further and use more energy in search of prey, lowering breeding success (Hamann et al., 2012). In common guillemots, lower prey abundance from high sea surface temperatures made individuals more likely to skip breeding (Reed et al., 2015).

Climate change is also increasing the frequency and severity of extreme weather events which is impacting seabirds at sea as well as at their breeding colonies (Hass et al., 2012). At sea, extreme weather events make foraging conditions hostile for seabirds as strong winds can carry individuals far away from their foraging and migration routes (Hass et al., 2012). This often results in the mass mortality of seabirds through starvation and lack of energy (Morley et al., 2016). In the North Atlantic, a series of storm events occurring between December 2013 and February 2014 caused the wreck of over 54000 seabirds (Morley et al., 2016). At the breeding colony, extreme weather events can destroy nests, kill chicks and make habitat unsuitable for future breeding (Newell et al., 2015). While these threats are impacting coastal and pelagic seabirds, pelagic species are experiencing the biggest impacts (Dias et al., 2019). One of the most threatened group of pelagic seabirds are the procellariiformes. 


\subsubsection{Procellariiformes}

Procellariiformes (tube nosed seabirds) consist of four families (Stidworthy \& Denk, 2018): Diomedeidae (albatrosses), Procellariidae (fulmars, shearwaters and petrels), Hydrobatidae (storm petrels) and Pelecanoididae (diving petrels). They have long life spans (up to 70 years for albatrosses), and like other long-lived species they have late maturity (8-10 years) and low fecundity (one chick per breeding season), which makes them particularly vulnerable to extinction (Ricklefs, 1990; Votier \& Sherley, 2017). Procellariiformes are also characterised with having high adult survival rates, and individuals will often skip breeding in a particular year if conditions are unfavourable and compromise their own survival (Öst et al., 2018). This is because in long-lived species, valuing your own survival over current reproduction maximises success in future reproductive attempts (Dobson \& Jouventin, 2010).

\subsubsection{Foraging behaviour of pelagic seabirds}

Pelagic seabirds forage in the highly dynamic marine environment where prey is patchily distributed and can change spatially and temporally over different scales. Historically, knowledge of how seabirds can forage in this environment remained unknown as our observations were limited to sightings from fishing vessels (Phillips et al., 2007). However, the advent of miniature tracking technology in the 1990s revolutionized our understanding of the pelagic lives of seabirds (Phillips et al., 2007; Weimerskirch, 2007).

We now know that pelagic seabirds forage predominantly around strong upwelling areas as they provide enhanced productivity and concentrated prey, making these areas a reliable food source for seabirds (Waggitt et al., 2018). Strong upwelling areas used by pelagic seabirds include ocean fronts, eddies and sloping bathymetric features such as continental shelves and undersea canyons (Evans et al., 2021; Kowalczyk et al., 2015; Pinaud et al., 2005). Procellariiformes, in particular, use olfactory navigation to locate sources of prey (Gagliardo et al., 2013; Nevitt, 2008). It is also speculated that, given the long life spans of pelagic seabirds, memory also plays a major role with younger individuals having to learn over time where foraging spots are located (Regular et al., 2013; Riotte-Lambert \& Weimerskirch, 2013). Procellariiformes are also considered some of the most efficient flyers on earth, capable of exploiting wind conditions to travel large distances using very little energy (Weimerskirch et al., 2012). In the case of wandering albatross (Diomedea exulans), studies found that when travelling with tailwinds, individuals were using as much energy as sitting on the water (Louzao et al., 2014).

During the non-breeding season, procellariiformes can cover vast distances in search of prey (Nevitt, 2008). For many, this involves migrating to prey rich areas to avoid hostile winder conditions back at the breeding site (Regular et al., 2014). The migrations performed by pelagic seabirds are some of the longest in the animal kingdom. For species, such as, sooty shearwaters (Puffinus griseus), individuals can cover a distance of 64 000km annually (Shaffer et al., 2006; Weimerskirch et al., 2015). 
During the breeding season, adults become central place foragers meaning they must return regularly to the breeding colony to fulfil breeding responsibilities (Burke \& Montevecchi, 2009). These responsibilities include, securing and defending the nest, incubating the egg, and feeding the chick once hatched (Stephens \& Krebs, 1986; Weimerskirch, 2007). During this time, adults must cope with having a reduced foraging range whilst also increasing their foraging effort to meet reproductive energy requirements (Ceia \& Ramos, 2015). As a result, seabirds have developed various foraging strategies. One strategy adopted by many seabirds such as Manx shearwaters (Puffinus puffinus), is a dual-foraging strategy where individuals alternate between multiple short trips and one long trip (Congdon et al., 2005; Tyson et al., 2017). This strategy is predominantly used during the chick-rearing stage where short trips are used to provision food for the chick while long trips are used to maintain the adults own body condition (Magalhães et al., 2008).

Another strategy used by seabirds is sexual foraging segregation where males and females forage in separate areas to reduce intra-specific competition. This strategy has been observed in many species such as giant petrels (Macronectes spp), tropical boobies (Sula spp.) and sooty shearwaters (Puffinus griseus) and is thought to arise when local prey availability is limited (Hedd et al., 2014; Lewis et al., 2005; Thiers et al., 2014). More recently, studies have found that individuals in many seabird population are able to specialize in fine scale foraging behaviour (Phillips et al., 2017). 'Individual specialisation', is when individuals consistently exploit a subset of a populations available habitat or diet and is thought to be a strategy to reduce intraspecific competition (Courbin et al., 2018; Phillips et al., 2017).

\subsection{Westland petrels}

The Westland petrel is an endemic burrowing procellariform found only on the West Coast of New Zealand's South Island, just south of Punakaiki (Baker et al., 2011). They are one of the largest species of petrel weighing around $1.2 \mathrm{~kg}$ (S. M. Waugh et al., 2015). While historic evidence suggests their range extended further north (Worthy \& Holdaway, 1993), today their breeding range is limited to just $16 \mathrm{~km}^{2}$ in the Paparoa National Park (Baker et al., 2011). They build their nesting burrows in dense native bush hillslopes forming colonies ranging from $<10$ to $>1000$ individuals (Baker et al., 2011). They have a population of around $13000-17000$ individuals consisting of around 6200 breeding pairs (Waugh et al., 2020). Unlike most seabirds, they breed during the austral winter with only $47 \%$ of individuals attempting to breed each year. While their population has been increasing since the 1970s, due to their limited breeding range, low number of breeding individuals and exposure to various threats, they are considered nationally endangered (BirdLife International, 2018; Waugh \& Wilson, 2017).

\subsubsection{Threats to Westland petrels}

Like many seabirds, one of the biggest threats to Westland petrels is predation from invasive mammalian predators (Waugh \& Wilson, 2017). While feral dogs have killed individuals in the past, a more serious threat comes from feral pigs, as they can destroy nesting burrows and predate on adults 
and their chicks (Waugh \& Wilson, 2017). Extreme weather events also pose a major threat to the Westland petrel (Waugh \& Wilson, 2017). In 2014, the remnants of a category five cyclone destroyed large part of their breeding colonies through landslips and treefall, trapping and killing individuals inside burrows (S. Waugh et al., 2015). At sea, like many seabirds, their biggest threat comes from commercial fisheries (Waugh \& Wilson, 2017; Waugh et al., 2018). Westland petrels currently rank $3^{\text {rd }}$ most at risk of incidental mortality from New Zealand fisheries (Richard et al., 2020). While early diet studies have shown that they predominantly feed on natural prey, fishery discards do make up $63 \%$ of chick diets indicating an increased reliance on fishery discards by adults during the chick rearing stage (Freeman \& Smith, 1998; A. N. Freeman, 1998).

\subsubsection{Westland petrel foraging behaviour}

During the non-breeding season, Westland petrels migrate to waters off southern Chile and Argentina to feed over the austral summer. When they return to New Zealand in March to breed, they become central place foragers. Their natural prey consists predominantly of deep sea species such as lanternfish (Myctophidae spp.) and squid (Cranchiidae spp., Histioteuthidae spp.), which perform diel vertical migrations up to surface waters to feed at night (A. N. Freeman, 1998; Loots et al., 2007). This makes Westland petrels largely nocturnal foragers (Poupart et al., 2020). During the breeding season, Westland petrels forage primarily around sloping bathymetric features in Hokitika, Haast and the Cook Strait (Waugh et al., 2018). Unlike other procellariiformes, Westland petrels display little to no evidence of using sexually dimorphic or dual foraging strategies to gather prey during their winter breeding season (Poupart et al., 2020; Waugh et al., 2018). This is despite foraging conditions during winter generally assumed to be more challenging for seabirds (Zotier, 1990). Furthermore, the foraging behaviour of Westland petrels exhibits a high level of individual variation suggesting that foraging is most influenced by individual choice (Waugh et al., 2018). Individual variation in foraging behaviour is of growing focus in seabird ecology as it can inform us on how plastic individual responses are to environmental changes and how this may influence the viability of their population (Phillips et al., 2017).

\subsection{Thesis aims and outline}

My thesis explores the variation in Westland petrel foraging behaviour in detail to understand more about the foraging strategies used by individuals and how the environment influences their behaviour.

This thesis contains two data chapters formatted for journal submission. In Chapter 2, I examined the variation in Westland petrel foraging behaviour at the population, individual and within individual level, to describe and categorise different foraging strategies and investigate how year, sex, and foraging site influence variation. In Chapter 3, I used point process modelling to investigate how environmental factors influence habitat selection and foraging characteristics of Westland petrels to understand the drivers of foraging patterns found in Chapter 2. In Chapter 4, I provide a general discussion outlining 
the main findings of my thesis and provide recommendations for conservation management and future research goals. 


\section{Chapter 2}

\section{Variation in Westland Petrel (Procellaria westlandica) foraging behaviour}

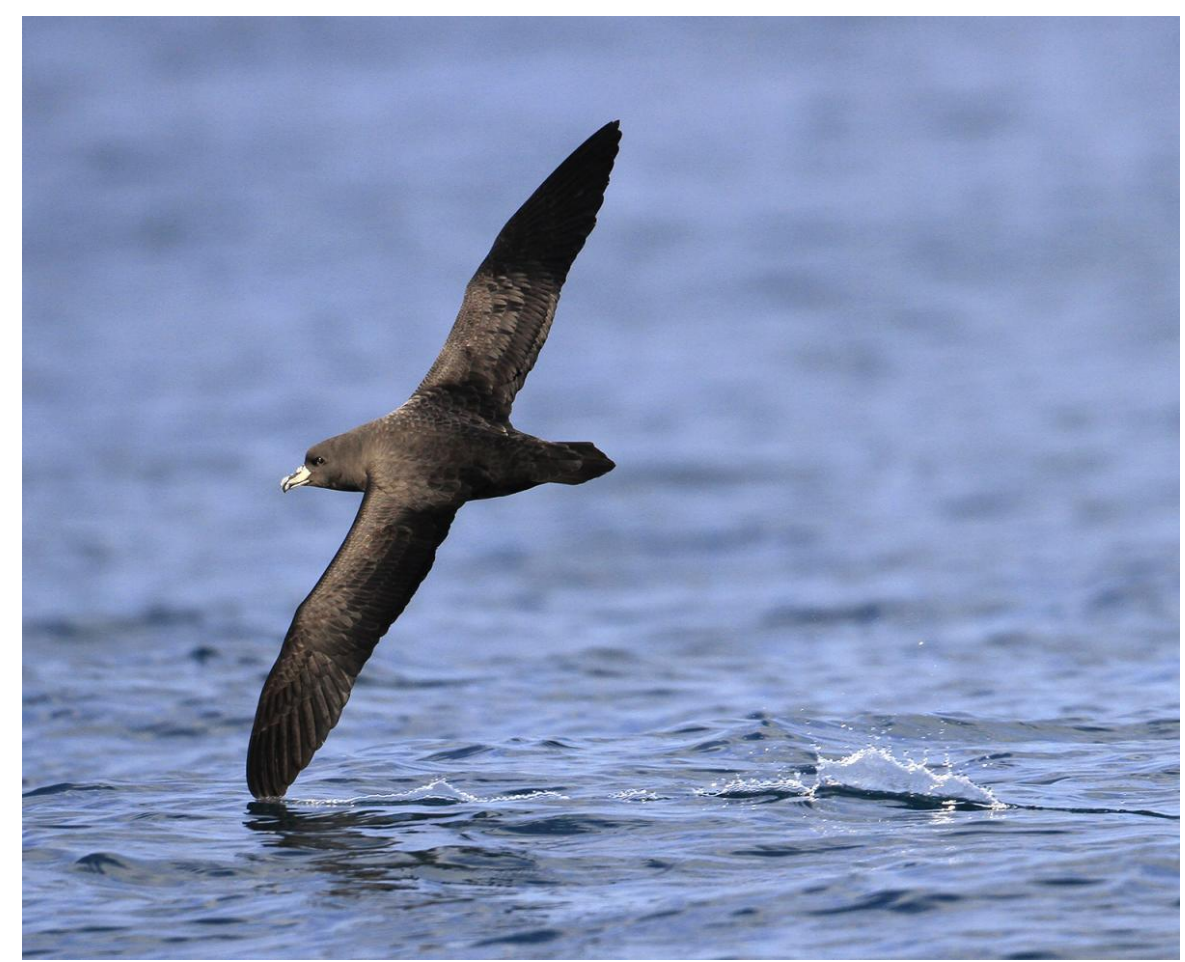

Westland petrel in flight, Cook Strait, 2017. Photo credit: @ Phil Battley 


\subsection{Introduction}

The way in which animals forage can have major impacts on survivability and reproductive success, ultimately affecting population viability (Louzao et al., 2014; Schoener, 1971). In order to forage successfully, the energy gained from foraging must exceed the energy used (MacArthur \& Pianka, 1966; Schoener, 1971). This becomes particularly challenging for Procellariiformes (tubed-nosed seabirds) who forage for patchily distributed prey in an immense, dynamic, and seemingly featureless ocean (Louzao et al., 2014; Nevitt, 2008). Furthermore, Procellariiformes invest high amounts of energy into raising a single chick each year (Shealer, 2002; Tessier \& Bost, 2020).

As a result, Procellariiformes have developed various foraging strategies to meet this energy-demanding lifestyle. During the non-breeding season, many Procellariiformes migrate vast distances, using olfactory and visual cues to locate prey rich waters (Nevitt, 2008; Weimerskirch et al., 2015). These migrations are some of the longest on earth, for example, $64000 \mathrm{~km}$ annually in the case of sooty shearwaters (Puffinus griseus), and allows individuals to avoid hostile winter conditions back at the breeding site (Regular et al., 2014; Shaffer et al., 2006).

During the breeding season, adults become central place foragers, meaning that they return to the colony after foraging to secure their nesting site, raise the chick and relieve their partner of nesting duties (Stephens \& Krebs, 1986; Weimerskirch, 2007). Once the egg hatches, adults must increase their foraging effort to get enough prey to feed their chick. In response to the increased energy demand, many seabirds, including shearwaters (Puffinus spp.), auks (Pinguinus spp.) and little penguins (Eudyptula minor), have adopted a dual-foraging strategy, where adults alternate between multiple short trips and one long trip (Saraux et al., 2011; Tyson et al., 2017; Wojczulanis-Jakubas et al., 2010). During short trips, adults prioritize provisioning food for the chick. On long trips however, adults travel to more productive waters to feed themselves and maintain their own body condition (Magalhães et al., 2008). Recent work on Manx shearwaters (Puffinus puffinus) found that parents are able to coordinate their short and long trips so that the chick is not left unattended (Tyson et al., 2017). This strategy enables seabirds to meet the energy requirements of reproduction without compromising their own survival.

Another strategy adopted by Procellariiformes during the breeding season is foraging segregation. This is where individuals of different sex and age classes forage at separate sites to reduce competition for food (González-Solís et al., 2007; Lewis et al., 2005). This has been reported in giant petrels (Macronectes spp), where males stay close to shore and scavenge on seal and penguin carcasses, whereas females actively forage at sea (González-Solís et al., 2000). Despite having multiple strategies adapted for specific breeding stage circumstances, $47 \%$ of global seabird population are declining (Dias et al., 2019). There is therefore an urgent need to understand more about seabird foraging behaviour, to 
help identify the causes of decline and assess how their foraging behaviour may influence future population viability.

Westland petrels (Procellaria westlandica) are a Procellariform species under threat, found only on the West Coast of New Zealand's South Island near Punakaiki (Waugh et al., 2020). Due to their limited breeding range $\left(16 \mathrm{~km}^{2}\right)$, small population (6200 breeding pairs), and ongoing threats from invasive feral pigs and extreme weather events, they are classified as endangered (BirdLife International, 2018; Waugh \& Wilson, 2017). Unlike most seabirds they breed during the winter, spending the summer months feeding in waters near southern Chile (Rayner et al., 2011). While they have been studied for over 50 years, it is only relatively recently that we have been able to gain insight into their pelagic foraging behaviour with the advent of novel tracking technology (Poupart et al., 2020; Rayner et al., 2011; Waugh et al., 2018). So far studies have revealed that Westland petrels forage predominantly around undersea canyons in Hokitika, Haast and the Cook Strait, feeding nocturnally on deep sea lanternfish (Myctophidae spp.) and squid (Cranchiidae spp., Histioteuthidae spp.), which migrate up to surface waters at night to feed (A. Freeman, 1998; Waugh et al., 2018). Despite high levels of individual variation in foraging activity (accounting for $40 \%$ of the variance), Westland petrels show no evidence of dual foraging or sexual foraging segregation (Poupart et al., 2020; Waugh et al., 2018).

Individual variation in foraging behaviour is of growing focus in seabird ecology as it affects the level of intra-specific competition, and can inform how individuals and the population will respond to future environmental and anthropogenic threats (Phillips et al., 2017). I examine the variation in Westland petrel foraging behaviour at the population level, individual level and within individual level to describe and categorise Westland petrel foraging behaviour, and investigate how year, sex, and foraging site influence variation.

\subsection{Methods}

Westland petrels are endemic to the West Coast of New Zealand's South Island. They breed in dense native bush foothills just outside Punakaiki $\left(-42.14681^{\circ} \mathrm{S}, 171.34173^{\circ} \mathrm{E}\right)$, in a wet temperate climate with an average annual temperature of $12.5^{\circ} \mathrm{C}$ and a mean annual rainfall of $2346 \mathrm{~mm}$. Their single breeding range of $16 \mathrm{~km}^{2}$ is split into 22 sub-colonies (Figure 1), ranging in size from $<10$ to $>1000$ individuals. This study focuses on the Scotsman's Creek area which contains four of the largest subcolonies and comprises $75 \%$ of the total population. Westland petrels are one of the largest species of petrel weighing around $1.2 \mathrm{~kg}$. They nest in burrows during the austral winter, laying a single egg in May-July. Once eggs hatch, adults rear the chick from August-November. Fledging occurs in November/December when the chicks, along with the rest of the population, migrate to South America to feed over the summer. 


\subsubsection{Tracking data collection}

Individuals were tracked across the breeding season (March-September) in 2011, 2012, 2015 and 2016 by Waugh et al (2018) using GPS data loggers (I-Got-U GT120, $44 \times 28 \times 11 \mathrm{~mm}, 25 \mathrm{~g}$, (Mobile Action Technology, 2016). Loggers were deployed on individuals from the largest sub-colony (Figure 1; Study) which contains around one third of the Westland petrel population. Loggers recorded the geographical coordinates, time, and flight speed $(\mathrm{km} / \mathrm{hr})$ for each location at 15 -minute intervals and were retrieved after birds had taken $\geq 1$ foraging trip.

I used data of breeding individuals tracked during the incubation period (May-July). Along with the information recorded by the loggers, the dataset also included the cumulative distance travelled and distance from the colony for each location (calculated by Waugh et al 2018). Locations within 500m of the colony were filtered out as the petrels are known to raft (rest on the water) before returning to the colony. In total this dataset contained 42 individuals tracked across the four years making a total of 68 foraging trips. Phenotypic and breeding information on each individual were sourced from a 10-year dataset of all banded individuals.

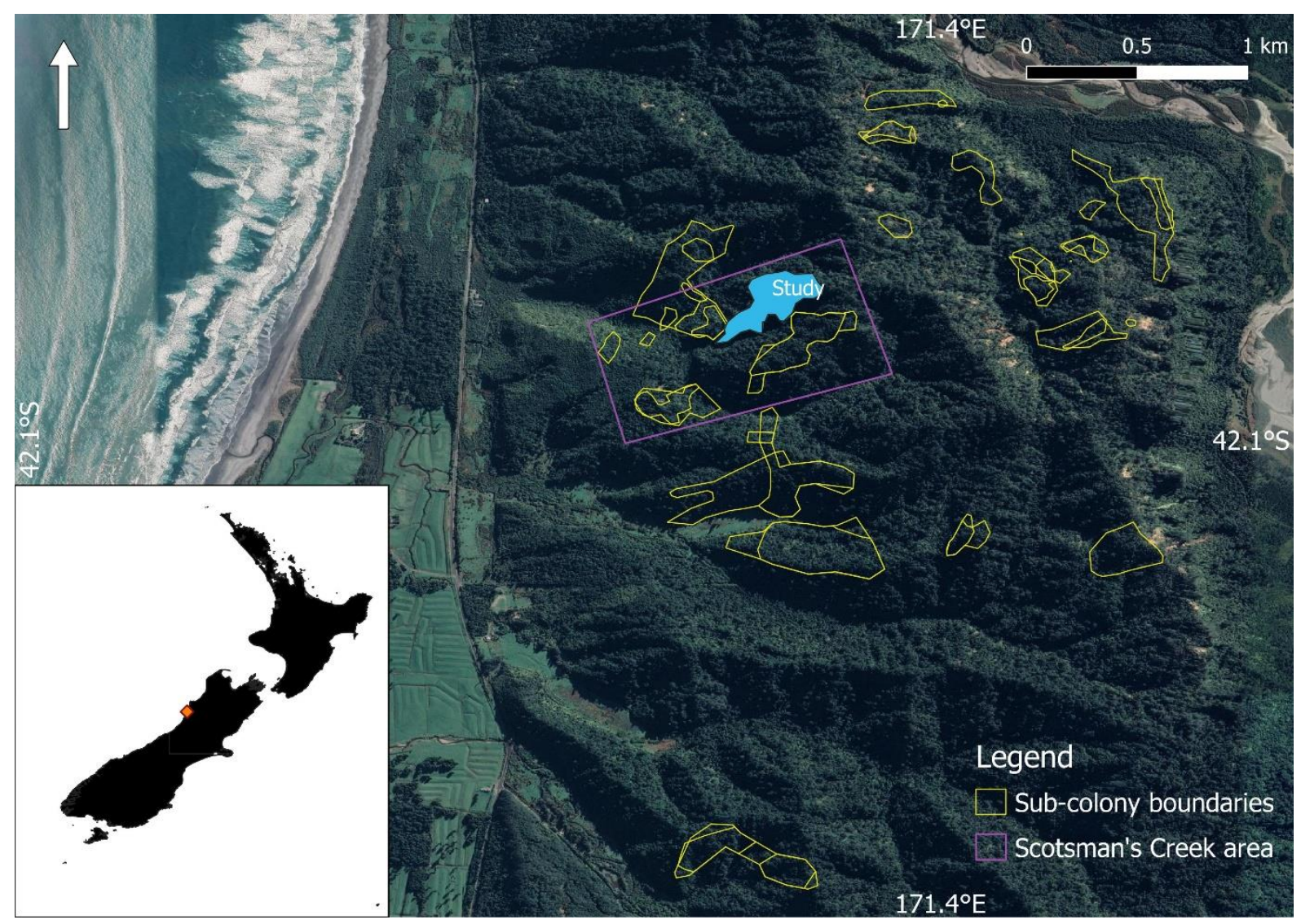

Figure 1: Westland petrel breeding range. The largest sub-colony (Study) is highlighted in blue and the Scotsman's Creek area is highlighted in purple. Punakiaki, New Zealand 


\subsubsection{First Passage Time Technique}

I used first passage time analysis (FPT) to split individual trips into foraging and travelling sections. While many studies use a kernel density approach to explore habitat use (Lees et al., 2016; Waugh et al., 2018), FPT analysis gives more accurate results by incorporating space and time (Fauchald \& Tveraa, 2003). FPT is defined as the time taken for an individual to pass through a circle of a given radius (Fauchald \& Tveraa, 2003). The longer it takes an individual to pass through the circle, the higher the FPT value. By moving the circle along a track, you can identify periods of high FPT values (foraging) and low FPT values (travelling). This allows the investigation of both the foraging and travelling behaviours of individuals (Fauchald \& Tveraa, 2003).

FPT analysis was conducted in R version 4.0.2 (R Core Team, 2020) for each foraging trip using the package 'adehabitatLT' (Calenge, 2006). Foraging trips were first assigned to their own separate tracks, and timestamps were standardised to 15-minute intervals to match the sampling rate of the data loggers. An important step in FPT analysis is selecting an appropriate radius for the circle. While some studies use a standard radius for all tracked individuals (Freitas et al., 2018; Paiva et al., 2010), because I was interested in individual foraging behaviours, I selected a radius for each trip. To do this, I ran the FPT analysis on each track for radii ranging from 1 to $100 \mathrm{~km}$. By plotting the log-transformed variance in FPT as a function of radius size, I was able to identify the scale of foraging (and thus the radii to use) for each trip by any peaks in log-variance (Figure 2A). For trips that showed foraging behaviour at multiple scales I selected the largest radii to use for the FPT analysis as small-scale foraging behaviours are often nested within larger foraging scales. Once radii were selected for each trip, I ran the FPT analysis and used Levielle's method (Lavielle, 1999, 2005) to segment the tracks into sections of high FPT and low FPT (Figure 2 B, C). Sections of low FPT were then identified as "Travelling" and sections of high FPT were identified as "Foraging" (Figure 2D). Of the 68 trips, two short trips were removed as they did not show any foraging behaviour and were therefore assumed to be individuals doing nonforaging behaviour such as bathing or circling close to the colony.

\subsubsection{Foraging behaviour characteristics}

After conducting the FPT analysis, I recorded the foraging scale (size of radius used in the analysis $[\mathrm{km}])$ and number of foraging bouts for each trip. I then calculated other characteristics such as the percentage of trip spent foraging (\%Foraging), the distance of foraging from the colony (Foraging distance $[\mathrm{km}]$ ), the duration of foraging (Foraging duration [hours]) and the distance travelled between foraging bouts (Dist trav between foraging $[\mathrm{km}]$ ). I also calculated general trip characteristics such as trip duration [days], total distance travelled (Tot Dist Travelled [km]), and the max distance reached from the colony (Max Dist Colony $[\mathrm{km}]$ ). The average travelling speed $\left[\mathrm{km} / \mathrm{h}^{-1}\right]$ for each trip was also calculated by averaging the flight speeds recorded by the data loggers for the tracked locations identified as "travelling" from the FPT analysis. 


\subsubsection{Analyses}

I ran a Spearman Rho correlation matrix using the rcorr function from the 'Hmisc' package (Harrell, 2019) to evaluate whether foraging behaviours (as mentioned in the previous paragraph) were correlated. To see what factors explain variation in each foraging behaviour, generalised linear mixed models (glmm) were run with year, sex, foraging site, foraging scale and the number of foraging bouts as fixed factors, using the 'Ime4' package (Bates et al., 2018). Foraging sites were broadly classified as "West Coast", "North" and "South" based on their foraging distance from the colony. The scale of foraging was classified into two groups ("large" and "small") based on its bimodal distribution (see results Figure 5 B). The number of foraging bouts per trip was also classified into two groups (" 1 " and " $>1$ " foraging bout). All models included bird ID as a random effect to account for individuals with multiple trips. Trip duration and total distance travelled were transformed using the square root function, and foraging distance, foraging duration, distance travelled between foraging areas and max distance from the colony were log-transformed to achieve normality. For fixed effects that showed significant results, multiple pairwise comparisons were run using Tukey's HSD post-hoc tests. To investigate the level of variation within individuals, I selected those that had multiple foraging trips recorded $(n=16)$ and plotted the duration and foraging distance of trips for each individual. Individuals that were recorded in multiple years $(n=7)$ were also plotted to compare yearly variation. 

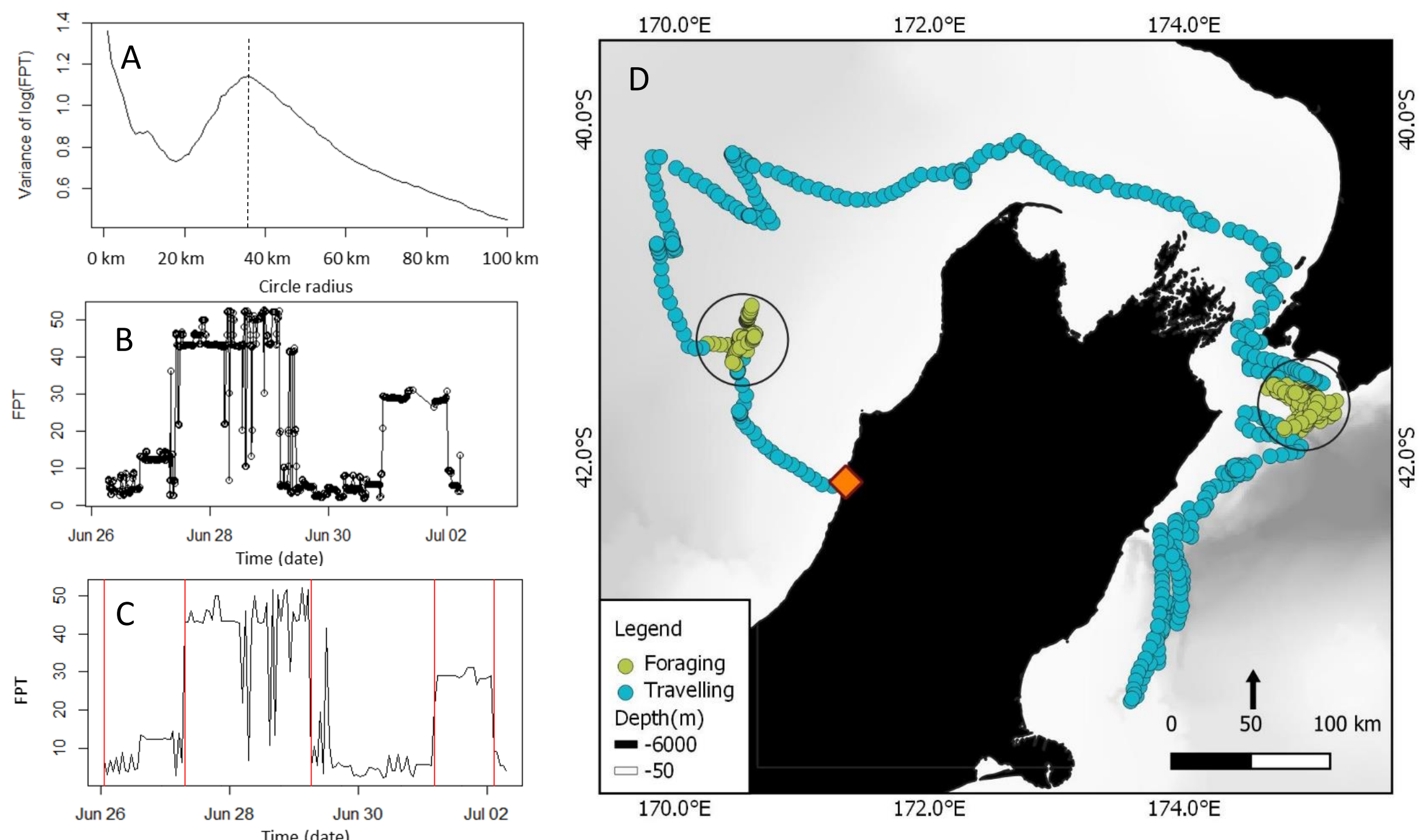

Figure 2: Example of FPT being used on one foraging trip. A) The variance in logFPT plotted against radius size for a single trip showing a peak in variance at a radius of $39 \mathrm{~km}$ (dashed line). B) Running the FPT analysis on the same trip using a radius of $39 \mathrm{~km}$. C) The separation of the trip into foraging and travelling sections using Levielle's method. D) The end result of the FPT analysis on the same trip. The circles represent the $39 \mathrm{~km}$ radius used in the analysis highlighting two bouts of foraging for this particular trip. 


\subsection{RESULTS}

Foraging trips lasted on average 5 days, ranging from $<1$ day to $>15$ days (Table 1). In a single trip, the petrels covered $100-5500 \mathrm{~km}$, with the average foraging trip covering around $1900 \mathrm{~km}$. The distribution of trip duration and total distance travelled showed no bimodal pattern and were skewed towards lower values (Figure $3 \mathrm{~A}, \mathrm{~B}$ ). Most individuals did not travel further than $500 \mathrm{~km}$ from the colony (Figure 3C) with the average max distance at $264 \pm 25 \mathrm{~km}$. The furthest individual reached $927 \mathrm{~km}$ from the colony. Individuals travelled at an average speed of $20 \mathrm{~km} / \mathrm{hr}$, ranging from $9-31.1 \mathrm{~km} / \mathrm{hr}$ (Table 1).
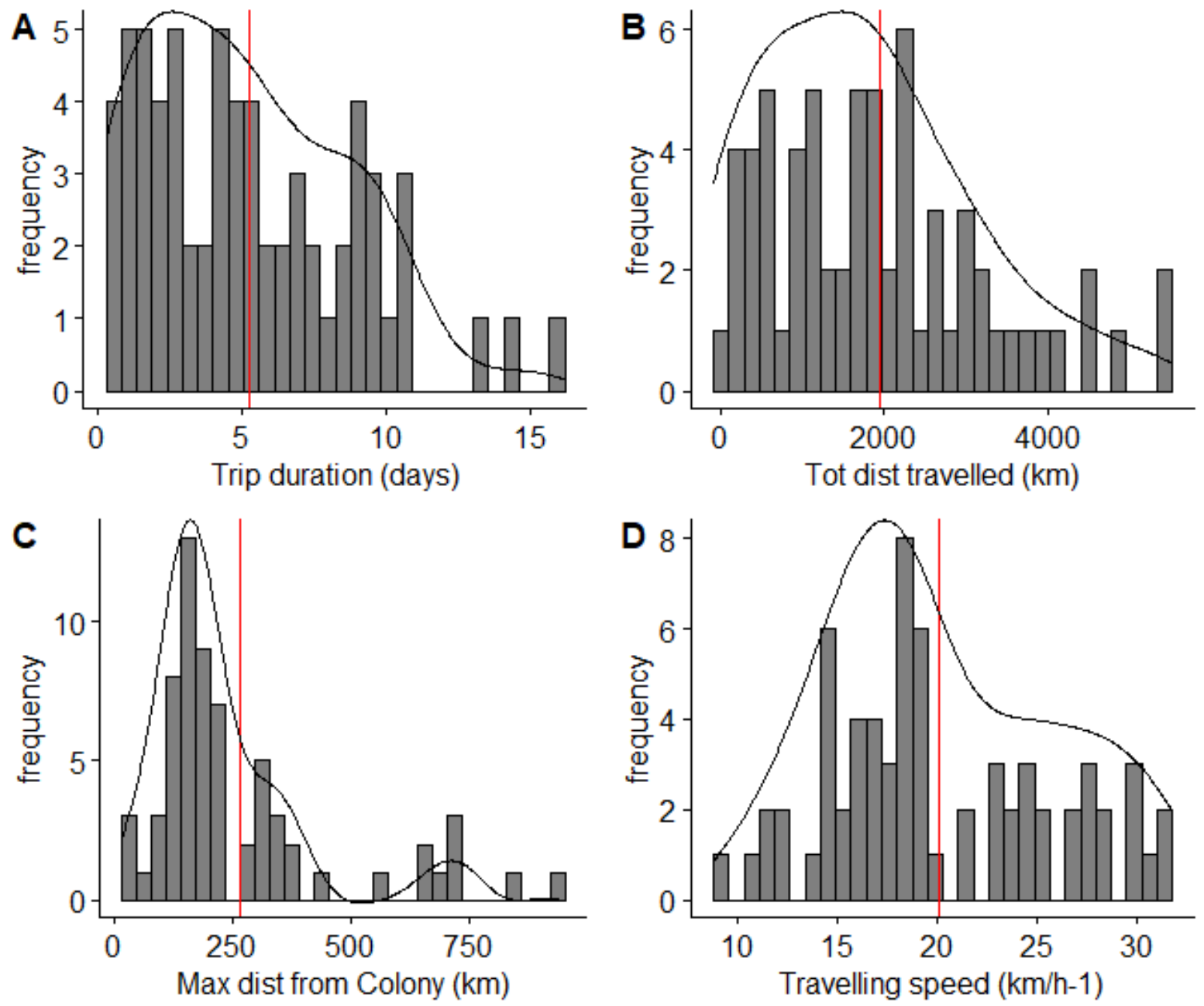

Figure 3: Frequency distribution of foraging trip characteristics of Westland petrels. The y-axis represents the number of foraging trips. Red lines indicate the mean and black lines represent the frequency distribution estimate. 
Table 1: Summary statistics of general foraging trip characteristics. Values are split by total population, sex (Female and Male), and year. The top two rows show total number (n) of individuals and trips. (U) represents an individual with unknown sex. Other values are mean \pm SE with the range shown in brackets underneath.

\begin{tabular}{|c|c|c|c|c|c|c|c|}
\hline \multirow[t]{2}{*}{ General trip summary } & \multirow[t]{2}{*}{ Total } & \multicolumn{2}{|c|}{ Sex } & \multicolumn{4}{|c|}{ Year } \\
\hline & & $\mathbf{F}$ & $\mathbf{M}$ & 2011 & 2012 & 2015 & 2016 \\
\hline \multirow[t]{2}{*}{ Number of individuals } & 42 & 19 & 22 & 11 & 6 & 16 & 16 \\
\hline & & & & & & & \\
\hline \multirow[t]{2}{*}{ Number of trips } & 66 & 28 & 36 & 17 & 11 & 18 & 20 \\
\hline & & & & & & & \\
\hline \multirow[t]{2}{*}{ Trip duration (days) } & $5.3 \pm 0.4$ & $6.6 \pm 0.8$ & $4.3 \pm 0.5$ & $2.5 \pm 0.4$ & $5.1 \pm 0.9$ & $8.1 \pm 0.9$ & $5.1 \pm 0.8$ \\
\hline & $(0.7-15.8)$ & $(0.4-15.8)$ & $(0.7-10.5)$ & $(0.4-5.1)$ & $(0.8-9.9)$ & $(1-15.8)$ & $(0.7-14.5)$ \\
\hline \multirow[t]{2}{*}{ Total distance travelled $(\mathrm{km})$} & $1945 \pm 166$ & $2438 \pm 297$ & $1594 \pm 177$ & $942 \pm 165$ & $2148 \pm 320$ & $2621 \pm 328$ & $2079 \pm 328$ \\
\hline & $(86-5523)$ & $(185-5523)$ & $(86-4091)$ & $(86-2081)$ & $(185-3497)$ & $(371-4891)$ & $(320-5523)$ \\
\hline \multirow[t]{2}{*}{ Max distance from colony (km) } & $264 \pm 25$ & $352 \pm 46$ & $201 \pm 25$ & $160 \pm 25$ & $321 \pm 59$ & $338 \pm 62$ & $255 \pm 43$ \\
\hline & $(23-927)$ & $(84-927)$ & $(23-677)$ & $(23-380)$ & $(84-677)$ & $(114-856)$ & $(86-927)$ \\
\hline \multirow[t]{2}{*}{ Travelling speed $\left(\mathrm{km} / \mathrm{h}^{-1}\right)$} & $20.1 \pm 0.7$ & $21.2 \pm 1.0$ & $19.3 \pm 0.9$ & $19.7 \pm 1.5$ & $23.1 \pm 1.9$ & $18.7 \pm 1.2$ & $19.9 \pm 1.1$ \\
\hline & $(9-31.1)$ & $(14.6-31.2)$ & $(9-31.2)$ & $(9-29.9)$ & $(14.9-31.2)$ & $(11.7-27.7)$ & $(11.4-31.2)$ \\
\hline
\end{tabular}




\subsubsection{Summary of FPT analysis}

The results of the FPT analysis revealed a variety of different foraging locations scattered predominantly around New Zealand's South Island (Figure 4). Most individuals (77\%) foraged along the West Coast of the South Island within 200km of the colony (Figure 5A). Those that went further either travelled South to forage around Haast and Southland, or North to forage around the Cook Strait and Kaikoura. One individual went North and foraged south of Hawkes Bay (Figure 4). Individuals displayed a variety of movement behaviours but could be broadly grouped into two types. Individuals either flew directly to and from foraging sites (Figure 4B) or took long looping trips far out to sea (Figure 4C). Of the two types of movement behaviours, the vast majority if trips displayed the directed movement behaviour (directed; $n=60$, looping; $n=6$ ). Interestingly for some of the looping trips, once the individual reaches the coastline, after flying far out to sea, they turn sharply to follow the coastline back to the colony (Figure 4).

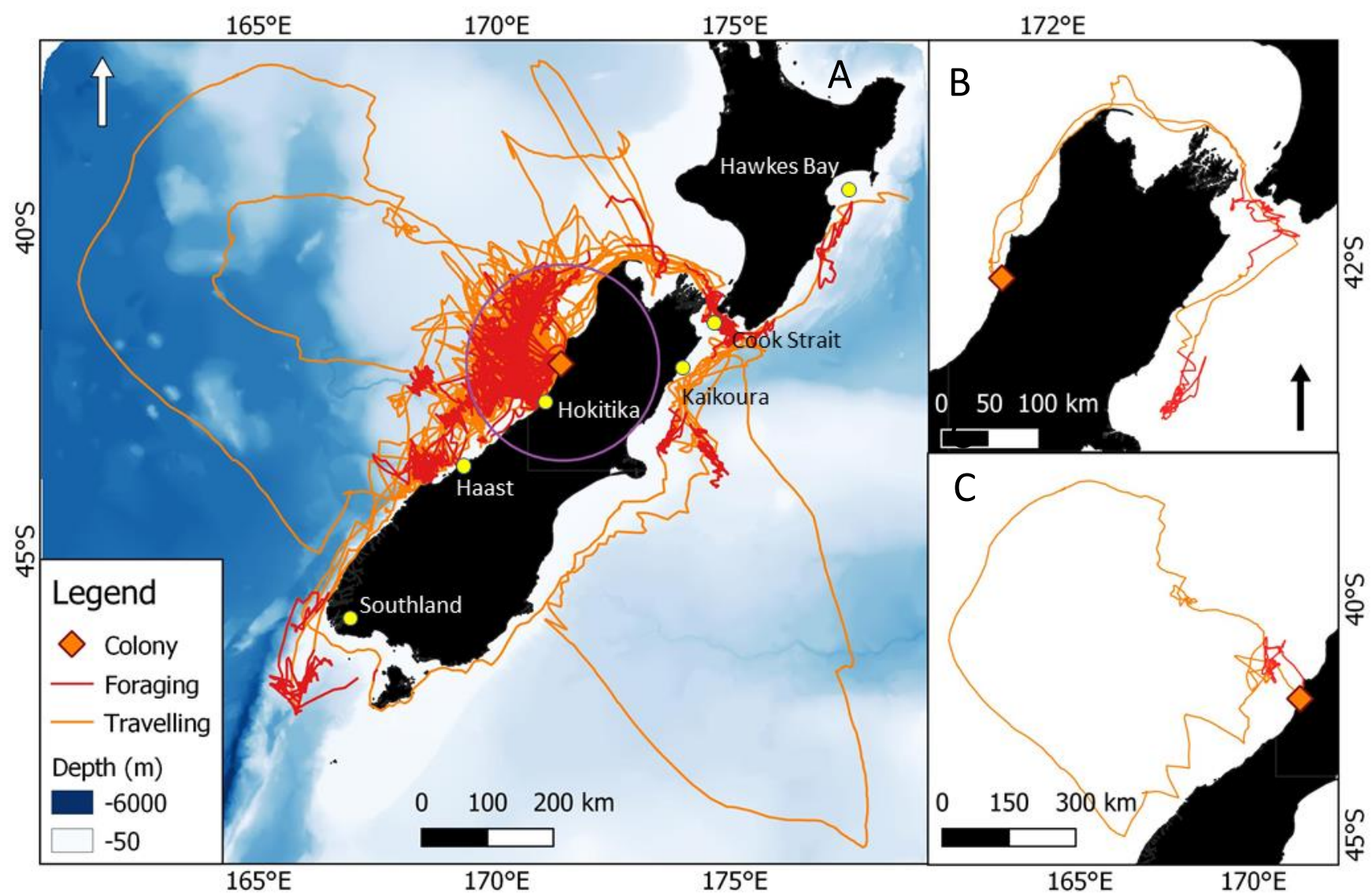

Figure 4: A) Foraging trips of all individuals with tracks split into foraging and travelling sections. The circle represents the $200 \mathrm{~km}$ distance from the colony. B) An example of a directed flight path. C) An example of a looping flight path.

Westland petrels showed a bimodal distribution in foraging scale with the majority of individuals foraging either at a smaller scale of around $20 \mathrm{~km}$ or a larger scale of around $85 \mathrm{~km}$ (Figure 5B). The mean foraging scale was $53 \pm 4 \mathrm{~km}$ (Table 2). Of the 66 foraging trips, 37 had only one foraging bout per 
trip (Figure 5C). Of the remaining 29 trips, 21 had two foraging bouts per trip. One individual had the highest number of foraging bouts with six in one trip (Figure 5C). On average foraging made up around $50 \%$ of the trip however, individuals ranged from it making up $12 \%$ to $97 \%$ of the trip (Table 2). Individuals spent on average $38.5 \pm 3$.8hrs foraging in a single trip with $74 \%$ of individuals spending $<50 \mathrm{~h}$ (Figure 5E). One individual spent over 200hrs foraging in a single trip (Figure 5E). On average individuals travelled $514 \pm 65 \mathrm{~km}$ between foraging bouts (Table 2). Most individuals (85\%) travelled less than $1000 \mathrm{~km}$ between foraging bouts however 2 individuals travelled almost $4000 \mathrm{~km}$ between foraging bouts (Figure 5F). Both foraging duration and distance travelled between foraging bouts were highly skewed towards lower values (Figure 5 E, F).
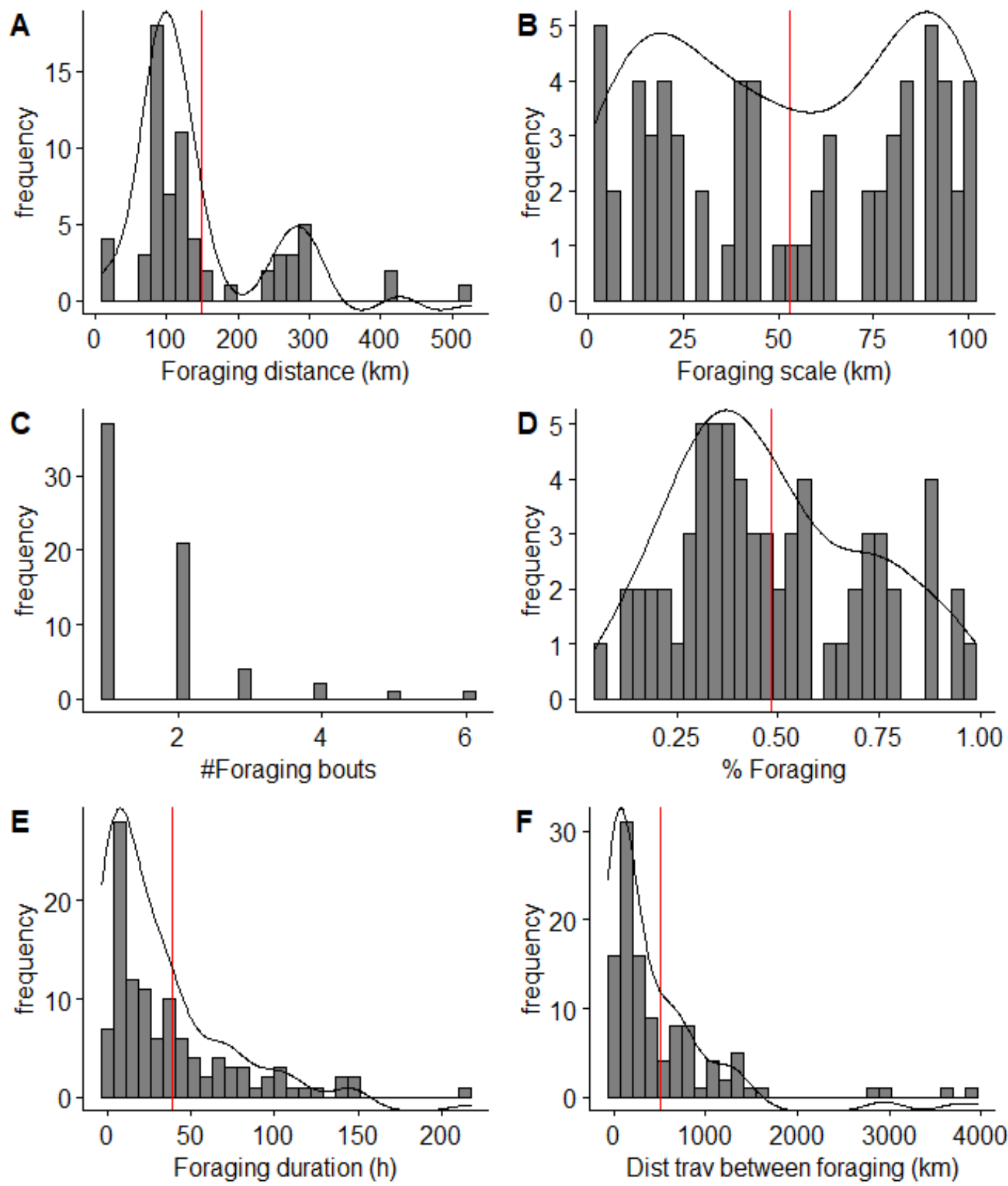

Figure 5: Frequency distribution of foraging characteristics determined from the first passage time analysis. The y-axis represents the number of foraging trips. Red lines indicate the mean and black lines represent the frequency distribution estimate. 
Table 2: Summary statistics of foraging characteristics derived from the first passage time analysis. Values are split by total population, sex (Male and Female), and year. Values are mean \pm SE with the range $r$ shown in brackets underneath.

\begin{tabular}{|c|c|c|c|c|c|c|c|c|}
\hline \multirow[t]{2}{*}{ FPT summary } & & \multirow[t]{2}{*}{ Total } & \multicolumn{2}{|c|}{ Sex } & \multicolumn{4}{|c|}{ Year } \\
\hline & & & $\mathbf{F}$ & $\mathbf{M}$ & 2011 & 2012 & 2015 & 2016 \\
\hline \multirow[t]{2}{*}{$\%$ Foraging } & $\mathrm{m} \pm \mathrm{SE}$ & $48 \pm 2.9$ & $52 \pm 4.3$ & $46 \pm 4.0$ & $50 \pm 6.8$ & $35 \pm 4.3$ & $59 \pm 5.3$ & $44 \pm 4.4$ \\
\hline & $\mathrm{r}$ & $(12-97)$ & $(6-89)$ & $(12-97)$ & $(6-94)$ & $(11-53)$ & $(17-97)$ & $(15-77)$ \\
\hline \multirow[t]{2}{*}{ Foraging distance $(\mathrm{km})$} & $\mathrm{m}+\mathrm{SE}$ & $149 \pm 13$ & $187 \pm 19$ & $120 \pm 15$ & $108 \pm 20$ & $229 \pm 38$ & $159 \pm 26$ & $129 \pm 15$ \\
\hline & $\mathrm{r}$ & $(1-728)$ & $(1-728)$ & $(1-611)$ & $(1-380)$ & $(7-611)$ & $(1-728)$ & $(1-316)$ \\
\hline \multirow[t]{2}{*}{ Foraging duration (h) } & $\mathrm{m}+\mathrm{SE}$ & $38.5 \pm 3.8$ & $47.6 \pm 6.8$ & $32.2 \pm 4.2$ & $25.3 \pm 6.4$ & $22.8 \pm 4.5$ & $61.7 \pm 9.4$ & $35.4 \pm 5.4$ \\
\hline & $\mathrm{r}$ & $(1.2-215.3)$ & $(2.8-215.3)$ & $(1.2-149.7)$ & $(3.2-105.3)$ & $(1.2-80.3)$ & $(5.7-215.3)$ & $(2.8-122.1)$ \\
\hline \multirow[t]{2}{*}{ Dist trav between foraging $(\mathrm{km})$} & $\mathrm{m} \pm \mathrm{SE}$ & $514 \pm 65$ & $678 \pm 124$ & $400 \pm 62$ & $275 \pm 71$ & $534 \pm 134$ & $543 \pm 130$ & $637 \pm 142$ \\
\hline & $\mathrm{r}$ & $(1-3885)$ & (18-3885) & $(1-3000)$ & (18-1334) & $(41-3000)$ & $(32-3885)$ & $(1-3632)$ \\
\hline \multirow[t]{2}{*}{ \#Foraging bouts per trip } & $\mathrm{m} \pm \mathrm{SE}$ & $1.6 \pm 0.1$ & $1.6 \pm 0.2$ & $1.6 \pm 0.2$ & $1.2 \pm 0.1$ & $2.1 \pm 0.5$ & $1.8 \pm 0.2$ & $1.5 \pm 0.2$ \\
\hline & $\mathrm{r}$ & $(1-6)$ & $(1-5)$ & $(1-6)$ & (1-3) & (1-6) & (1-4) & (1-3) \\
\hline \multirow[t]{2}{*}{ Foraging scale $(\mathrm{km})$} & $\mathrm{m}+\mathrm{SE}$ & $53 \pm 4$ & $63 \pm 6$ & $45 \pm 5$ & $38 \pm 8$ & $48 \pm 9$ & $68 \pm 6$ & $56 \pm 8$ \\
\hline & $\mathrm{r}$ & $(3-100)$ & $(3-100)$ & $(3-100)$ & $(3-100)$ & $(3-80)$ & $(12-100)$ & $(4-100)$ \\
\hline
\end{tabular}




\subsubsection{Correlation of characteristics}

The number of foraging bouts per trip was positively correlated with trip duration $(\mathrm{p}<0.01)$, total distance travelled $(\mathrm{p}<0.01)$ and max distance from the colony $(\mathrm{p}=0.03)$. Foraging duration showed positive correlation with max distance from the colony $(\mathrm{p}<0.01)$ and foraging distance $(\mathrm{p}=0.01)$, and a negative correlation with the number of foraging bouts per trip ( $\mathrm{p}=0.01$; Table 3 ). Foraging distance was also positively correlated with travelling speed $(\mathrm{p}<0.01)$ and foraging scale $(\mathrm{p}=0.01$; Table 3$)$. Foraging scale and \%Foraging were also positively correlated $(\mathrm{p}<0.01)$. The distance travelled between foraging bouts was positively correlated with trip duration $(\mathrm{P}<0.01)$ and negatively correlated with $\%$ Foraging $(\mathrm{p}<0.01$; Table 3$)$. Travelling speed was positively correlated with max distance from the colony $(\mathrm{p}<0.01)$.

Table 3: Correlation coefficients from the pairwise Spearman Rho correlation of foraging characteristics.

Bold values indicate statistically significant correlations and underlined values indicate high correlation.

\begin{tabular}{|c|c|c|c|c|c|c|c|c|c|c|}
\hline & $\begin{array}{c}\text { Trip } \\
\text { Duration }\end{array}$ & $\begin{array}{l}\text { Tot Dist } \\
\text { Travelled }\end{array}$ & $\begin{array}{c}\text { Max Dist } \\
\text { Colony }\end{array}$ & $\begin{array}{c}\text { Travelling } \\
\text { speed }\end{array}$ & $\begin{array}{l}\text { Foraging } \\
\text { distance }\end{array}$ & $\begin{array}{c}\text { Foraging } \\
\text { scale }\end{array}$ & $\begin{array}{c}\text { \# Foraging } \\
\text { areas per } \\
\text { trip } \\
\end{array}$ & $\%$ Foraging & $\begin{array}{l}\text { Foraging } \\
\text { duration }\end{array}$ & $\begin{array}{l}\text { Dist trav } \\
\text { between } \\
\text { foraging }\end{array}$ \\
\hline Trip Duration & - & - & - & - & - & - & - & - & - & - \\
\hline Tot Dist Travelled & 0.9 & - & - & - & - & - & - & - & - & - \\
\hline Max Dist Colony & 0.77 & 0.79 & - & - & - & - & - & - & - & - \\
\hline Travelling speed & 0 & 0.23 & 0.33 & - & - & - & - & - & - & - \\
\hline Foraging distance & 0.47 & 0.52 & 0.79 & 0.35 & - & - & - & - & - & - \\
\hline Foraging scale & 0.5 & 0.46 & 0.47 & 0.18 & 0.29 & - & - & - & - & - \\
\hline \# Foraging bouts per trip & 0.44 & 0.39 & 0.26 & 0.11 & 0.07 & 0.06 & - & - & - & - \\
\hline$\%$ Foraging & 0.21 & 0.1 & 0.07 & 0.18 & -0.05 & 0.44 & 0.02 & - & - & - \\
\hline Foraging duration & 0.48 & 0.37 & 0.34 & 0.03 & 0.22 & 0.53 & -0.23 & 0.61 & - & - \\
\hline Dist trav between foraging & 0.34 & 0.49 & 0.47 & 0.16 & 0.48 & 0.02 & -0.07 & -0.26 & 0.11 & - \\
\hline
\end{tabular}

\subsubsection{Factors explaining variation in Westland petrel foraging behaviour}

Year explained variation in trip duration, foraging distance, \%Foraging and foraging duration (Table 4). Trip duration was longer in 2015 compared 2011 and 2012 (Figure 6A; glmm; $F_{3,56}=4.7$, $p<0.01$ ). Foraging duration was also higher in 2015 compared to 2011 and 2012 (Figure 6B, glmm; F $3,55=4.4$, p <0.01). In 2011, the total distance travelled was significantly lower than 2015 and 2016 (Figure 6C, glmm; $\mathrm{F}_{3,49}=3.4, \mathrm{p}=0.02$ ) with individuals remaining much closer to the colony compared to other years (Figure 6F). Although year did not explain variation in the max distance travelled from the colony $\left(\mathrm{glmm} ; \mathrm{F}_{3,52}=2.2, \mathrm{p}=0.09\right)$ post hoc analysis showed that max distance travelled from the colony was much lower in 2011 compared to 2015 and 2016 (Tukey; $2015 \mathrm{z}=2.8, \mathrm{p}=0.02 ; 2016: \mathrm{z}=2.7, \mathrm{p}=0.02$ ). Individuals in 2012 foraged further than other years (Figure 6D; glmm; $F_{3,58}=3.3, p=0.02$ ) with an average foraging distance of $\sim 230 \mathrm{~km}$ compared to $<160 \mathrm{~km}$ in the other three years. Foraging location was also more varied in 2012, taking place on the West Coast, Haast, Cook Strait, Kaikoura and Hawkes Bay (Figure 6F). One individual in 2012 travelled north to forage in the Cook Strait and Kaikoura then followed the coastline around the South Island, stopping to forage near Stewart Island and Haast before 
returning to the colony (Figure 6F). Despite foraging further in 2012, foraging made up a smaller proportion of trips compare to 2011 and 2015 (Figure 6E; glmm; $F_{3,56}=3.0, p=0.03$ ). Petrels in both 2015 and 2016 exhibited looping behaviour however foraging location differed with no foraging taking place at the northern site in 2015 and none taking place at the southern site in 2016 (Figure 6)

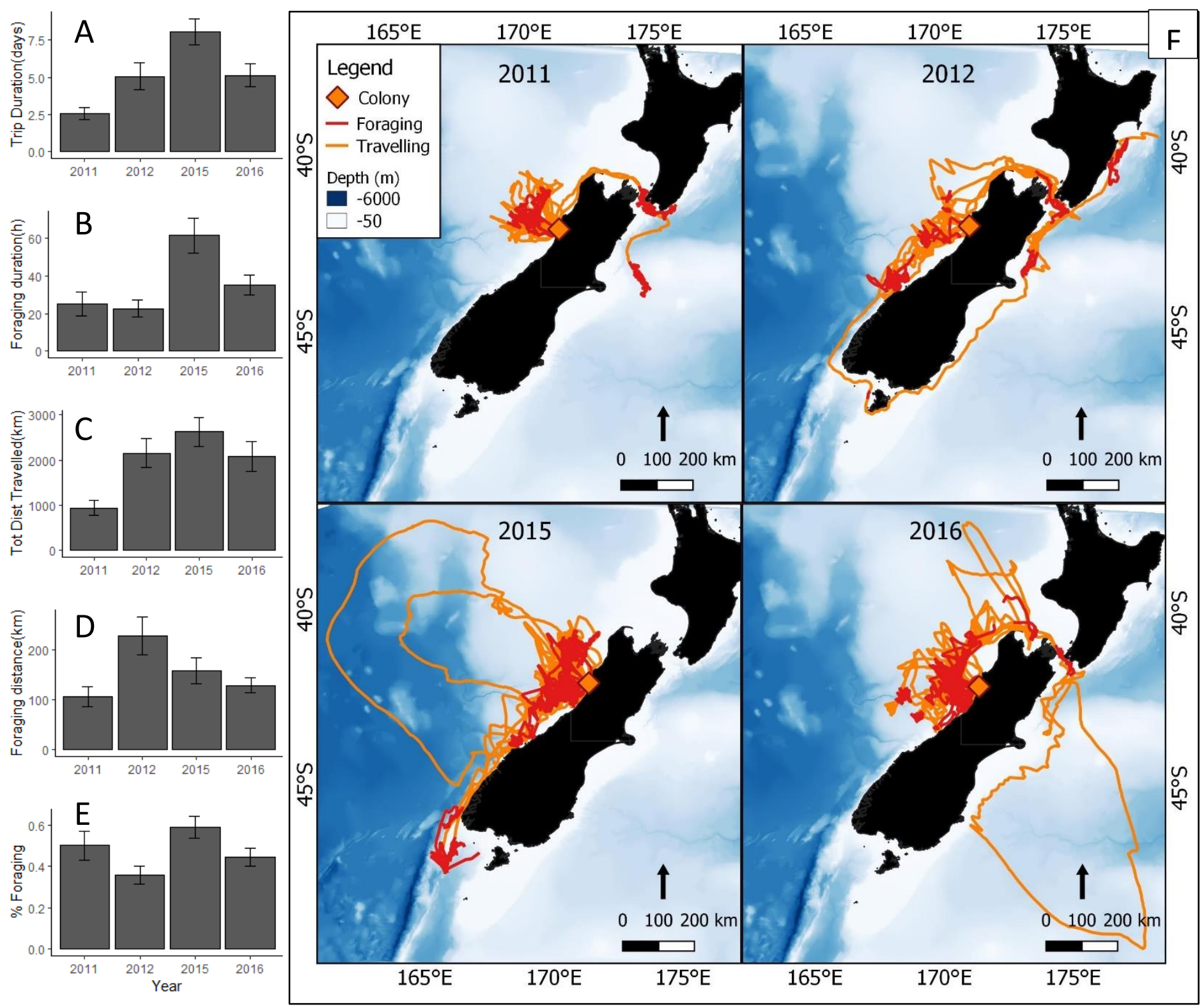

Figure 6: Bar plots (A-E) show the means \pm SE of foraging characteristics that showed significant difference among years. The map (F) shows the foraging locations and movement behaviours of Westland petrels for each year. 
Table 4: Results of GLMM for each foraging characteristic. * represents level of significance $(*=0.05, * *=0.01, * * *=0.001)$. Significance among years and foraging sites were determined using Tukey post-hoc tests.

\begin{tabular}{|c|c|c|c|c|c|c|}
\hline & Sum.sq & Mean.sq & NumDF & DenDF & $\mathrm{F}$ value & $\operatorname{Pr}(>\mathrm{F})$ \\
\hline \multicolumn{7}{|c|}{ sqrt(Trip duration) } \\
\hline Year & 5.49 & 1.83 & 3 & 56 & 4.750 & $0.005 * *$ \\
\hline Sex & 0.36 & 0.18 & 2 & 56 & 0.461 & 0.633 \\
\hline Foraging site & 2.13 & 1.06 & 2 & 56 & 2.762 & 0.072 \\
\hline \#Foraging bouts & 3.44 & 3.44 & 1 & 56 & 8.937 & $0.004 * *$ \\
\hline Foraging scale & 1.24 & 1.24 & 1 & 56 & 3.222 & 0.078 \\
\hline \multicolumn{7}{|c|}{$\log (\max$ dist from colony) } \\
\hline Year & 1.8421 & 0.614 & 3 & 52.249 & 2.2405 & 0.09442 . \\
\hline Sex & 0.4215 & 0.2108 & 2 & 40.613 & 0.7691 & 0.47007 \\
\hline Foraging site & 6.3337 & 3.1669 & 2 & 53.989 & 11.5553 & $6.65 \mathrm{E}-05 * * *$ \\
\hline \#Foraging bouts & 0.6708 & 0.6708 & 1 & 55.766 & 2.4475 & 0.12337 \\
\hline Foraging scale & 1.2114 & 1.2114 & 1 & 54.934 & 4.4202 & $0.04011 *$ \\
\hline \multicolumn{7}{|c|}{ sqrt(Tot Dist Travelled) } \\
\hline Year & 1645.83 & 548.61 & 3 & 49.19 & 3.4098 & $0.02458 *$ \\
\hline Sex & 190.11 & 95.06 & 2 & 35.508 & 0.5908 & 0.55923 \\
\hline Foraging site & 947.82 & 473.91 & 2 & 52.45 & 2.9455 & 0.06133 \\
\hline \#Foraging bouts & 1073.38 & 1073.38 & 1 & 55.165 & 6.6715 & $0.01248 *$ \\
\hline Foraging scale & 297.48 & 297.48 & 1 & 55.044 & 1.849 & 0.17945 \\
\hline \multicolumn{7}{|c|}{ Travelling Speed } \\
\hline Year & 25.22 & 8.41 & 3 & 53 & 0.401 & 0.753 \\
\hline Sex & 16.55 & 8.28 & 2 & 33 & 0.395 & 0.677 \\
\hline Foraging site & 152.02 & 76.01 & 2 & 55 & 3.680 & $0.032 *$ \\
\hline \#Foraging bouts & 12.71 & 12.71 & 1 & 56 & 0.606 & 0.439 \\
\hline Foraging scale & 0.82 & 0.82 & 1 & 51 & 0.039 & 0.844 \\
\hline \multicolumn{7}{|l|}{ \%Foraging } \\
\hline Year & 0.41 & 0.14 & 3 & 56 & 3.011 & $0.038 *$ \\
\hline Sex & 0.02 & 0.01 & 2 & 56 & 0.170 & 0.844 \\
\hline Foraging site & 0.11 & 0.06 & 2 & 56 & 1.212 & 0.305 \\
\hline \#Foraging bouts & 0.00 & 0.00 & 1 & 56 & 0.001 & 0.970 \\
\hline Foraging scale & 0.34 & 0.34 & 1 & 56 & 7.472 & $0.008 * *$ \\
\hline \multicolumn{7}{|c|}{$\log ($ Foraging distance $)$} \\
\hline Year & 83811 & 27937.1 & 3 & 58 & 3.335 & $0.025 *$ \\
\hline Sex & 54436 & 27217.9 & 2 & 58 & 3.249 & $0.046 *$ \\
\hline \#Foraging bouts & 5311 & 5311.1 & 1 & 58 & 0.634 & 0.429 \\
\hline Foraging scale & 14838 & 14837.7 & 1 & 58 & 1.771 & 0.188 \\
\hline \multicolumn{7}{|c|}{$\log ($ Foraging duration) } \\
\hline Year & 12228.7 & 4076.2 & 3 & 55 & 4.459 & $0.007 * *$ \\
\hline Sex & 440.8 & 220.4 & 2 & 26 & 0.241 & 0.788 \\
\hline Foraging site & 4512.7 & 2256.4 & 2 & 65 & 2.468 & 0.093 \\
\hline \#Foraging bouts & 5504.2 & 5504.2 & 1 & 84 & 6.020 & $0.016 *$ \\
\hline Foraging scale & 7919.3 & 7919.3 & 1 & 85 & 8.662 & $0.004 * *$ \\
\hline \multicolumn{7}{|c|}{$\log ($ Dist trav between foraging) } \\
\hline Year & 1336106 & 445369 & 3 & 41 & 1.120 & 0.352 \\
\hline Sex & 1120878 & 560439 & 2 & 21 & 1.409 & 0.267 \\
\hline Foraging site & 780262 & 390131 & 2 & 43 & 0.981 & 0.383 \\
\hline \#Foraging bouts & 385908 & 385908 & 1 & 72 & 0.970 & 0.328 \\
\hline Foraging scale & 52771 & 52771 & 1 & 70 & 0.133 & 0.717 \\
\hline
\end{tabular}


Sex explained variation in foraging distance with females $(n=19)$ foraging significantly further than males $(\mathrm{n}=22)\left(\mathrm{glmm} ; \mathrm{F}_{3,58}=3.33, \mathrm{p}=0.02\right)$. Females foraged on average $\sim 190 \mathrm{~km}$ from the colony compared to $\sim 120 \mathrm{~km}$ in males. Females also tended to have longer trip duration, have a higher total distance travelled and reach a further max distance from the colony than males (Table 1) although this was not statistically significant (Table 4).

The number of foraging bouts per trip explained variation in trip duration, foraging duration and the total distance travelled (Table 4). Individuals that had $>1$ foraging bout had longer trips than those that had just one foraging bout per trip ( $\mathrm{glmm} ; \mathrm{F}_{1,56}=8.9$, $\mathrm{p}<0.01$ ). The average trip duration for individuals that had $>1$ foraging bout was 6.8 days compared to those that only had one foraging bout at 3.9 days. Despite having longer trips, individuals that had $>1$ foraging bout spent less time foraging (34h) compared to those that had just one foraging bout $(47 \mathrm{~h})\left(\mathrm{glmm} ; \mathrm{F}_{1,84}=6.0, \mathrm{p}=0.01\right)$. Individuals that had $>1$ foraging bout also had a higher total distance travelled $(\sim 2600 \mathrm{~km})$ than those that had only one foraging bout $(\sim 1500 \mathrm{~km})\left(\mathrm{glmm} ; \mathrm{F}_{55.16}=6.6, \mathrm{p}=0.01\right)$.

The scale of foraging explained variation in the proportion of trip spent foraging, the duration of foraging and the max distance from the colony (Table 4). Foraging made up a higher proportion of the trip for individuals foraging at larger scales, making up 57\% of the trip compared to $40 \%$ for individuals foraging at smaller scales $\left(\mathrm{glmm} ; \mathrm{F}_{56}=7.4, \mathrm{p}<0.01\right)$. Individuals foraging at larger scales also foraged for longer $\left(\mathrm{glmm} ; \mathrm{F}_{85}=8.6, \mathrm{p}<0.01\right)$ and reached a higher max distance from the colony $(\mathrm{glmm}$; $\left.\mathrm{F}_{54.93}=4.4, \mathrm{p}=0.04\right)$ than those foraging at smaller scales.

\subsubsection{Foraging Site}

Foraging site explained variation in travelling speed and max distance from the colony (Table 4). Individuals that foraged at the northern foraging site travelled faster than those foraging on the West Coast (Figure 7A; glmm; $F_{3,55}=3.6, p=0.03$ ). Individuals that foraged at the southern site also tended to travel faster than those on the West Coast (Figure 7A) although it was not significant (Tukey; z=-1.5, $\mathrm{p}=0.25$ ). The max distance reached from the colony was significantly lower at the West Coast foraging site compared to the northern and southern sites ( $\mathrm{glmm} ; \mathrm{F}_{2,54}=11.5$, $\left.\mathrm{p}<0.01\right)$. On average, individuals reached a max distance of $\sim 200 \mathrm{~km}$ at the West Coast foraging site compared to $\sim 550 \mathrm{~km}$ at the northern and southern sites. Despite the northern and southern sites being located much further away than the West Coast, foraging site did not explain variation in trip duration (glmm; $\mathrm{F}_{56}=2.7, \mathrm{p}=0.07$ ) or total distance travelled (glmm; $\mathrm{F}_{52}=2.95, \mathrm{p}=0.06$ ). Further investigation revealed that trip duration and distance travelled are highly variable on the West Coast compared to the other foraging sites (Figure 7 B, C). Trip duration on the West Coast ranged between 1-14 days with individuals travelling anywhere between $86 \mathrm{~km}$ and $5522 \mathrm{~km}$ in a single trip. Furthermore, when comparing the flight paths among the three sites, petrels at both the northern and West Coast sites exhibited looping behaviour whereas petrels at the southern foraging site exhibited more directed flight behaviour (Figure 8). 

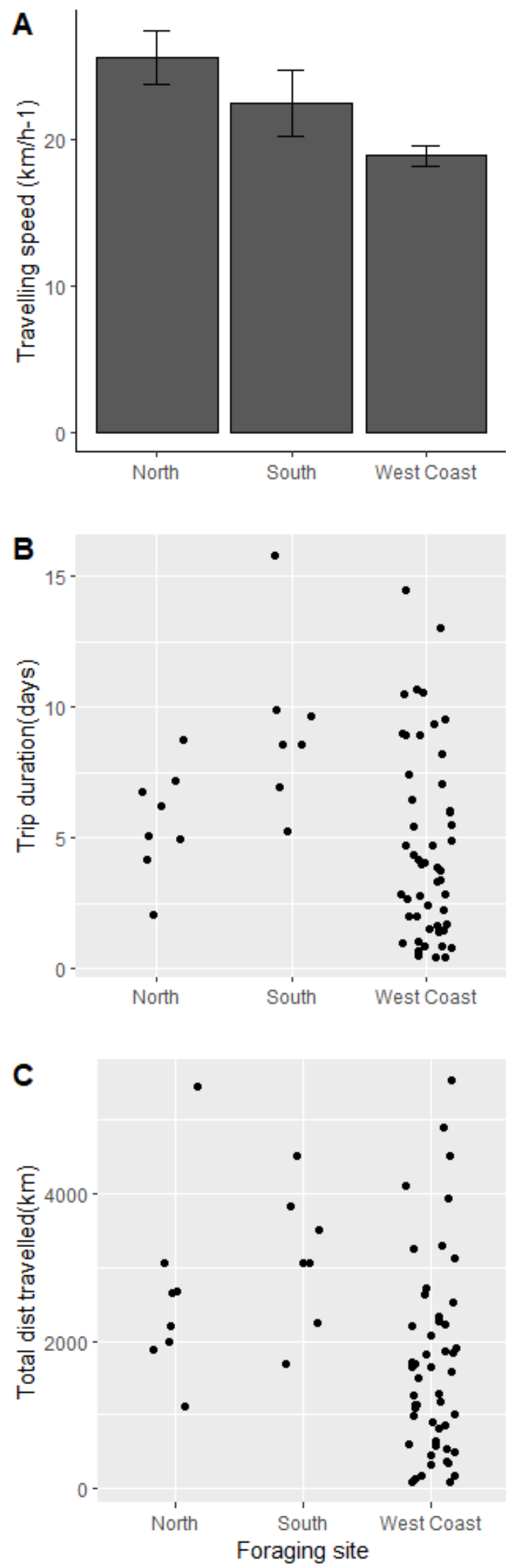

Figure 7: Comparison of foraging characteristics among foraging sites. A) shows mean \pm SE. B, C) points represent individual foraging trips.

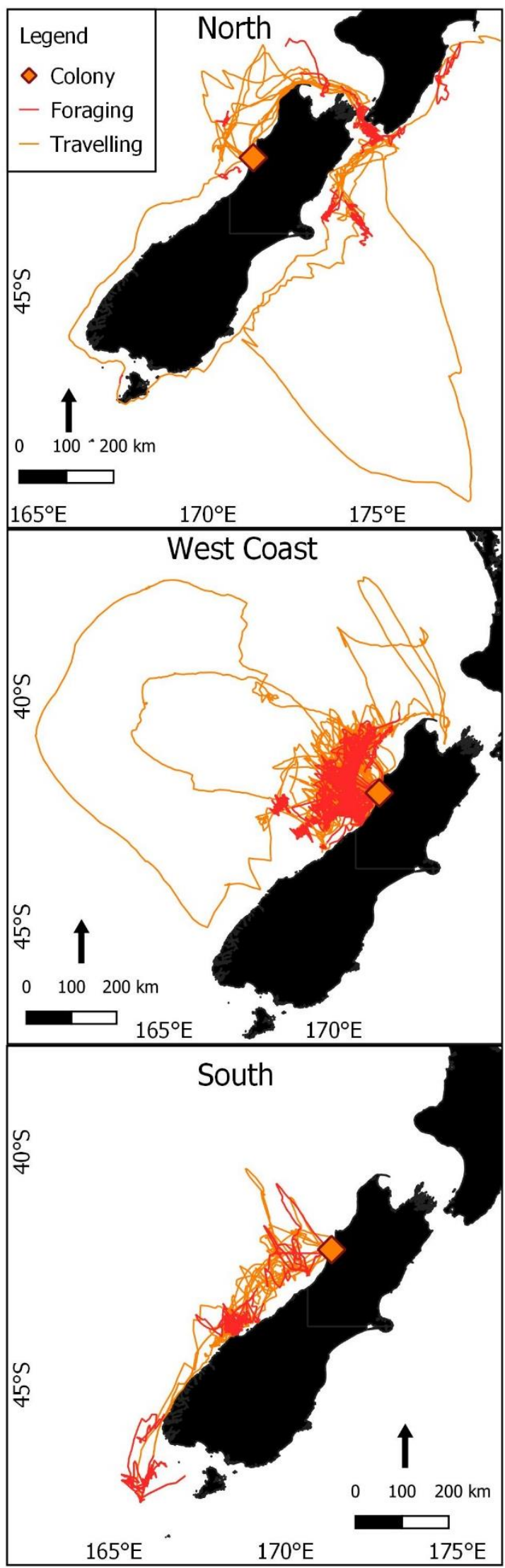

Figure 8: Comparison of flight behaviours and foraging locations among the three foraging sites. 


\subsubsection{Distance travelled between foraging bouts}

None of the fixed factors (Year, sex, foraging site, \#Foraging bouts or foraging scale) could explain variation in the distance travelled between foraging bouts (Table 4). Further analysis using phenotypic characteristics revealed that wing length explained this variation; birds with longer wing lengths travelled shorter distances between foraging bouts (Figure 9; glmm; $\mathrm{t}_{13.78}=-2.38, \mathrm{p}=0.03$ ). Phenotypic characteristics did not explain variation in any of the other foraging characteristics (Appendix S1).

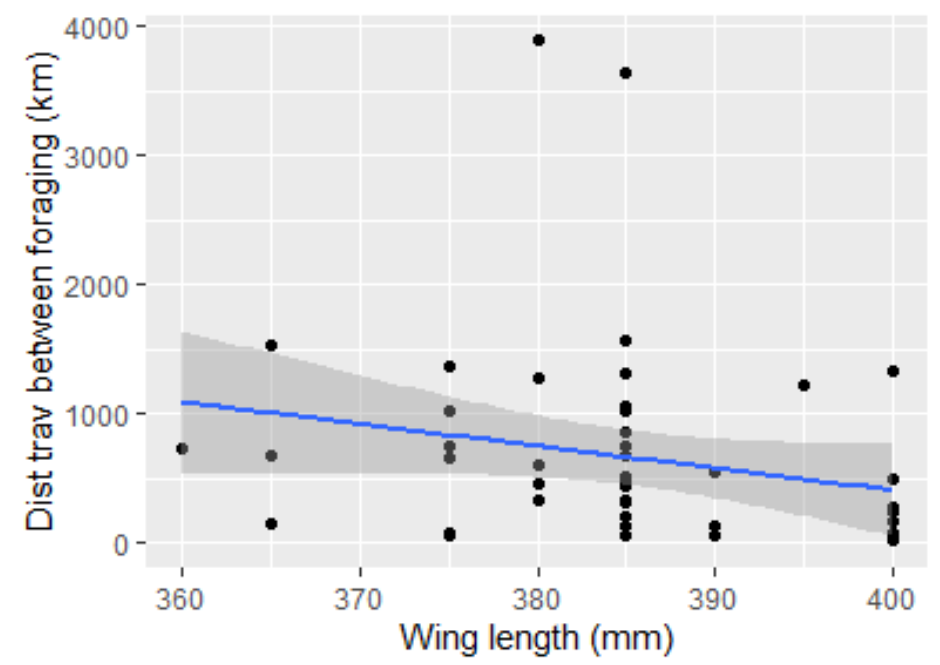

Figure 9: Relationship between wing length and the distance travelled between foraging bouts.

\subsubsection{Within individual variation}

Of the 42 individuals tracked, 16 had more than one foraging trip recorded. For trip duration and foraging distance, individuals appear to show different levels of variation. Some individuals were relatively consistent in trip duration and foraging distance while others varied considerably (Figure 10). For example, individual F2 had both trips last around 3 days foraging on the West Coast, around 100km form the colony (Figure 11). Conversely, individual M7 took a short 1-day trip to the West Coast and two longer trips lasting around 5 days. Although M7's longer trips were roughly the same duration, they varied considerably in foraging distance (Figure 10) with one trip going south to forage around Haast $(300 \mathrm{~km})$ and the other going north to forage south of Hawkes Bay (500km) (Figure 11).

Of the 16 individuals with multiple trips, 7 were recorded over multiple years. Some of these individuals had relatively consistent behaviour. Individual M3 was tracked in 2011 and 2016 and in both years had similar trip duration (1-5 days) and foraging distance (Figure 10). In both years M3 foraged at the West Coast foraging site (Figure 12). Other individuals varied considerably between years. Individual F5 had a much longer foraging trip and foraged further in 2016 compared to 2015 (Figure 10). In 2015, F5 went out for a short 4-day trip to forage on the West Coast (Figure 12), travelling no further than $150 \mathrm{~km}$ from the colony. This is compared to 2016 where F5 went out for almost 10 days and foraged $300 \mathrm{~km}$ from the colony in the Cook Strait (Figure 12). Unlike the fast directed trip in 2015, in 2016, F5 took a 
long looping trip to the southeast of New Zealand, travelling almost $1000 \mathrm{~km}$ from the colony, before returning to the southern east coast of New Zealand's South Island and following the coast back up to the Cook Strait (Figure 12).
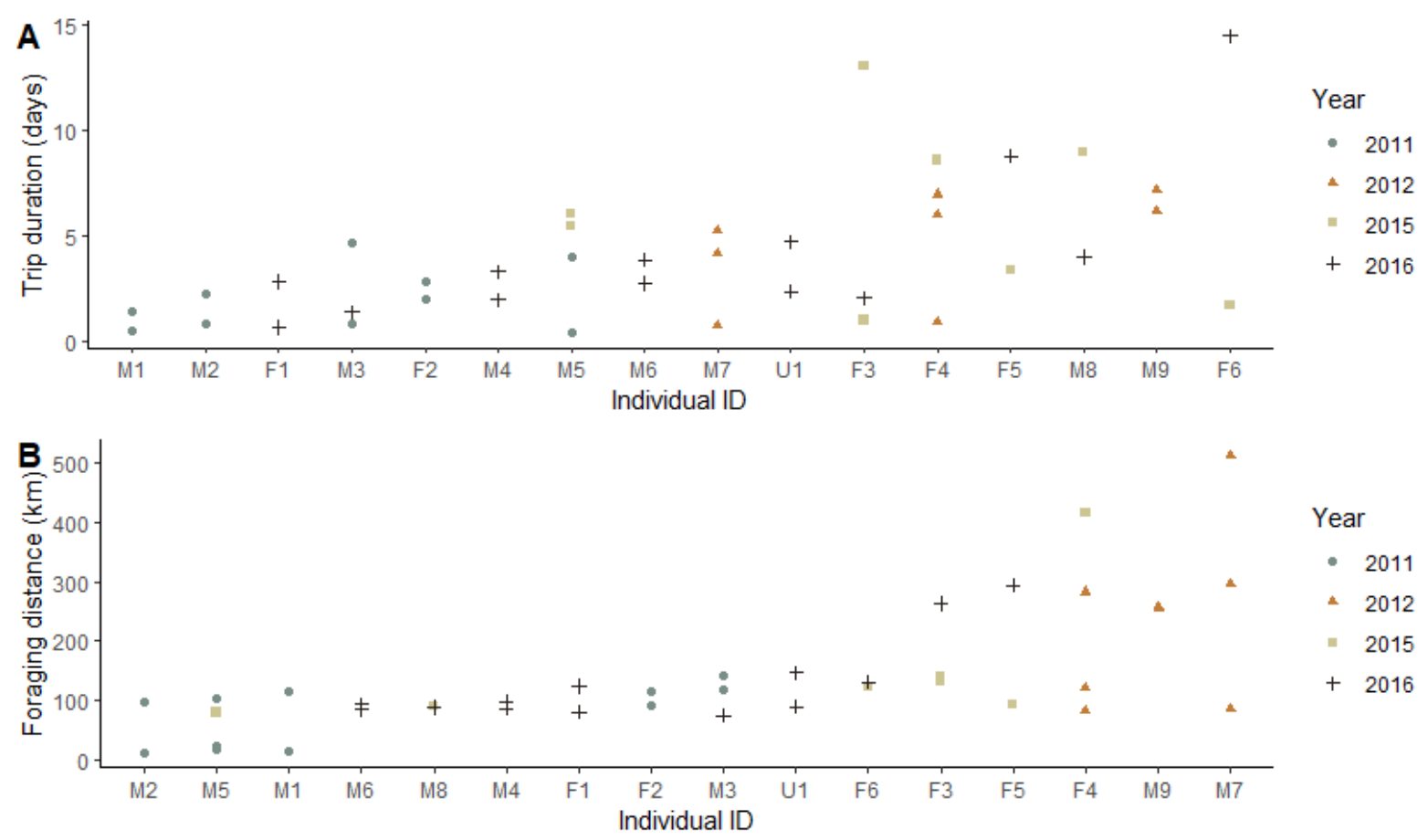

Figure 10: Comparison of foraging variation for individuals with multiple trips recorded. Individuals are ordered by y-axis value (lowest to highest). Shapes and colours distinguish different years. Sex is shown in individual ID's; M (male), F (female) and U (unknown)

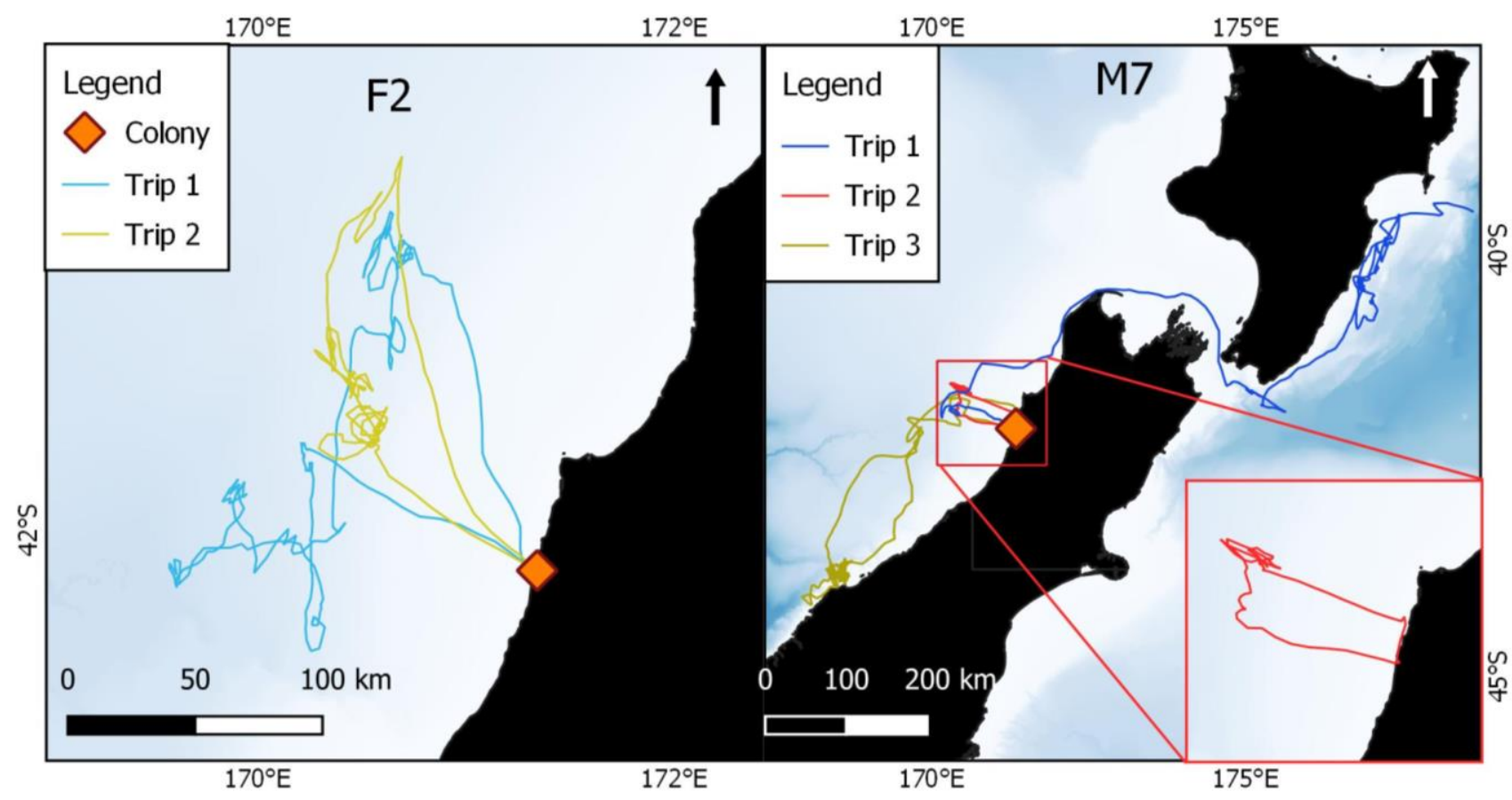

Figure 11: Comparison of the variation in foraging trips between individual F2 (relatively consistent trips) and M7 (varied foraging trips) 


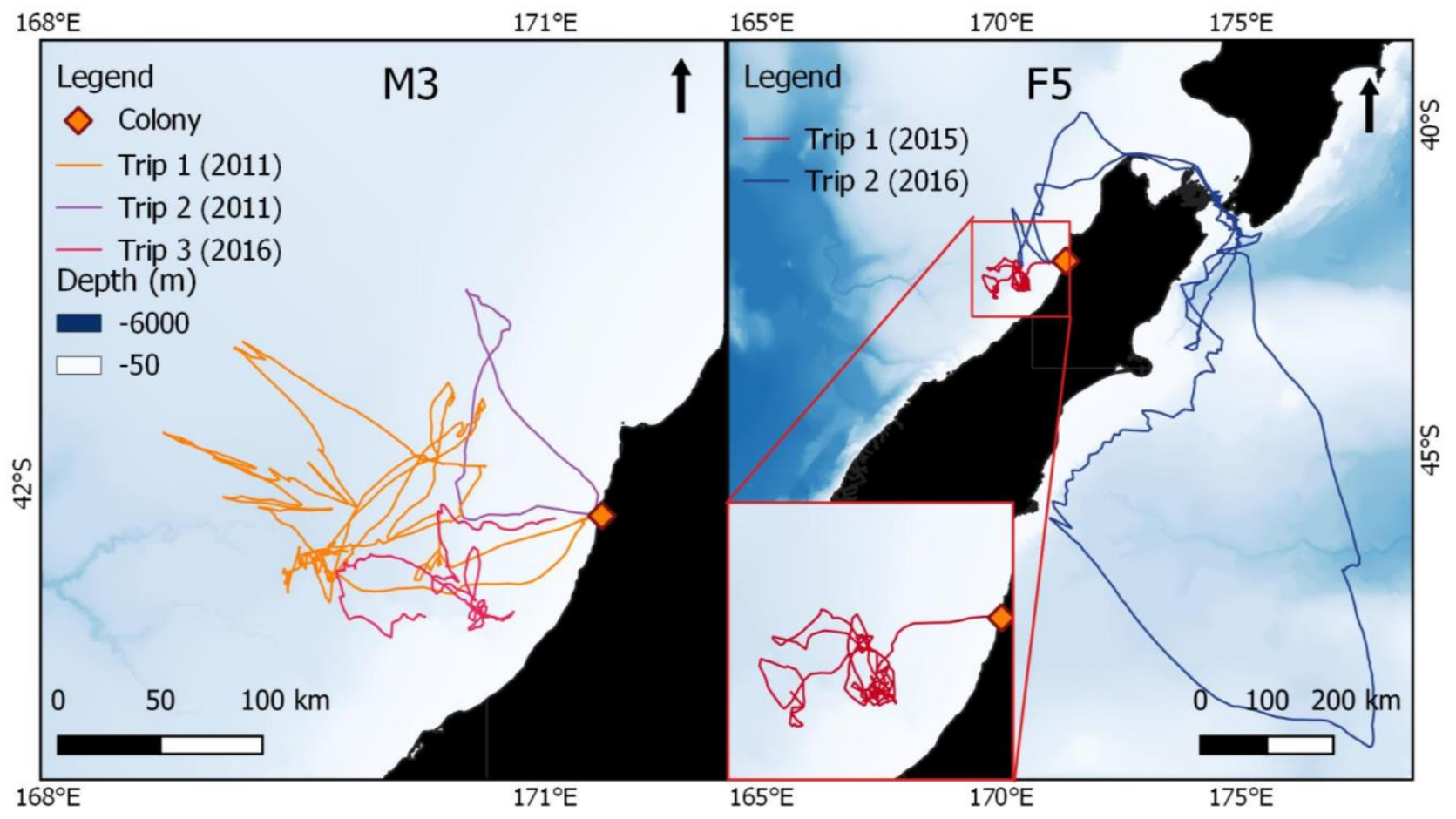

Figure 12: Comparison of the variation in foraging trips for individuals tracked across multiple years.

\subsection{Discussion}

There is increasing focus in seabird ecology on understanding individual variation in foraging behaviour as it can inform us on aspects such as the level of intra-specific competition and how individuals respond to environmental change (Phillips et al., 2017). I examined the variation in Westland petrel foraging behaviour at the population, individual and within individual level to 1) describe and categorise their foraging strategies, and 2) investigate what factors explained this variation. I found considerable variation in foraging behaviour at all levels. While most individuals foraged along the West Coast some went as far north as Hawkes Bay while others foraged as far south as Southland. Westland petrels also appeared to forage at two different scales and displayed a variety of flight behaviours. Most of the variation was explained by year with individuals taking longer trips and travelling further in 2015 whereas individuals in 2011 took shorter trips and travelled less. Interestingly, sex was also important with females foraging further than males. This suggests there is some degree sexual segregation occurring in Westland petrels despite little evidence from previous studies (Poupart et al., 2020; Waugh et al., 2018). Finally, foraging site explained surprisingly little of the variation due to the high variability of foraging behaviour at the West Coast foraging site.

\subsubsection{Westland petrel foraging strategies}

The results of the first passage time analysis revealed that Westland petrels forage mainly on the West Coast of the South Island within $200 \mathrm{~km}$ of the colony. They also exploited areas to the north such as the Cook Strait and Kaikoura and to the south such as Haast and Southland. This is consistent with 
Waugh et al's (2018) findings in which Westland petrels feed predominantly around deep-sea canyons and continental shelves in these areas. It is common for seabirds to forage around these types of features as they are often highly productive due to strong upwelling bringing deep sea nutrients up to the surface (Evans et al., 2021). The fact that most individuals foraged on the West Coast suggests that this area is especially productive (Louzao et al., 2011; Poupart et al., 2020). This is likely because the wet climate and mountainous terrain of the West Coast brings extra nutrients into the water through terrestrial runoff (Stevens et al., 2019). Each year the West Coast receives 2500-13000mm of rain which produces 128 billion $\mathrm{m}^{3}$ of runoff into the sea (West Coast Regional Council, 2020).

The First Passage Time analysis also found that Westland petrels searched for prey at two different foraging scales. This was expected as this hierarchical foraging strategy is used by many marine top predators to search for patchily distributed prey over large areas (Bailey et al., 2019; Freitas et al., 2018). In general, it is expected that individuals will begin searching for prey at large scales before switching to smaller nested scales based on environmental cues or by encountering the first prey item (Paiva et al., 2010; Sommerfeld et al., 2013). For central place foragers, it is also expected that the scale of foraging is linked with how far individuals forage from the colony (Garthe et al., 2016). For Cory's shearwaters (Calonectris diomedea) which use a dual foraging strategy, individuals foraged at small scales during short trips and large scales during long trips out to sea (Paiva et al., 2010). However, my results found no link between foraging scale and the length of trips or how far individuals foraged from the colony. Similar findings in common murres (Uria aalge) suggest that memory could explain this behaviour (Regular et al., 2013). Individuals that have repeatedly foraged in the same area are unlikely to search over a large scale because they remember where consistent prey patches are located. This could occur regardless of the trip length as experienced individuals use their memory to specifically target a certain foraging area then switch to fine scale area restricted searching to locate prey patches (Regular et al., 2013). Less experienced individuals who have yet to learn the location of good prey patches, may take short trips from the colony or follow other individuals further away and begin large scale searching to find prey (Regular et al., 2013). However, because the age of the individuals in this study were unknown, I was unable to test this hypothesis.

The petrels also displayed a wide variety of flight behaviours with some taking long looping flight paths far out to sea while others showed directed movement to and from foraging areas (Figure 4). This range of flight behaviours can be broadly classified as "looping" and "commuting" behaviour (Nevitt, 2008; Weimerskirch, 2007). Looping behaviour tends to be more exploratory and opportunistic where the individual continuously searches along its flight path (Nevitt, 2008). Commuting behaviour, on the other hand, is where the individual commutes directly to and from a particular foraging site in a relatively straight fashion (Nevitt, 2008). Unlike looping trips, commuting trips are thought to be guided by the individuals experience as their flight paths suggest they 'know' where to find prey (RiotteLambert \& Weimerskirch, 2013). Both strategies are often used by Procellariiformes during the 
breeding season but often at different stages (Weimerskirch, 2007). In wandering albatross (Diomedea exulans), individuals adopt the looping strategy during the incubation period but switch to commuting trips during the chick-rearing stage (Weimerskirch et al., 1993). Here, Westland petrels exhibited both strategies during the incubation period, however the vast majority were commuting. Furthermore, I found that individuals with smaller wing lengths tended to travel further between foraging areas. This may suggest that these long looping trips are being performed by younger, less experienced, individuals who have yet to learn where good prey patches are located (Riotte-Lambert \& Weimerskirch, 2013). Similar findings in Murphy's petrel (Pterodroma ultima) found that looping trips were undertaken by lighter individuals (Clay et al., 2019). However, given that some individuals displayed both commuting and looping trips (Figure 12), the decision on which strategy to use may be more closely aligned with environmental conditions or prey availability (Clay et al., 2019).

Interestingly, closer inspection of the looping flight paths revealed some intriguing behaviour. Despite travelling hundreds of kilometres out to sea, each individual was able to fly directly back to land in almost a straight path before turning sharply to follow the coastline back to the colony. This is likely down to the petrel's ability to use olfactory navigation (Gagliardo et al., 2013). While many studies have confirmed that procellariiformes are able to use smell to find prey (Gagliardo et al., 2013; Pollonara et al., 2015), it is hypothesized that they are also capable of smelling land (Nicolson, 2018). This would explain the sharp turn close to the shore as once in sight of land they can visually follow the coastline back to the colony (Nicolson, 2018).

\subsubsection{Factors influencing foraging behaviour}

Foraging behaviour varied considerably between years and was likely linked to the El Niño-Southern Oscillation (Waugh et al., 2018). In 2015, individuals had longer foraging trips and travelled further than other years. This was likely a result of a strong El Niño event in 2015 bringing higher sea surface temperatures to the West Coast, affecting local prey availability, and forcing the petrels to travel further in search of food (Oliver et al., 2017). Many studies have found negative impacts of El Niño events on seabird populations due to altered prey availability (Ancona et al., 2011; Catry et al., 2013; McDuie et al., 2018; Wingfield et al., 2018). However, Waugh et al (2018) found that breeding success remained high in 2015 and that chick mass was heavier indicating that it was a good year for foraging. Furthermore, Westland petrels also displayed wider dietary niche widths in 2015 (Waugh et al., 2018), suggesting that they were feeding on a wider variety of prey. Similar findings in blue-footed boobies (Sula nebouxii) suggest that seabirds are able to negate the negative impacts on El Niño events by feeding on a wider variety of prey (Ancona et al., 2012).

Conversely, individuals in 2011 tended to have shorter trips and travelled the least of any year. One explanation could be that prey availability near the colony was high as a result of 2011 being a strong La Niña year and therefore individuals did not have to travel as far in search of prey. La Niña events 
often bring cooler waters and increased ocean mixing resulting in higher primary production (Moum et al., 2013; Wingfield et al., 2018). Higher precipitation on the West Coast in 2011 also resulted in increased terrestrial runoff and likely contributed to increased ocean productivity resulting in higher prey abundance (Renwick, 2012).

However, La Niña events also tend to bring about more extreme weather events. In 2011 the West Coast was hit by a major storm event that resulted in the death of over 250000 prions (Pachyptila spp.), the largest mass death of seabirds ever recorded in New Zealand (Miskelly et al., 2012). Therefore the Westland petrels may have taken shorter trips and foraged closer to the colony to actively avoid this storm event (Weimerskirch \& Prudor, 2019). Similar findings have been found species such as frigate birds (Fregata minor), red-footed boobies (Sula sula), and pelicans (Pelecanus occidentalis) which show avoidance to tropical cyclones (Weimerskirch \& Prudor, 2019; Wilkinson et al., 2019). As breeding success in many seabirds is highly dependent on adult survival, this avoidance behaviour may be a strategy to help ensure future population viability (Öst et al., 2018).

Interestingly, individuals in 2012 tended to forage further than other years with foraging making up a smaller proportion of trips. Individuals also foraged in a wider variety of locations in 2012 compared to other years (Figure 6). This suggests that local prey availability near the colony may have been depleted, forcing individuals to travel further and spend more time searching for prey. However, due to the small sample size in 2012 it is difficult to draw any strong conclusions.

Despite previous studies finding little evidence of sexually dimorphic foraging behaviour (Poupart et al., 2020; Waugh et al., 2018), I found that females foraged further from the colony than males. While males tended to forage around $120 \mathrm{~km}$ from the colony, females foraged closer to $200 \mathrm{~km}$. Furthermore, out of the 22 males tracked in this study, only 2 foraged further than the West Coast. This suggests that there is some degree of sexual segregation occurring in Westland petrel foraging. Sexual segregation occurs in seabirds when prey availability near the colony is limited and is often the case that the larger sex forages closer to the colony (Miller et al., 2018; Paiva et al., 2017). This can be down to many reasons. In giant petrels (Macronectes halli), competition drives segregation with larger males outcompeting females for prime fishing spots (González-Solís et al., 2000). Alternatively, in tropical boobies (Sula spp.) segregation is driven by the partitioning of nesting duties with larger females taking longer incubation shifts and shorter trips (Lewis et al., 2005). Although I was unable to compare the morphology of Westland petrels between sexes due to a lack of data, Poupart et al (2020) did find that males are larger than females. This would support the idea that males are outcompeting females for prime foraging spots. Alternatively, males may be required to return regularly to the colony to defend and repair the nesting burrow and therefore take shorter trips (Hedd et al., 2014). This is the case for Sooty shearwaters (Puffinus griseus) and allows females to forage further in more productive waters to replenish the energy lost from egg formation (Hedd et al., 2014; Lewis et al., 2002). Further study is 
required to confirm if sexual segregation is occurring in Westland petrels and whether this is driven by competition or the partitioning of nesting duties.

Individuals that went south to forage displayed more directed commuting flight behaviour compared to those that foraged north. Furthermore, individuals that went north foraged in a wider variety of locations compared to those that went south. This is likely down to a combination of prey availability and individual experience (Nevitt, 2008; Weimerskirch, 2007). The wider variety of northern foraging locations suggests that prey is less predictable/abundant and, as a result, individuals have to be more opportunistic. This would explain why some individuals that foraged in the Cook Strait then went on to forage around Kaikoura and Hawkes Bay. It would also explain why some, possibly younger, less experienced individuals, resorted to using a looping foraging strategy (Riotte-Lambert \& Weimerskirch, 2013). Conversely, the directed commuting behaviour of southern individuals suggests they are more experienced, flying directly to predictable foraging areas based on memory (Weimerskirch, 2007). However, given the small sample size of individuals that went north $(n=7)$ and south $(n=6), I$ acknowledge that my conclusions are limited.

Compared to the northern and southern foraging sites, the West Coast site exhibited a high level of individual variation in foraging behaviour. Individuals showed considerable variation in trip duration and total distance travelled during foraging trips, with many being on par with those that went to the northern and southern sites. One explanation is that, like the northern site, prey could be unpredictable on the West Coast (Phillips et al., 2017). Indeed, Waugh et al's (2018) findings that chlorophyll-a levels were less stable on the West Coast suggests that ocean productivity is highly variable. This could explain why some individuals foraging at the northern and southern sites initially foraged on the West Coast as they likely did not find enough prey. It would also explain why some individuals ended up going on long looping trips to find prey. For common guillemots (Uria aalge) and Atlantic puffins (Fratercula arctica), local prey shortages forced individuals to take longer trips in search of prey resulting in lower breeding success (Burke \& Montevecchi, 2009; Fayet et al., 2021). However, chick survival rates are relatively high in Westland petrels suggesting that although prey might be unpredictable, breeding individuals are managing to forage successfully (S. M. Waugh et al., 2015).

Another explanation to the high level of variation on the West Coast could be individual specialisation (Phillips et al., 2017; Weimerskirch, 2007). This is where individuals specialise in fine scale foraging behaviours to reduce intraspecific competition. Individual specialisation has been found in grey-headed albatross (Thalassarche chrysostoma) where adults from the same sub-colony were able to breed successfully despite showing high inter-individual variation in movement strategies and consistently exploited different foraging areas (Bonnet-Lebrun et al., 2018). However, when looking at within individual foraging behaviour, I found that some individuals were more constant than others indicating that there are both specialist and generalist individuals in the Westland petrel population. This may not 
be uncommon as similar findings have been found in wandering albatross and Cory's shearwaters (Ceia et al., 2012; Zango et al., 2019). In the case of the Cory's shearwaters, individuals that were moderately specialists had higher breeding success than both highly specialised and generalist individuals (Zango et al., 2019). This suggests that having some degree of plasticity in foraging strategy is beneficial when prey is unpredictable. However, given the short-term tracking of individuals in this study it is uncertain whether this variation in individual consistency is down to the degree of specialisation, the level of experience or simply in response to prey availability and environmental conditions.

\subsubsection{Implications for population viability and conservation}

Variation in foraging behaviour is fundamentally important for population viability as it reduces intraspecific competition and increases resilience to environmental change (Louzao et al., 2014; Schoener, 1971). Populations that lack variation in foraging behaviour are therefore at a serious disadvantage (Phillips et al., 2017). The Westland petrels demonstrated a variety of foraging strategies. The variation between years both among and within individuals shows plasticity in foraging behaviour indicating some resilience to environmental change (Gilmour et al., 2018). Furthermore, the variation observed on the West Coast suggests individuals could be specializing to reduce intra-specific competition (Phillips et al., 2017). However, the variation on the West Coast combined with the evidence of sexual segregation suggests that prey near the colony could be limited (Paiva et al., 2017). While sexual segregation may reduce intra-specific competition (Miller et al., 2018), it may also cause sex-specific mortality as females forage further and become more exposed to extreme weather events and the fishing industry (Beck et al., 2021; Gianuca et al., 2019).

Like many marine top predators, seabirds are often regarded as useful indicators of marine ecosystem health (Parsons et al., 2008; Piatt et al., 2008). Therefore, changes in Westland petrel foraging behaviour or declines in breeding success likely reflect the degradation of marine habitat in which their prey resides. As a result, changes seen in the Westland petrels can then tell us about the condition of other seabird populations that use the same foraging habitat (Waugh et al., 2018). The Westland petrel population has been increasing since the 1970s due to high adult and fledgling survival rates (S. M. Waugh et al., 2015). This combined with results from this study suggests that despite the variation in foraging behaviour, individuals are managing to forage successfully. However, Westland petrels have low breeding frequency with less than $50 \%$ of individuals attempting to breed each year (S. M. Waugh et al., 2015). Like many long-lived species, individuals will only attempt breeding if conditions are favourable and do not risk their own survival (Dobson \& Jouventin, 2010). This suggests that marine conditions are not favourable and that there is only enough prey to allow half the population to breed. To date no tracking has been conducted on non-breeding Westland petrels during the breeding season therefore their foraging behaviour remains unknown. 
With the environment expected to become more unpredictable and extreme with climate change (Michaels et al., 2006), we could see Westland petrel foraging behaviour shift to a more generalist foraging strategy (Zango et al., 2019). While this could be seen as beneficial, Westland petrels are known to eat fishery discards, particularly during chick rearing (A. Freeman, 1998). With the West Coast predicted to be more unpredictable in the future, we could see a higher reliance on fishery discards by Westland petrels, increasing the risk of incidental mortality from fisheries. This may already be occurring as in the past 5 years, Westland petrels have risen from $10^{\text {th }}$ to $3^{\text {rd }}$ most at risk from New Zealand commercial fishery impacts (Richard et al., 2020; Richard et al., 2015). Because the majority of individuals forage on the West Coast, conservation management should focus on increasing the number of marine protected areas (MPA) and expanding the current important bird area (IBA) on the West Coast (Bird, 2014) to cover core foraging areas used by the Westland petrels and limit the cooccurrence with inshore trawl fisheries (Waugh et al., 2018).

\subsubsection{Limitations and future research}

While this study revealed a variety of different foraging strategies and provided insight into individual foraging behaviour, it only gives a small insight into their behaviour. Although many individuals were tracked, the majority recorded only one foraging trip. Future research should focus on long-term tracking of individuals to better understand the level of individual specialisation, how this changes throughout the year and how this influences breeding decisions and success. Further research should also focus on tracking non-breeding individuals to help understand the low breeding frequency of Westland petrels. 


\section{Chapter 3}

\section{Environmental drivers of Westland petrel (Procellaria westlandica) foraging strategies}

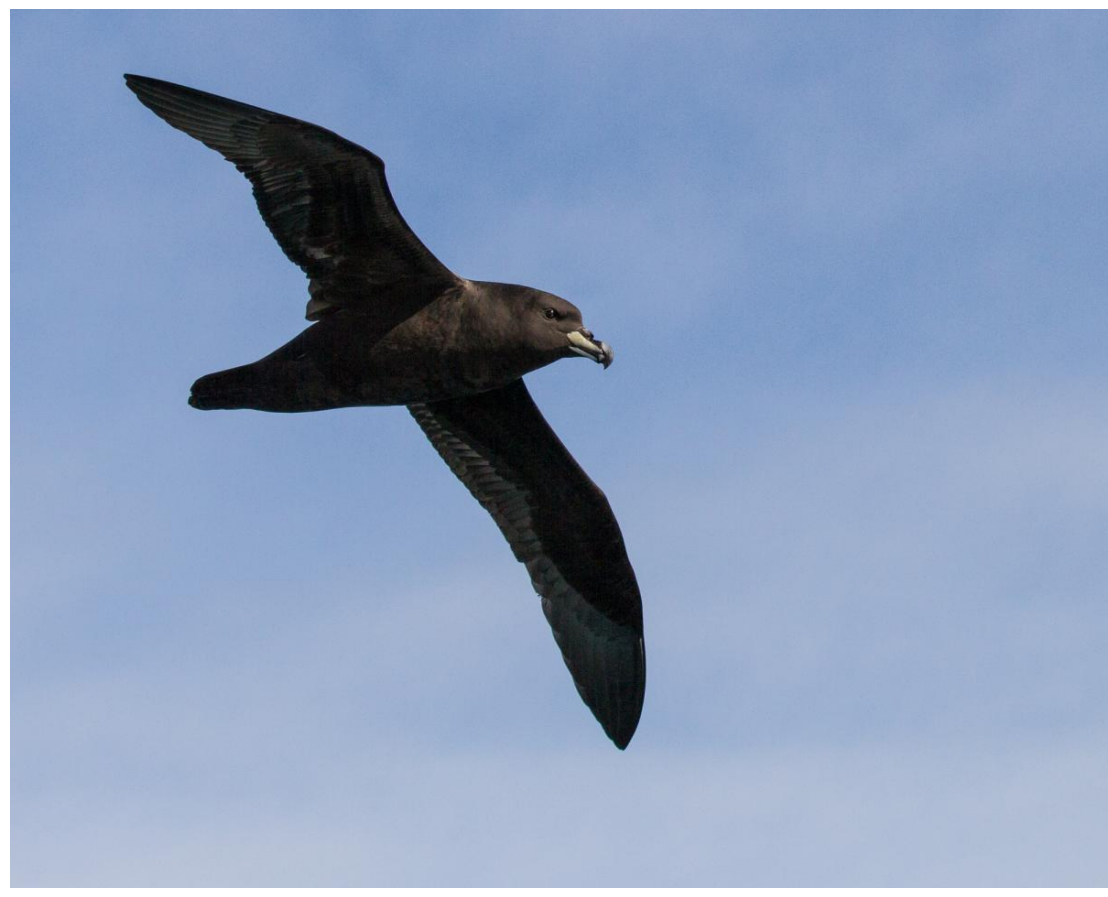

Westland petrel in flight, Kaikoura, 2012. Photo credit: (C Patrick Shortley 


\subsection{Introduction}

The environment can have a major influence on the population viability of animals through impacts on breeding success and survival rates (Shaffer, 1981). These impacts are often mediated through the foraging success of individuals (Pinaud et al., 2005). The marine environment is a highly dynamic system where conditions can change spatially and temporally on different scales (Louzao et al., 2014; Vilchis et al., 2006). For pelagic seabirds, this makes foraging particularly challenging as the environment can influence foraging success through changes in prey availability as well as the flight conditions the birds experience (De Pascalis et al., 2020; Sydeman et al., 2012). This becomes particularly important in the breeding season when adults have to sustain the high energy costs of rearing a chick whilst having a reduced foraging range (Phillips et al., 2019; Tessier \& Bost, 2020).

In the marine environment, prey is patchily distributed in both space and time (Louzao et al., 2014; Paiva et al., 2010). Pelagic seabirds predominantly forage around continental shelves, ocean fronts and eddies, as constant upwelling of nutrients makes these areas highly productive (Evans et al., 2021; Navarro \& González-Solís, 2009). During the breeding season, these areas offer a predictable and reliable source of prey, which is important, as individuals need to increase prey catch rates in order to raise their chick (Pinaud et al., 2005; Weimerskirch, 2007). However, environmental variability can alter productivity levels and prey abundance at these upwelling sites. As a result, seabirds have developed various strategies to cope with fluctuations in prey availability during the breeding season. Some species such as Manx shearwaters and Streaked shearwaters adopt a dual foraging strategy where individuals alternate between multiple short trips and one long (Ochi et al., 2016; Tyson et al., 2017). Other species such as giant petrels and albatross show foraging segregation whereby individuals of different sex or age class forage in separate areas (González-Solís et al., 2007; Phillips et al., 2004). Both of these strategies tend to arise in years when prey is either depleted or more unpredictable (Navarro \& González-Solís, 2009; Paiva et al., 2017).

Wind plays a major role in seabird foraging success as it affects their foraging movements and how much energy is used in flight (Spear \& Ainley, 1997a, 1997b). As a result, seabirds have evolved morphological features and behavioural strategies to make flying more efficient (Spear \& Ainley, 1997a; Weimerskirch et al., 2012). Procellariiformes such as albatross and petrels are some of the most efficient fliers on earth through a combination of wing morphology and dynamic soaring flight behaviour (Weimerskirch et al., 2000). During the breeding season, the strength and direction of wind can influence the ability of seabirds to reach profitable foraging areas (Navarro \& González-Solís, 2009). Therefore, adults must balance the potential gains from reaching highly productive foraging areas with the energy used flying into unfavourable wind conditions (Navarro \& González-Solís, 2009; Ventura et al., 2020). Studies on the flight strategies of seabirds in relation to wind are few and far between, but a recent study on Gadfly petrels has shown that individuals are able to memorize wind 
patterns and adjust their flight paths to optimize efficiency (Ventura et al., 2020). Similarly, a study on wandering albatross found that individuals exhibited tacking behaviour (a technique used in sailing), whereby individuals fly in a zig-zag fashion to increase flight efficiency when travelling into headwinds (Richardson et al., 2018).

Westland petrels are an endangered endemic Procellariform which breed only the West Coast of New Zealand's South Island (S. M. Waugh et al., 2015; Waugh et al., 2020). Like most seabirds, the environment is expected to have a major influence on their foraging behaviour especially during the breeding season in the austral winter (Poupart et al., 2020). We know that they feed predominantly around deep-sea canyons in Hokitika, Haast and the Cook Strait with their main source of prey consisting of deep sea lanternfish (Myctophidae spp.) and squid (Cranchiidae spp., Histioteuthidae spp.) (A. Freeman, 1998; Waugh et al., 2018). Despite previous studies finding little evidence of sexually dimorphic foraging strategies (Poupart et al., 2020; Waugh et al., 2018), in Chapter 2 I found evidence of sexual foraging segregation occurring in the population. Furthermore, while the majority of individuals foraged on the West Coast, individuals displayed a high level of individual variation in foraging and flight strategies.

To understand these patterns found in Chapter 2, I investigated how environmental factors influence habitat selection and foraging characteristics of Westland petrels to better understand the drivers of different foraging strategies.

\subsection{Methods}

\subsubsection{Data collection}

A full description of the study site, species and logger deployment is provided in Chapter 2. Briefly, tracking data of Westland petrels were collected by Waugh et al (2018) during the incubation period from 2011-2016. A total of 42 individuals were tracked giving 66 individual foraging trips. Foraging trips were split into "foraging" and "travelling" sections using first passage time analysis. Trip characteristics such as trip duration, total distance travelled, and distance travelled between foraging bouts were calculated. The foraging locations of Westland petrels were classified into three foraging sites based on the distance of foraging from the colony. These were "North", "West Coast" and "South" (Figure 1). 


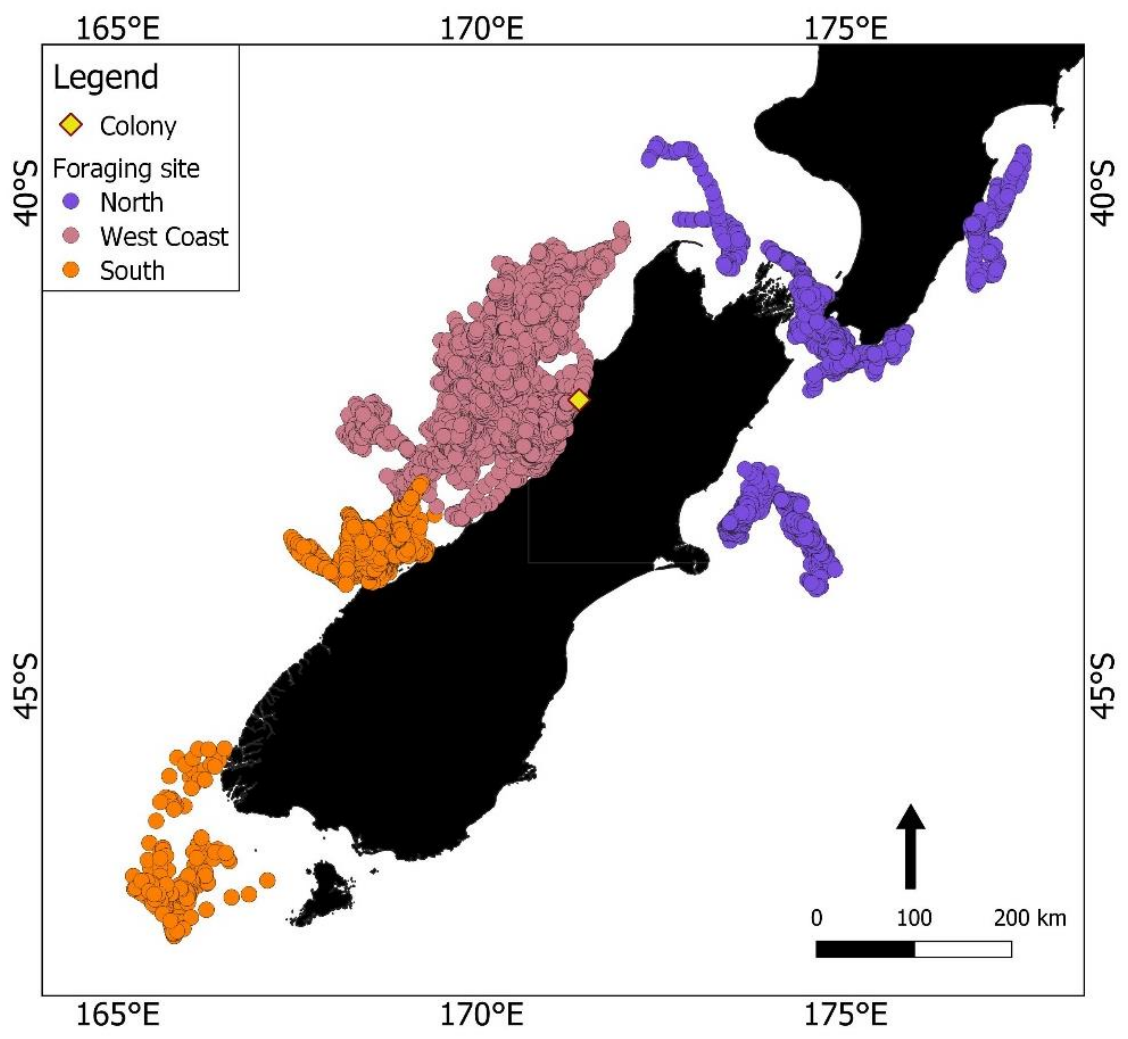

Figure 1: Foraging locations of Westland petrels split into the three foraging sites

\subsubsection{Environmental variables}

Four dynamic oceanographic variables were sourced from the Copernicus Marine Environmental Monitoring Service (CMEMS). These variables were daily sea surface temperature (SST; ${ }^{\circ} \mathrm{C}$ ), daily chlorophyll-a concentrations (Chl-a; $\mathrm{mg} \mathrm{m}^{-3}$ ), six hourly windspeeds $\left(\mathrm{ms}^{-1}\right)$ and six hourly wind direction ( ${ }^{\circ}$ from North). The bearing of wind direction was calculated from north and easterly windspeeds. Two static variables, seafloor depth $(\mathrm{m})$ and bathymetric slope $\left(^{\circ}\right)$ were also included. Seafloor depth data was sourced from NIWA (New Zealand Regional Bathymetry, 2016) and converted into a raster contour layer using the 'TIN interpolation' function in QGIS 3.4 (QGIS Development Team, 2020). The depth raster layer was then uploaded into $R$ version 4.0.2 ( $R$ Core Team, 2020) where bathymetric slope was calculated from depth contour lines using the 'terrain' function from the 'raster' package (Hijmans et al., 2015). Further details on the oceanographic data can be found in Appendix S2. To extract the environmental values for my tracking data, all oceanographic raster data was uploaded to QGIS, and values were sampled to the nearest pixel using the 'sample raster' function. After extracting the oceanic data for the tracked locations, tracking timestamps were then matched to the correct daily/6 hourly oceanic averages in Microsoft Excel. 


\subsubsection{Westland petrel resource selection}

To investigate what environmental factors influence resource selection in Westland petrels, I used point process modelling (PPM). This is a common approach used in many studies to analyse selection in presence-only data as it compares true tracking locations with randomly generated dummy locations using logistic regression (Renner et al., 2015). In this study I conducted PPM using the IntegratedNested Laplace Approximation (INLA) approach which uses the Stochastic Partial Differential Equation (SPDE) to account for the spatial autocorrelation associated with telemetry data (LezamaOchoa et al., 2020; Renner et al., 2015). To limit temporal autocorrelation, only the locations identified as "foraging" in chapter 2 were used in the model.

To create the dummy locations, a boundary was first constructed in $\mathrm{R}$ by creating a kernel utilization distribution (kUD) of the "travelling" locations (adehabitatHR package). I used the "travelling" locations for the boundary as this created an appropriate study area of where the petrels are "capable" of foraging. After creating the boundary, the resulting polygon was then exported to QGIS 3.4 and clipped to remove areas that overlapped land. The polygon was clipped as procellariiformes will not fly over land masses unless to reach the colony (Ricklefs, 1990). Dummy locations then were randomly generated within this boundary using the 'random point generator' function. Around 170000 dummy points were created based on advice from Renner et al (2015) to have ten times as many dummy points than presences points. The coordinates of the dummy points were extracted using the 'vector analysis' function in QGIS and timestamps were assigned by copying the timestamps of the "foraging" locations 10 times and randomly shuffling them in Excel. This resulted in 10 dummy locations for every timestamped "foraging" location. Environmental values were then extracted from the oceanographic raster data in the same way as the tracking data.

All modelling was done in $\mathrm{R}$ using the ' $R$-INLA' package (Lindgren \& Rue, 2015). To incorporate the SPDE in the model, a mesh was constructed using the foraging and dummy locations with the travelling kUD set as the boundary (Figure 2). The mesh was then transformed into a model matrix using the 'inla.spde.make.A' function and environmental covariates and model parameters were defined using the 'inla.stack' function. Before running the model, I ran a Pearson's rank correlation matrix using the 'rcorr' function (Harrell, 2019) to see if any environmental covariates could be removed from the model. There was no significant correlation between any of the environmental factors (Appendix S3) therefore all were kept in the model. The final model to test selection (presence vs absence) in Westland petrels was:

$$
\begin{gathered}
y \sim \text { Bathymetric Slope }+ \text { Seafloor Depth }+\log (\text { Chl a })+S S T+\text { Windspeed } \\
+\log (\text { Wind direction })+(1 \mid S P D E)+(1 \mid \text { BirdID })
\end{gathered}
$$


Where $\mathrm{y}$ is the binary response, presence ( $\mathrm{y}=1$; foraging locations) and absence ( $\mathrm{y}=0$; dummy locations). The environmental covariates were included as fixed effects and the SPDE and Bird ID as random effects. Chl-a and wind direction were log-transformed to achieve normality. Because INLA does not use p-values, the significance of variables was determined by examining the overlap of their $2.5 \%$ and 97.5\% posterior estimates with zero (Renner et al., 2015).

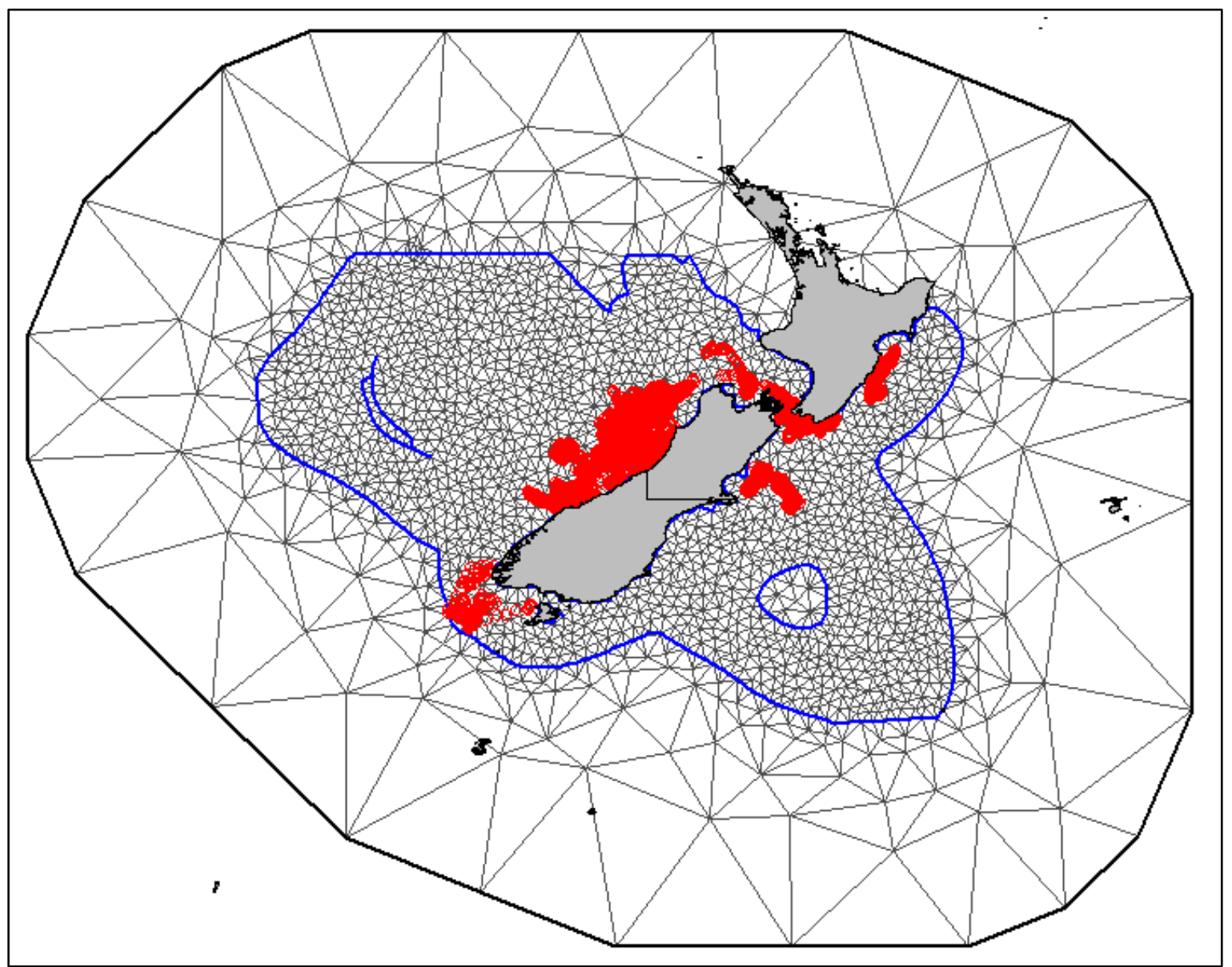

Figure 2: The mesh created for the SPDE in the INLA model. Red dots represent the tracked foraging locations of Westland petrels (Procellaria westlandica). The blue outline represents the travelling kUD boundary.

To compare habitat selection among foraging sites, I ran the INLA model separately for each of the three foraging sites respectively. Before running the INLA model, generalised linear models were run (' $g l m$ ' function) with all the environmental variables (bathymetric slope, seafloor depth, Chl-a, SST, wind speed and wind direction) as fixed factors, to see if there were differences in environmental characteristics among sites. To compare the means of environmental factors among sites, multiple pairwise comparisons were made using Tukey HSD post-hoc tests. To investigate whether habitat selection within foraging sites differs at the individual level, I ran the INLA model separately for each individual. For individuals with multiple trips recorded, the INLA model was run once for all trips combined except for the case where the individual went to multiple foraging sites. This was done as 
differences in environmental factors among sites may skew the results for that individual. For the individual level model, Bird ID was removed as a random effect. To investigate why foraging behaviour on the West Coast was so variable (as found in chapter 2), I focused in on the West Coast foraging trips and ran the INLA model for each year and each sex respectively.

\subsubsection{Environmental influence on foraging characteristics}

Generalised linear mixed models (glmm) were run to test the effect of dynamic oceanic variables (Chla, SST, windspeed and wind direction) on trip duration, total distance travelled, and distance travelled between foraging bouts. Bird ID was included as a random effect in the glmm to account for birds with multiple trips recorded. Seafloor depth and bathymetric slope were not included in the analysis because they were unlikely to affect my focal foraging characteristics. For each foraging trip, Chl-a and SST averages were calculated for the "foraging" locations and windspeed and wind direction were calculated for the "travelling" locations ("foraging" and "travelling" locations were classified in Chapter 2). Glmm's were run on all foraging trips to test the overall effect of dynamic oceanic variables but were also run on West Coast foraging trips separately to investigate the drivers of high individual foraging variation.

\subsection{Results}

All three foraging sites had similar Chl-a concentrations and windspeeds (Figure 3 A, B; Appendix S4). The southern foraging site was steeper than north and West Coast foraging sites (Figure 3C; Tukey; North: $\mathrm{z}=3.3$, $\mathrm{p}<0.01$; West Coast: $\mathrm{z}=-8.7, \mathrm{p}<0.01$ ). While the northern site was steeper than the West Coast (Tukey; $\mathrm{z}=-4.7, \mathrm{p}<0.01$ ), they both had similar depths of around 500m (Figure 3D, Tukey; $\mathrm{z}=0.7$, $\mathrm{p}=0.73$ ). The southern foraging site was the deepest of the three sites with an average depth of almost 900m (Tukey; North: $\mathrm{z}=3.4, \mathrm{p}<0.01$; West Coast: $\mathrm{z}=-3.7$, $\mathrm{p}<0.01$ ). Sea surface temperature on the West Coast was significantly higher than the southern site (Tukey; $\mathrm{z}=2.5, \mathrm{p}=0.02$ ) but not the northern site (Figure 3E; Tukey; $\mathrm{z}=2.1, \mathrm{p}=0.07$ ). There was no significant difference in wind direction between the three foraging sites (Appendix S4), but wind at the northern and West Coast sites generally came from a north easterly direction whereas the wind at the southern foraging site came from either the North or South (Figure 3F). 

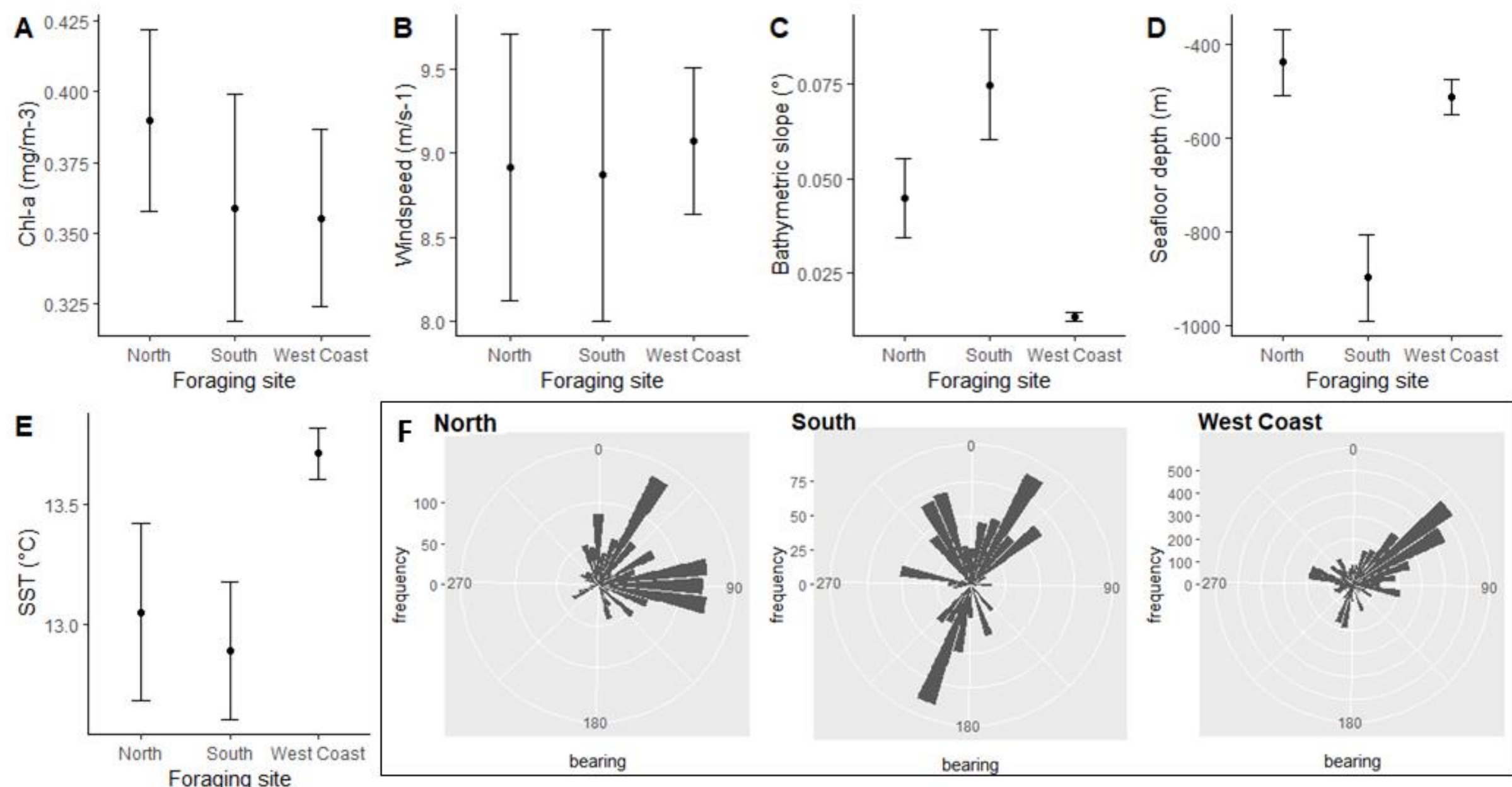

Figure 3: Comparison of environmental characteristics among the three foraging sites. Plots A-E show mean \pm SE. Plot $F$ shows the wind direction (direction the wind is blowing from) for each foraging. "frequency" in plot F refers to the number of tracked "foraging" locations. Significance among foraging sites was determined using Tukey post-hoc tests. 


\subsubsection{Habitat selection among foraging sites}

For all three foraging sites, Westland petrels showed the strongest selection for bathymetric slope (Figure 4), foraging in areas where the seafloor was steeper than the surrounding environment. Individuals that went north showed the strongest selection for steep bathymetry (posterior mean $=0.25$; $\mathrm{SD}=0.03$ ) followed by those that went south (posterior mean $=0.16$; $\mathrm{SD}=0.02$ ) and lastly by those that foraged on the West Coast (posterior mean $=0.11 ; \mathrm{SD}=0.02$ ). The petrels showed negative selection for Chl-a at the northern and West Coast foraging sites, with individuals foraging in areas with lower Chl-a concentrations than the surrounding environment (Figure 4; North: posterior mean $=-0.02$, $\mathrm{SD}=0.01$; West Coast: posterior mean=-0.01, $\mathrm{SD}=0.005$ ). Petrels at the southern site did not show selection for Chl-a (posterior mean=-0.012; $\mathrm{SD}=0.007$ ), despite also tending to forage in areas with lower Chl-a concentrations (Figure 4). Windspeed was only important for petrels at the northern site with individuals foraging in areas with lower windspeeds (Figure 4; posterior mean $=-0.001 ; \mathrm{SD}=0$ ). Wind direction was important at both the northern and southern sites (Figure 4). However, petrels at the northern site showed positive selection (posterior mean $=0.008$; $\mathrm{SD}=0.001$ ), tending to fly into headwinds, whereas petrels at the southern site showed negative selection (posterior mean $=-0.002$; SD $=0.001$ ), tending to fly with tailwinds. Westland petrels did not show selection for seafloor depth or SST at any of the foraging sites (Figure 4).

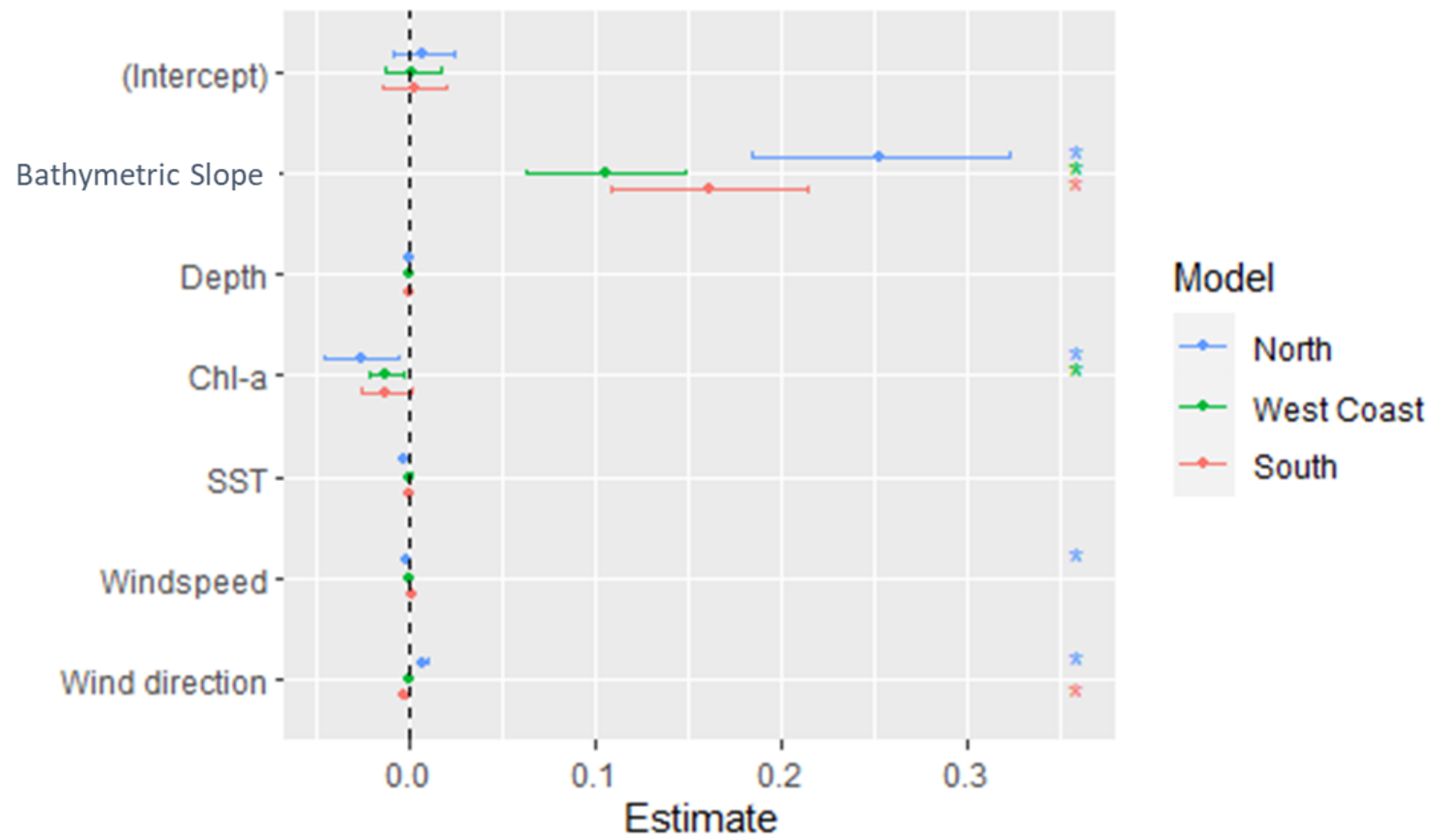

Figure 4: Habitat selection coefficient estimates for each oceanic variable from the INLA analysis. Points represent coefficient estimates for each foraging site and error bars are $2.5 \%$ and $97.5 \%$ posterior estimates. Significant results are represented with *. 


\subsubsection{Habitat selection within sites at the individual level}

In contrast to the population level analysis (Figure 4), Chl-a had a stronger influence than bathymetric slope for individuals foraging within the West Coast foraging site (Figure 5). Only 3 of the 34 individuals that foraged within the West Coast site showed selection for bathymetric slope (Figure 5). Although Chl-a was negatively selected for at the population level, within the West Coast site, selection varied with individuals foraging in areas with higher and lower Chl-a concentrations than the surrounding environment (Figure 5). In contrast to the population level analysis, windspeed and wind direction also had a stronger influence on individuals within the West Coast site (Figure 5). Conversely, windspeed and wind direction had a weaker influence on individuals within the Northern and Southern sites (Figure 5). Like the population level analysis, seafloor depth and SST had no influence on habitat selection within any of the foraging sites (Figure 5). 


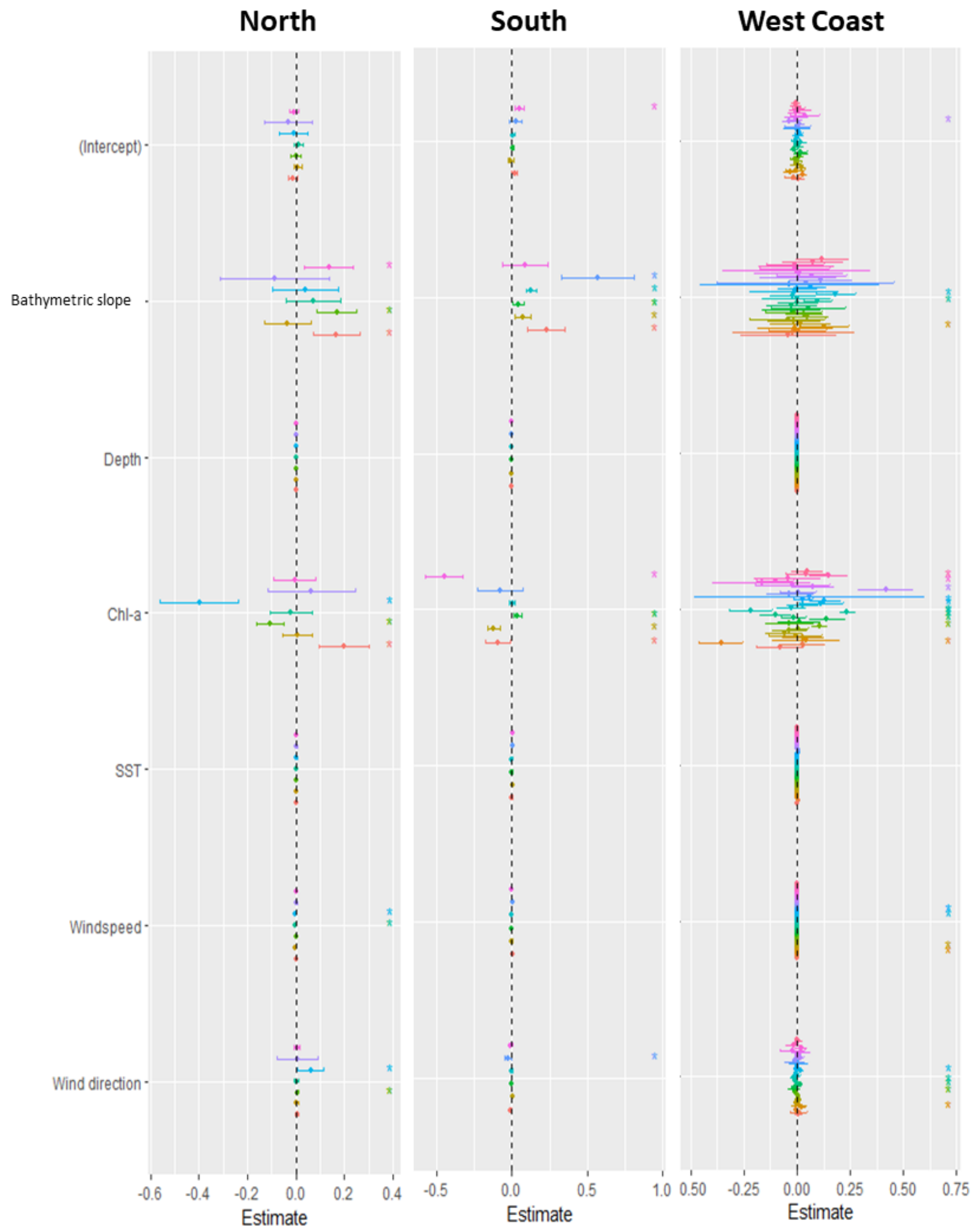

Figure 5: Habitat selection coefficient estimates for each foraging site. Points represent coefficient estimates for each individual with error bars representing $2.5 \%$ and $97.5 \%$ posterior estimates. Significant results are represented with *. Points are coloured to help distinguish between individuals. 


\subsubsection{Habitat selection within the West Coast foraging site by year}

In $2015(n=12)$ and $2016(n=14)$, individuals showed strong selection for bathymetric slope (Figure 6; 2015: posterior mean $=0.068, \mathrm{SD}=0.026 ;$ 2016: posterior mean $=0.095, \mathrm{SD}=0.031$ ), foraging predominantly around the steeply sloping Hokitika canyon (Figure 7). Individuals in 2011 (n=9) did not show selection for bathymetric slope (posterior mean=0.019, $\mathrm{SD}=0.032$ ), foraging north of the Hokitika canyon where the seafloor is flatter (Figure 7). In 2015, individuals showed strong positive selection for Chl-a (Figure 6; posterior mean=0.038, $\mathrm{SD}=0.006$ ), foraging in areas where Chl-a concentrations were higher (Figure 7). Chlorophyll-a concentrations along the West Coast appear to be higher in 2015 and lowest in 2016 (Figure 7). Individuals in 2011 and 2016 did not show selection for Chl-a (Figure 6). In 2016, individuals showed positive selection for wind direction (Figure 6; posterior mean $=0.004, \mathrm{SD}=0.001$ ), generally flying into headwinds. Individuals did not show selection for seafloor depth, SST or windspeed in any year (Figure 6).

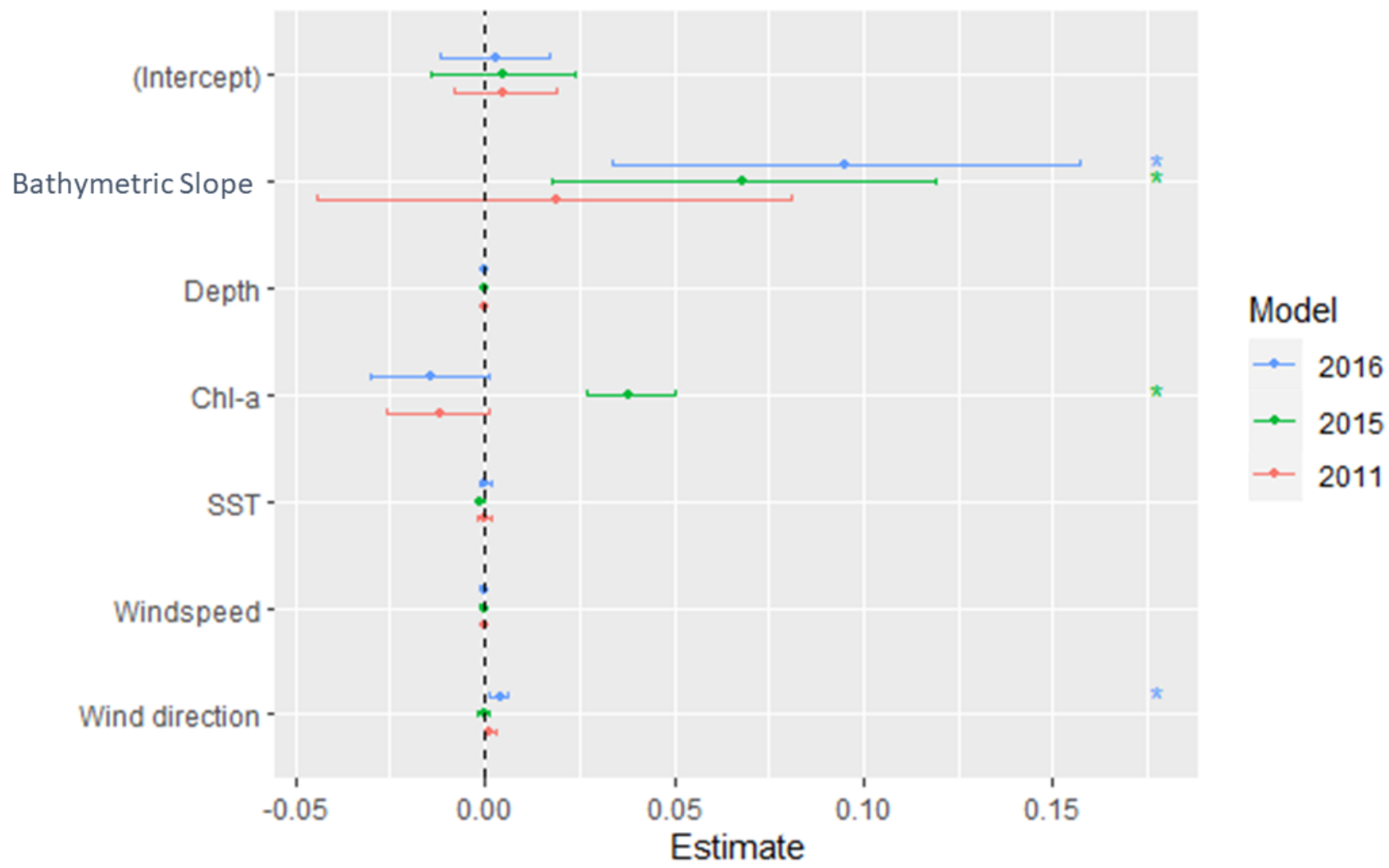

Figure 6: INLA habitat selection coefficients for West Coast foraging trips by year. Points represent coefficient estimates for each year. Error bars represent the $2.5 \%$ and $97.5 \%$ posterior estimates and * represents significance. 


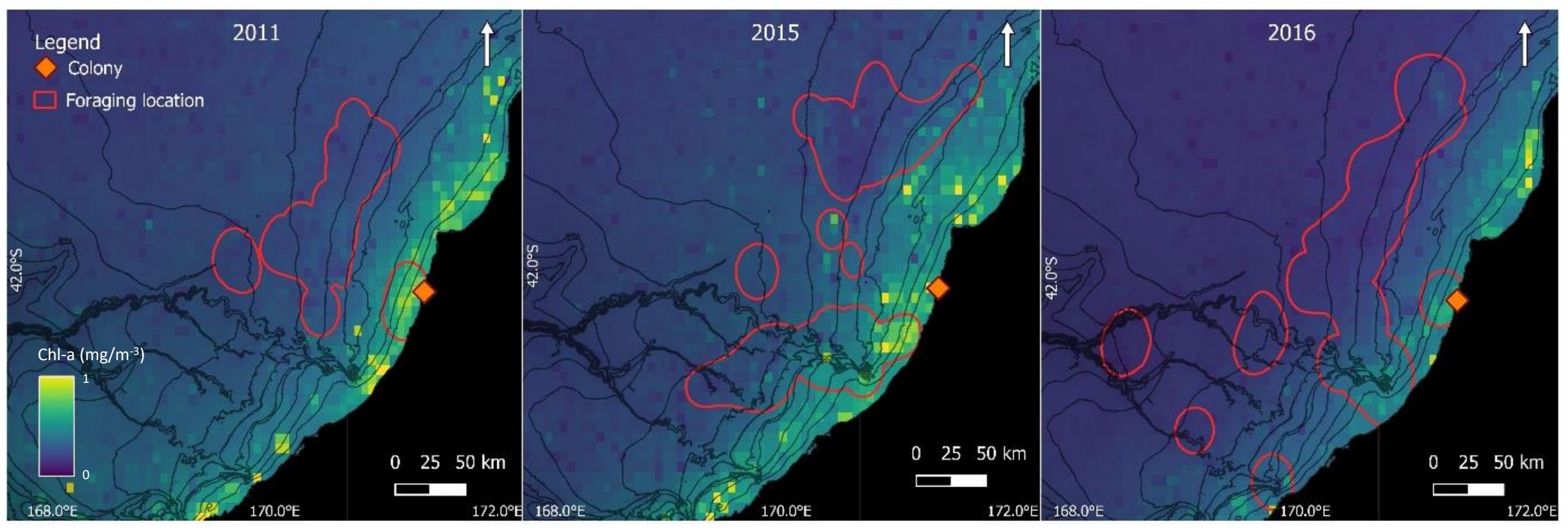

Figure 7: West Coast foraging locations by year in relation to Chl-a concentrations and bathymetry. Red outlines were made by creating a kernel utilisation distribution (kUD) of the petrels tracked "foraging" locations. Contour lines represent ocean depth by -50m intervals. The South Island land mass is shown in black. 


\subsubsection{Habitat selection within the West Coast foraging site by sex}

Males ( $n=20)$ and females ( $n=13)$ both showed selection for Chl-a (Figure 8), however males tended to forage in areas where Chl-a concentrations were lower (posterior mean $=-0.015, \mathrm{SD}=0.005$ ), whereas females foraged in areas where Chl-a concentrations where higher $($ posterior mean $=0.023, \mathrm{SD}=$ 0.007). Males showed strong positive selection for bathymetric slope (Figure 8; posterior mean $=0.101$, $\mathrm{SD}=0.022$ ), foraging predominantly around the steeply sloping Hokitika canyon (Figure 9). Conversely, females showed no selection for bathymetric slope (Figure 8; posterior mean=-0.01, SD=0.029), foraging over a range of steep and flat areas (Figure 9). Neither sex showed selection for seafloor depth, SST, windspeed or wind direction (Figure 8).

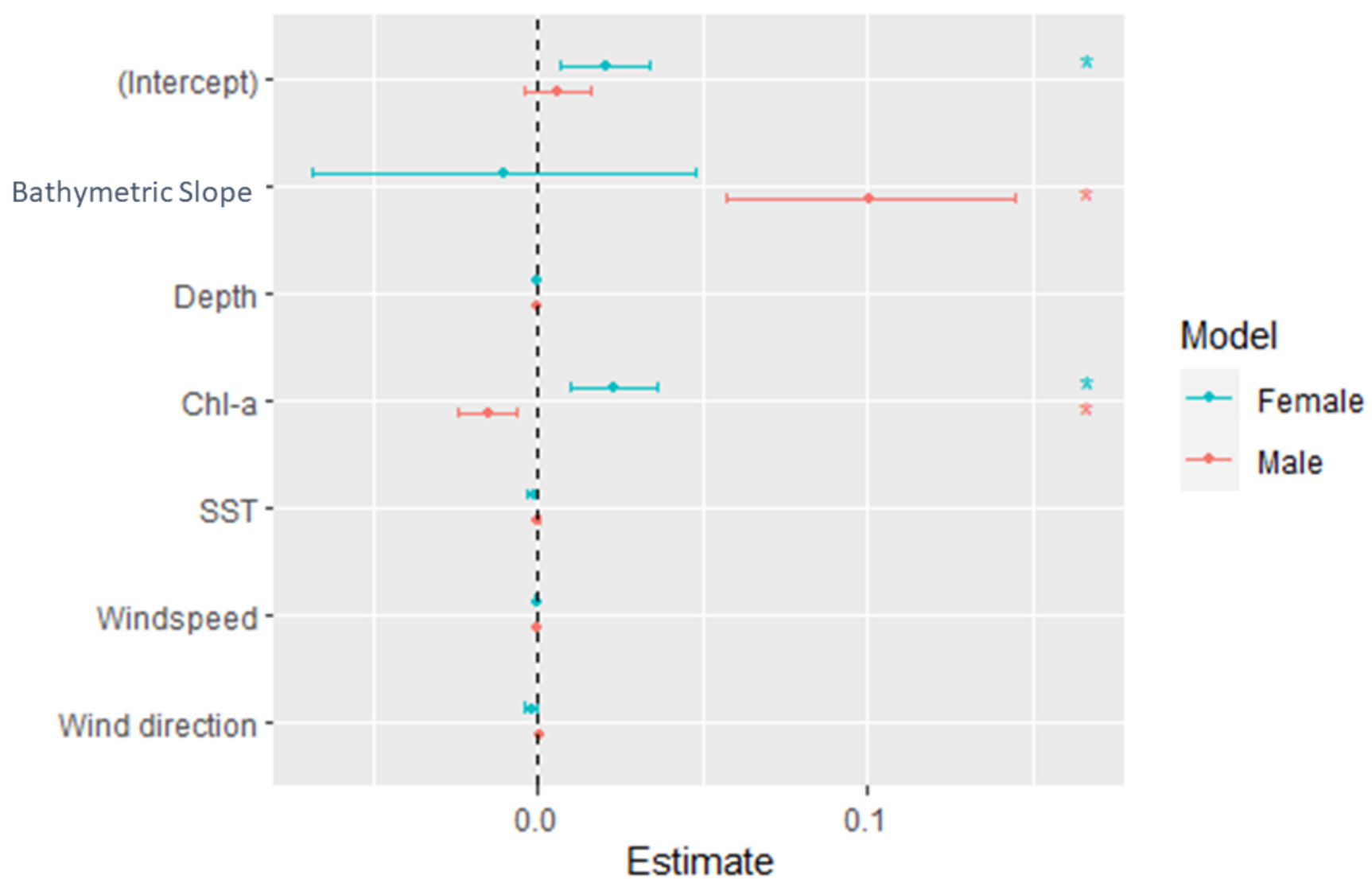

Figure 8: INLA habitat selection coefficients for males and females at the West Coast foraging site. Points represent the coefficient estimate and error bars represent the $2.5 \%$ and $97.5 \%$ posterior estimates. * represents significant results. 


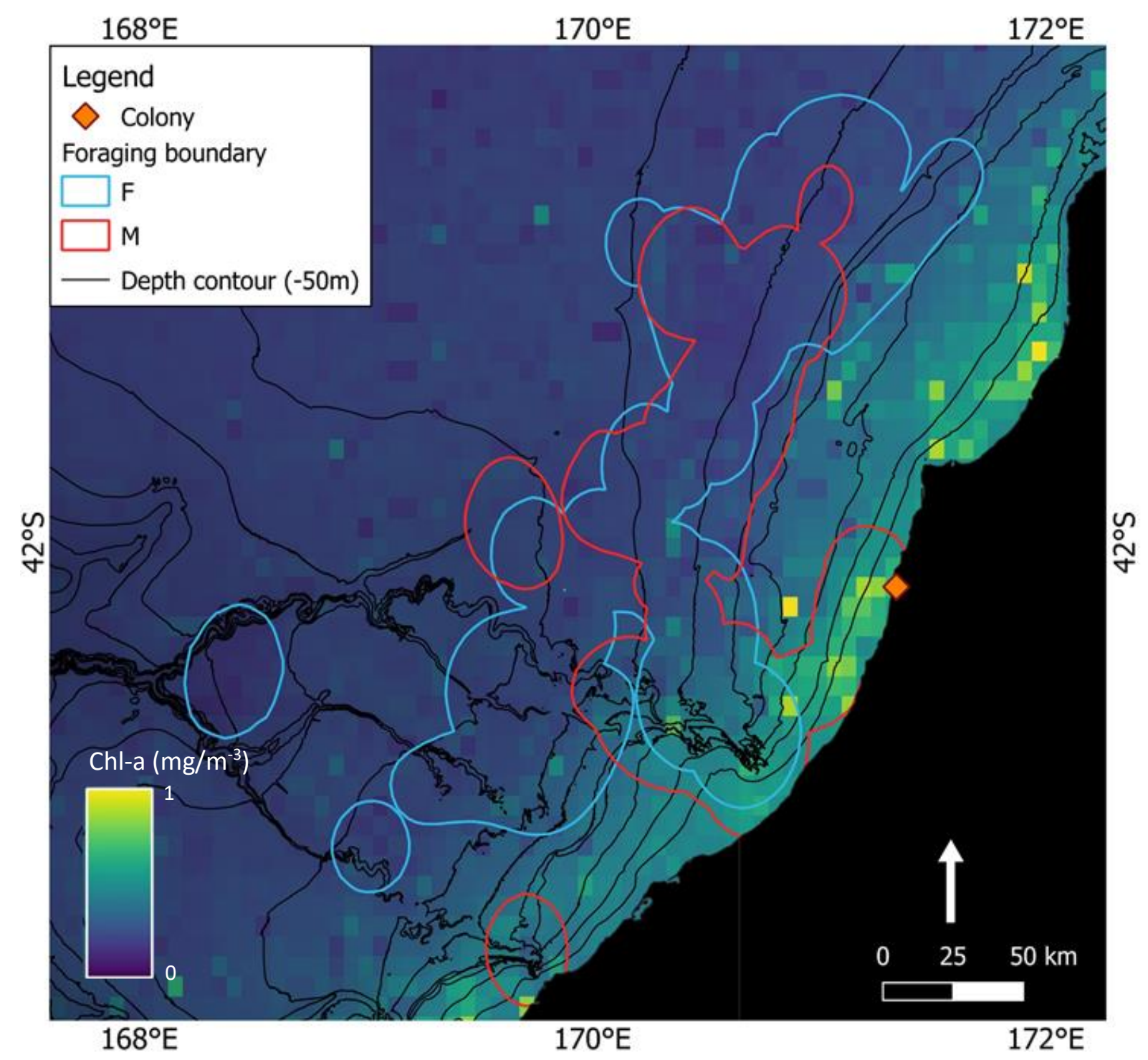

Figure 9: Foraging location for males (red) and females (blue) at the West Coast foraging site in relation to bathymetry and chlorophyll-a concentrations. Red outlines were made by creating a kernel utilisation distribution (kUD) of the petrels tracked "foraging" locations. The South Island land mass is shown in black.

\subsubsection{Environmental influence on foraging characteristics}

Sea surface temperature was negatively correlated with trip duration and total distance travelled (Table 1), with individuals taking longer trips and travelling further at lower sea surface temperatures. However, foraging trips within the West Coast showed no relationship with SST (Table 1). Neither Chla, windspeed or wind direction influenced trip duration or total distance travelled (Table 1). However, the distance travelled between foraging areas was positively correlated with windspeed (Table 1) with individuals travelling further between foraging areas at higher windspeeds (Figure 10). Although wind direction was not significant, closer inspection of the looping foraging trips showed that wind direction influenced the flight behaviour of some individuals, exhibiting tacking flight behaviour (flying in a zigzag fashion) when travelling against the direction of the wind Figure 11). 
Table 1: Summary of generalised linear mixed models (glmm) used to assess the influence of oceanic variables on foraging characteristics for all trips and trips on the West Coast. Significant results are highlighted in bold.

\begin{tabular}{|c|c|c|c|c|c|c|c|c|c|c|}
\hline & \multicolumn{5}{|c|}{ All Foraging trips } & \multicolumn{5}{|c|}{ West Coast Foraging trips } \\
\hline & Estimate & Std.Error & df & t value & p-value & Estimate & Std.Error & $\mathrm{df}$ & t value & p-value \\
\hline \multicolumn{11}{|c|}{ Total Distance Travelled } \\
\hline (Intercept) & 9764.09 & 3453.45 & 59.29 & 2.83 & 0.006 & 5744.31 & 5084.85 & 44.92 & 1.13 & 0.265 \\
\hline Chla & -1714.02 & 1013.32 & 58.93 & -1.69 & 0.096 & -1141.39 & 1189.47 & 45.79 & -0.96 & 0.342 \\
\hline SST & -595.20 & 245.73 & 59.26 & -2.42 & 0.019 & -343.49 & 357.93 & 45.40 & -0.96 & 0.342 \\
\hline Wind_S & 120.68 & 69.23 & 54.82 & 1.74 & 0.087 & 144.97 & 72.71 & 43.71 & 1.99 & 0.053 \\
\hline Wind_D & -0.93 & 2.43 & 53.55 & -0.38 & 0.703 & -1.32 & 2.49 & 40.42 & -0.53 & 0.598 \\
\hline \multicolumn{11}{|c|}{ Trip Duration } \\
\hline (Intercept) & 24.77 & 9.62 & 59.26 & 2.58 & 0.013 & 12.73 & 14.25 & 43.93 & 0.89 & 0.376 \\
\hline Chla & -2.97 & 2.82 & 58.91 & -1.05 & 0.296 & -1.17 & 3.35 & 45.85 & -0.35 & 0.728 \\
\hline SST & -1.40 & 0.68 & 59.20 & -2.05 & 0.045 & -0.65 & 1.00 & 44.81 & -0.65 & 0.521 \\
\hline Wind_S & 0.18 & 0.19 & 54.68 & 0.92 & 0.363 & 0.28 & 0.21 & 44.68 & 1.36 & 0.182 \\
\hline Wind_D & -0.01 & 0.01 & 53.34 & -0.91 & 0.365 & -0.01 & 0.01 & 42.14 & -1.19 & 0.242 \\
\hline \multicolumn{11}{|c|}{ Distance Travelled Between Foraging Bouts } \\
\hline (Intercept) & 973.59 & 785.96 & 54.13 & 1.24 & 0.221 & -1952.00 & 1499.00 & 67.84 & -1.30 & 0.197 \\
\hline Chla & -265.31 & 210.78 & 128.68 & -1.26 & 0.21 & 65.14 & 250.90 & 73.91 & 0.26 & 0.796 \\
\hline $\mathrm{SST}$ & -88.90 & 56.71 & 57.34 & -1.57 & 0.123 & 131.10 & 108.20 & 68.10 & 1.21 & 0.230 \\
\hline Wind_S & 69.19 & 12.34 & 126.77 & 5.61 & $<0.001$ & 55.14 & 14.28 & 86.72 & 3.86 & $<0.001$ \\
\hline Wind_D & 0.35 & 0.55 & 120.91 & 0.64 & 0.521 & 0.02 & 0.59 & 80.15 & 0.04 & 0.968 \\
\hline
\end{tabular}

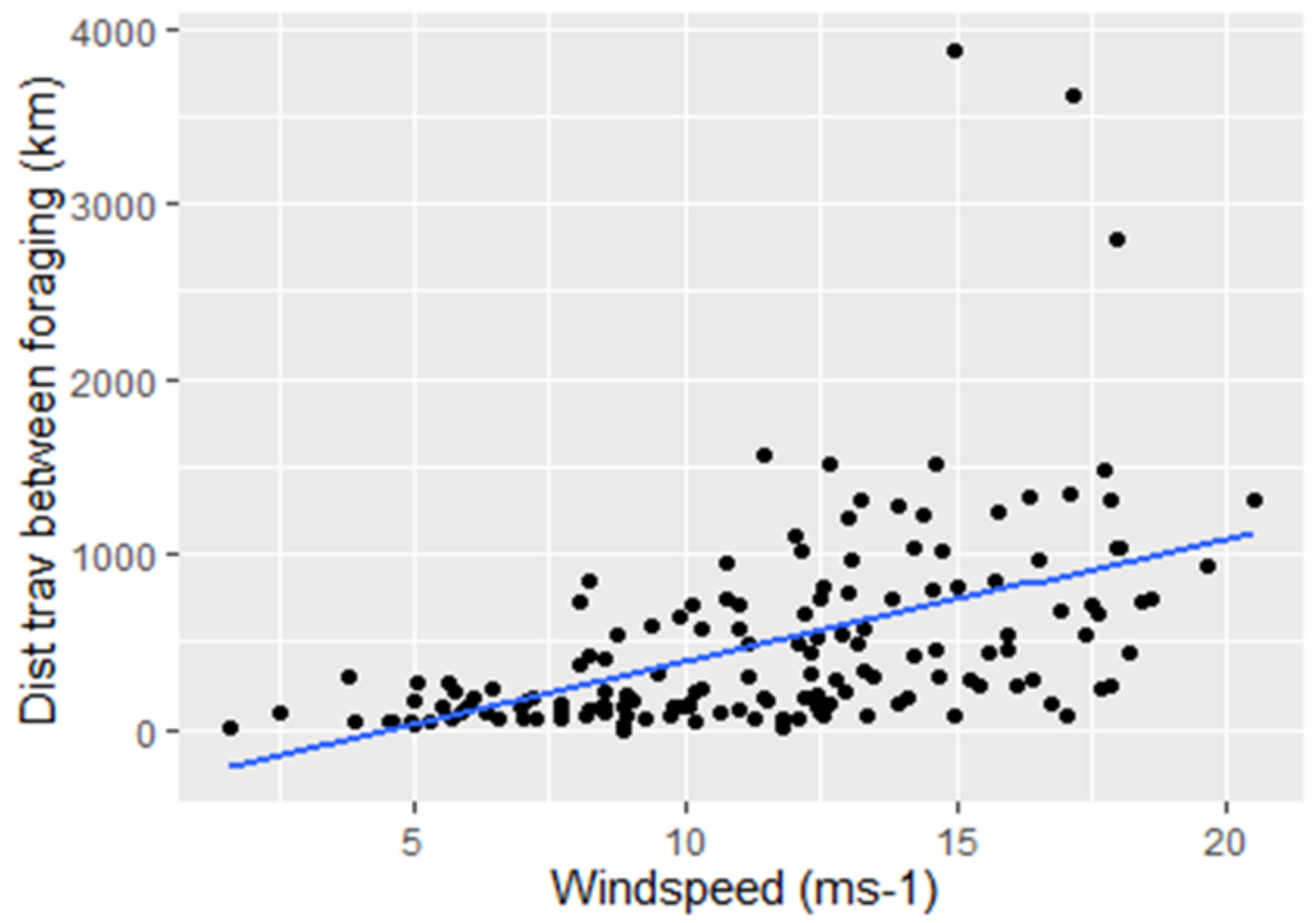

Figure 10: Average windspeeds in relation to distance travelled between foraging bouts. 


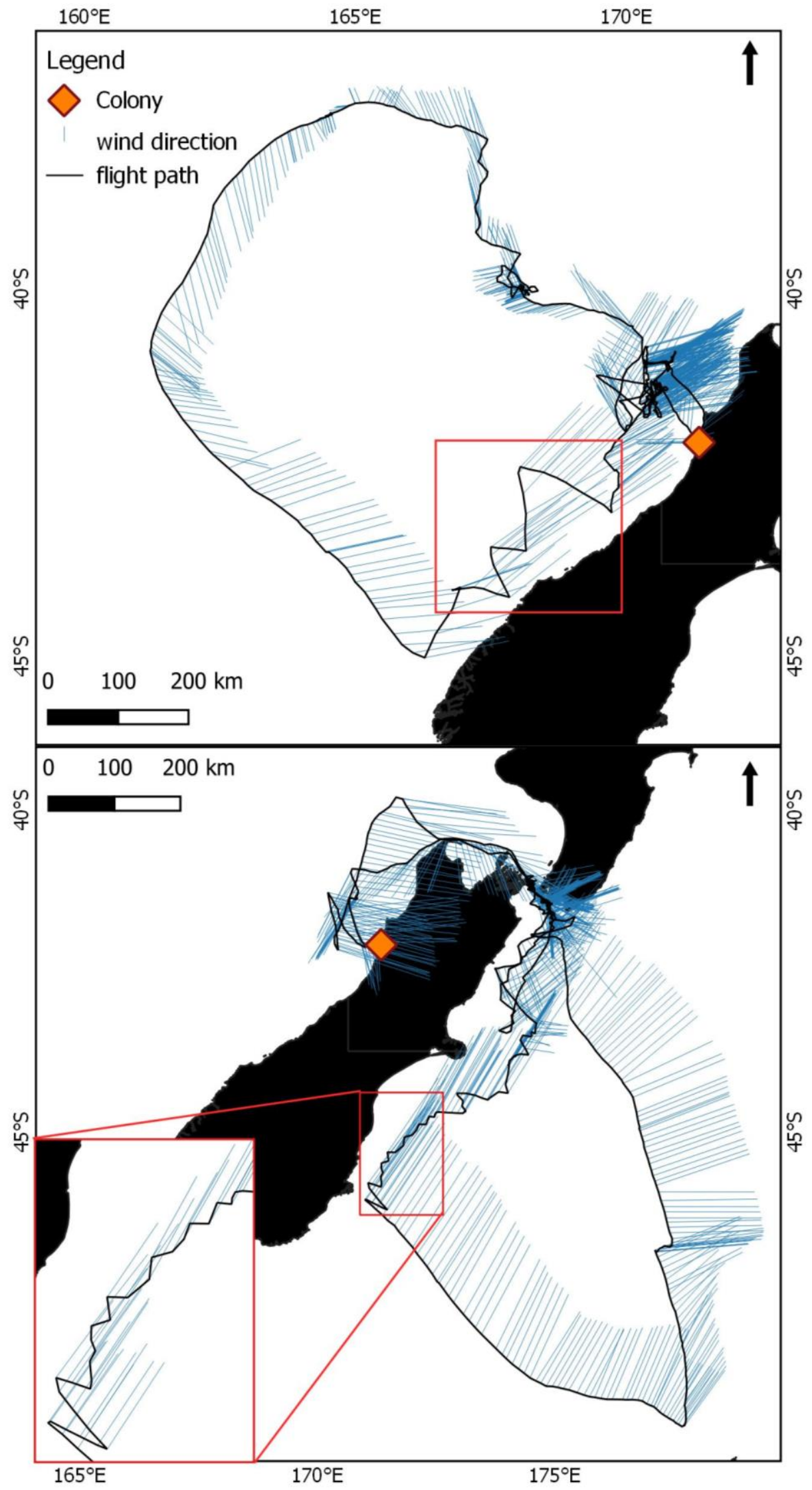

Figure 11: Flight paths of two looping trips in relation to wind (blue lines). The length of blue lines represents windspeed and the angle of blue lines represent the direction the wind is blowing from. Red outlines highlight areas of tacking behaviour. 


\subsection{Discussion}

Foraging success in seabirds is highly influenced by the marine environment and can have flow on effects for population viability (Pinaud et al., 2005). I examined the influence of oceanic factors on the habitat selection and foraging characteristics of Westland petrels to better understand the drivers of different foraging strategies. Overall, at the population level, the petrels showed the strongest selection for areas of steep sloping bathymetry at all three foraging sites. At the northern and West Coast foraging sites, the petrels selected areas with lower chlorophyll-a concentrations than the surrounding environment. No selection for chlorophyll-a was observed at the southern site. Differences in selection for wind direction were observed between the northern and southern sites with petrels flying into headwinds at the northern site whereas petrels flew with tailwinds at the southern site. Within foraging sites however, chlorophyll-a had a greater influence on habitat selection than bathymetric slope, particularly for individuals at the West Coast foraging site.

Within the West Coast foraging site, habitat selection differed among years. Individuals in 2015 and 2016 showed strong selection for steep sloping areas around the Hokitika canyon whereas individuals in 2011 foraged further north in areas with flatter bathymetry. Individuals in 2015 also selected areas with higher chlorophyll-a concentrations whereas individuals in 2011 and 2016 showed no selection for chlorophyll-a. Habitat selection on the West Coast also differed between sexes with males foraging in areas with steep bathymetry and lower chlorophyll-a concentrations whereas females foraged in areas with higher chlorophyll-a concentrations and showed no selection for bathymetric slope.

I also found that trip duration and total distance travelled were negatively correlated with sea surface temperature suggesting that individuals were travelling further to reach colder, more productive, waters (Pinaud et al., 2005). Finally I found that the distance travelled between foraging bouts was positively related to windspeed suggesting that some individuals have less flight control at higher windspeeds (Riotte-Lambert \& Weimerskirch, 2013).

\subsubsection{Habitat selection among foraging sites}

At all three foraging sites, Westland petrels showed the strongest selection for bathymetric slope, foraging predominantly around steep bathymetric features such as undersea canyons and continental shelves. This supports findings from Waugh et al (2018) and suggests that these areas offer a reliable source of prey for the petrels. Undersea canyons and continental shelve are well known for being productivity hotspots as constant upwelling brings deep-sea nutrients up to the surface (De Leo et al., 2010; Munroe et al., 2013). It is also likely that these areas provide refuge for the petrels deep-sea prey during daylight hours (Loots et al., 2007; Poupart et al., 2020).

Westland petrels also showed negative selection for Chlorophyll-a. It is not unusual for seabirds to show a disassociation with chlorophyll-a distributions as it means they are feeding on higher trophic 
organisms (Grémillet et al., 2008). Chlorophyll-a is produced by primary producing phytoplankton which are, in turn, fed upon by zooplankton (Armengol et al., 2019; Grémillet et al., 2008). Therefore, areas with high zooplankton abundance should show decreased chlorophyll-a levels and the increased abundance of planktivorous fish (Grémillet et al., 2008; Loots et al., 2007). The distribution of lanternfish (Myctophidae spp.), which make up the majority of Westland petrel diets, has been found to be inversely related to chlorophyll-a levels (A. Freeman, 1998; Loots et al., 2007).

Although chlorophyll-a levels were similar across sites, petrels at the southern site showed no selection for it. This could be as a result of the disassociation between prey and chlorophyll-a explained above (Grémillet et al., 2008). Alternatively, based on the directed flight paths of these individuals (Chapter 2, Figure 8), another explanation could be that these individuals are more experienced and are therefore relying more on memory than environmental cues to find prey (Regular et al., 2013). However, given the small number of individuals that went south, it could also be the result of a small sample size.

In contrast to habitat selection at the population level, within foraging sites, individuals were more influenced by chlorophyll-a than bathymetric slope. This likely reflects the hierarchical nature of seabird foraging behaviour (Regular et al., 2013). At larger scales, individuals select for bathymetric features associated with strong upwelling (Regular et al., 2013). Once individuals reach these upwelling areas and begin searching for prey at smaller scales, chlorophyll-a becomes more important as it influences the location of prey patches (Carroll et al., 2017). Although chlorophyll-a had a stronger influence within foraging sites, selection varied considerably at the West Coast site with individuals showing selection for areas with higher and lower chlorophyll-a concentrations. This suggests that foraging conditions on the West Coast are highly variable. Primary production on the West Coast is highly sporadic as it is driven mainly by terrestrial runoff and strong winds (Stevens et al., 2019). However, it may also reflect intra-specific competition with some individuals foraging in areas with high prey abundance (low chlorophyll-a concentrations) while others are forced to forage in areas with low prey abundance (high chlorophyll-a concentrations) (Mendez et al., 2017).

\subsubsection{Habitat selection within the West Coast foraging site by year and sex}

Habitat selection at the West Coast foraging site differed among years. Individuals in 2015 and 2016 showed strong selection for bathymetric slope with foraging concentrated around the Hokitika canyon (Figure 7). However, in 2011 bathymetric slope was not important as foraging took place closer to the colony, away from the Hokitika canyon (Figure 7). Furthermore, petrels in 2011 showed no selection for any of the other oceanic factors. This could be explained by an extreme storm event that occurred in 2011 (Miskelly et al., 2012). Extreme weather events can make foraging very dangerous for seabirds and can often result in the mass mortality of individuals (Miskelly et al., 2012; Morley et al., 2016). As a result, many seabirds show avoidance behaviour to extreme weather events by altering flight paths or by staying close to the colony (Nicoll et al., 2017; Weimerskirch \& Prudor, 2019). This mean that in 
2011, Westland petrels may have been prioritizing their own survival (by remaining close to the colony) rather than searching for profitable foraging areas (Wingfield et al., 2018; Öst et al., 2018).

Unlike in 2011 and 2016, individuals in 2015 showed strong selection for areas with higher chlorophylla concentrations. This suggests that the petrels were feeding in areas with lower prey abundance. One explanation could be that prey abundance was lower because 2015 was a strong El Niño year (Waugh et al., 2018). El Niño events are well known for lowering prey availability for seabirds by decreasing prey abundance or changing prey distributions (Evans et al., 2021; Zarn et al., 2020). However, Waugh et al (2018) found that chick mass was higher in 2015 suggesting that it was a good year for foraging. Furthermore, wider dietary niche widths in 2015 (Waugh et al., 2018) suggest that Westland petrels were feeding on a wider variety of prey. Many other seabirds such as blue-footed boobies (Sula nebouxii) and frigatebirds (Fregata spp.) display wider diets in response to El Niño events (Ancona et al., 2012; Zarn et al., 2020). In some cases, this is due to the lower abundance of their main prey source (Webb \& Harvey, 2015; Zarn et al., 2020). However, given the high levels of Chl-a on the West Coast in 2015 (Figure 7), an alternative explanation is that higher levels of primary production make other, more nutritious prey sources, more accessible to the petrels (Ancona et al., 2012). Either way, flexibility in diet should offer resilience to changes in the environment (Zarn et al., 2020).

Similar to 2011, individuals in 2016 showed no selection for chlorophyll-a. However, unlike 2011, chlorophyll-a concentrations along the West Coast were much lower in 2016 (Figure 7). This suggests that marine productivity was exceptionally low in 2016. This could be a result of a marine heatwave that occurred over the austral summer of 2015 and 2016 (Oliver et al., 2017). During marine heatwaves higher ocean temperatures weaken upwelling and reduce ocean mixing causing the stratification of the water column (Piatt et al., 2020; Smale et al., 2019). This prevents nutrients from the deep ocean reaching surface waters resulting in lower marine productivity (Jackson et al., 2018; Oliver et al., 2021). For deep-sea species, negative impacts from marine heatwaves tend to have a lag effect as warmer waters tend to persist in the deep ocean long after the heatwave event (Jackson et al., 2018). This lageffect from marine heatwaves has been attributed to major declines in Hoki (Macruronus novaezelandiae) stocks on the West Coast (Chiswell \& Sutton, 2020). For Westland petrels, this might explain why Waugh et al (2018) found that chick survival rates were lower in 2016 as the marine heatwave likely reduced the abundance of deep-sea prey meaning adults had less food to feed their chicks.

Habitat selection on the West Coast also differed significantly between sexes. Males showed positive selection for bathymetric slope and negative selection for chlorophyll-a. However, females showed positive selection for chlorophyll-a and no selection for bathymetric slope. This suggests that males are foraging in higher quality areas than females. One explanation could be that prey is limited on the West Coast and therefore males are outcompeting females for prime foraging areas around the Hokitika 
canyon (González-Solís et al., 2000; Thiers et al., 2014). This is supported by my findings in chapter 2 that females foraged further than males. Sexual foraging segregation is not uncommon in seabirds and often arises from limited prey availability (Reyes-González et al., 2021). In Cory's shearwaters, sexual segregation was more common in years with increased environmental stochasticity (Paiva et al., 2017). During these years female shearwaters foraged further and had lower body condition than males suggesting that they were foraging in lower quality areas (Paiva et al., 2017). Due to a lack of data, I was unable to compare the body condition of Westland petrels between sexes, however this warrants further investigation.

Sea surface temperature was negatively correlated with trip duration and the total distance individuals travelled. However, sea surface temperature did not influence foraging trips at the West Coast foraging site. Furthermore, sea surface temperature was the highest at the West Coast foraging site. This suggests that high sea surface temperatures on the West Coast are reducing prey availability, causing some individuals to take longer foraging trips to the northern and southern sites where waters are colder and more productive. Similar results have been found in yellow-nosed albatross and brown boobies (Pinaud et al., 2005; Soanes et al., 2021). In general, high sea surface temperatures reduce marine productivity through ocean stratification (Roxy et al., 2016). This can cause fish populations to migrate to cooler waters or lower fish recruitment by causing spatial mismatches between larval fish and their planktonic prey (Hamann et al., 2012; Laurel et al., 2021). In both cases, seabirds are often forced to travel further in search of food. Rising sea surface temperatures over the past few decades, combined with more frequent marine heatwaves have made marine productivity on the West Coast highly unstable (Chiswell \& O'Callaghan, 2021). This instability could explain why sea surface temperature did not explain the duration or distance of trips within the West Coast site as individuals are likely taking a wide range of foraging trips in search of prey.

\subsubsection{The influence of wind on Westland petrel foraging behaviour}

The distance individuals travelled between foraging bouts was most explained by windspeed with individuals travelling further between foraging bouts at higher windspeeds. Furthermore, in Chapter 2, I found that longer distances between foraging bouts were being performed by individuals with smaller wing lengths suggesting that these birds could be younger and less experienced (Riotte-Lambert \& Weimerskirch, 2013). One explanation could be the differences in wing loading between individuals with smaller and larger wings (De Pascalis et al., 2020). Wing loading refers to the relationship between body mass and wing area (Spear \& Ainley, 1997a). For seabirds, species with high wing loading such as auks and shags tend to have a smaller wing area relative to their body mass compared to low wing loading species such as albatross that have a large wing area relative to their body mass (Elliott et al., 2013; Weimerskirch et al., 2012). While having high wing loading allows individuals to fly faster into the wind, it lowers their turning ability (Spear \& Ainley, 1997b; Wakefield et al., 2009). For Westland 
petrels this could mean that individuals with smaller wings have less control of their flight at higher windspeeds resulting in longer distances travelled between foraging bouts.

Petrels at the northern and southern foraging sites showed opposing selection for wind direction. Individuals that went north showed positive selection, flying predominantly into north easterly headwinds whereas those that went south showed negative selection, flying with northerly tailwinds. In general, flying into headwinds is more energetically expensive for seabirds compared to flying with tailwinds (Mitchell et al., 2020; Warham, 1977). Therefore, it would be expected that travelling south with tailwinds is more efficient. A study on wandering albatross (Diomedea exulans) found that when flying with tailwinds, individuals used similar energy levels to that of sitting on the water (Weimerskirch et al., 2000). However, during the breeding season, adults often face the opposing wind conditions on the return trip back to the colony (Ventura et al., 2020). It therefore may be more beneficial to exploit tailwinds on the return journey once individuals are exhausted from foraging (Collins et al., 2020). However, the added body mass from foraging may increase the wing loading of individuals making it more efficient to exploit headwinds on the return journey at it allows individuals to fly faster (Wakefield et al., 2009). In contrast, a study on black-legged kittiwakes found that prey availability plays a bigger role than wind in the foraging distribution of breeding individuals (Collins et al., 2020). This suggests that for the Westland petrel, the benefits gained from foraging north or south, may outweigh the costs of flying into unfavourable wind conditions.

Closer inspection of the looping trips showed that some Westland petrels displayed tacking behaviour (ie the zig-zag flight movement while travelling into strong headwinds). Tacking is a strategy used in sailing to travel efficiently against the direction of the wind (Sachs, 2016). To date there has been little reporting of this behaviour in seabirds however it has been recognised as a flight strategy used by albatross (Richardson et al., 2018; Weimerskirch \& Robertson, 1994). Here I have shown that Westland petrels are also capable of using tacking behaviour suggesting that it may be a strategy adopted more widely by seabirds. Further study is needed to better understand the movement strategies seabirds use to exploit wind conditions in the marine environment.

\subsubsection{Future population viability}

My findings suggest that the marine environment at the Westland petrels main foraging site on the West Coast is highly variable, and that prey is therefore unpredictable. This high unpredictability may explain why breeding propensity (the proportion of individuals that attempt to breed each year) is unusually low in Westland petrels (46\%) as adults are not finding enough food to be able to invest into breeding (S. M. Waugh et al., 2015). With marine heatwaves predicted to increase in frequency with climate change, this could decrease the number of breeding individuals further as prey becomes more unpredictable and harder to find (Oliver et al., 2017; Oliver et al., 2018). Furthermore, rising ocean temperatures could cause prey distributions to migrate southwards to cooler waters, forcing the petrels 
to travel further and use more energy in search of food (Hamann et al., 2012). Climate change is also predicted to increase the occurrence of extreme weather events which could impact Westland petrel survival rates as more frequent weather events make foraging conditions increasingly hostile (Ummenhofer \& Meehl, 2017). However, the variation in foraging strategies suggests that Westland petrels can adapt their behaviour to different environmental conditions and may therefore show some resilience to the negative effects of climate change. 


\section{Chapter 4 \\ General Discussion}

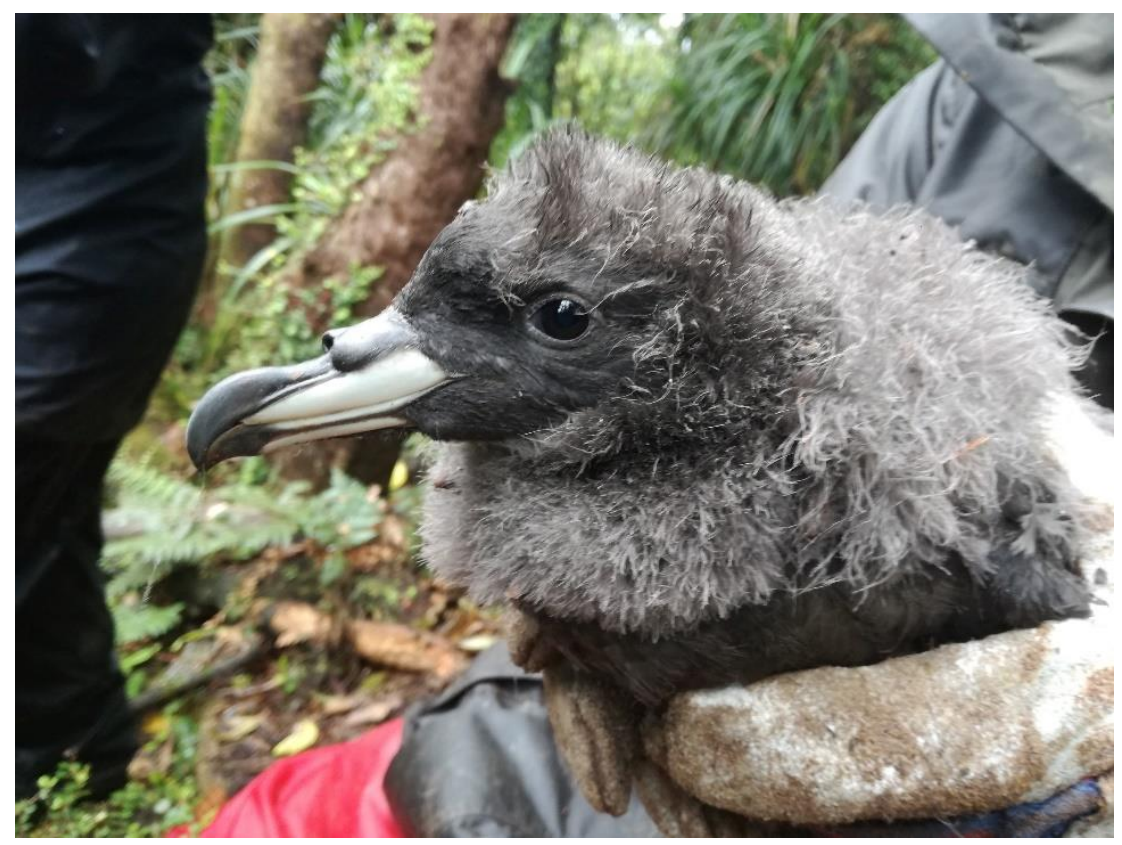

Juvenile Westland petrel, Punakaiki, 2019. Photo credit: Susan Waugh

Nearly half of all seabird populations are on the decline (Dias et al., 2019). Therefore, there is an urgent need to identify factors influencing seabird population viability. The viability of a population can be highly influenced by the foraging success of individuals as it can impact survivability and breeding success (Schoener, 1971; Shaffer, 1981). For pelagic seabirds, foraging success is particularly challenging as they feed on patchily distributed prey in a highly dynamic marine environment (Louzao et al., 2014; Nevitt, 2008). As a result, seabirds have adopted various foraging strategies such as dual foraging and sexual foraging segregation (González-Solís et al., 2007; Tyson et al., 2017; Weimerskirch, 2007). Because seabirds are highly influenced by the marine environment, understanding more about their foraging behaviour can tell us a lot about the health of the marine ecosystem and help identify the drivers of global seabird declines (Parsons et al., 2008; Piatt et al., 2008).

Westland petrels (Procellaria westlandica) are an endangered endemic procellariform found only on the West Coast of New Zealand's South Island (Waugh et al., 2020). Unlike other seabirds, previous studies on their foraging behaviour have found little to no evidence of dual foraging or sexual foraging segregation (Poupart et al., 2020; Waugh et al., 2018). Furthermore, they exhibit a high level of individual variation in foraging behaviour (Waugh et al., 2018). 
To understand more about the variation in Westland petrel foraging behaviour, I examined the variation in foraging behaviour at the population, individual and within individual level to describe and categorise their foraging behaviour (Chapter 2), investigate how intrinsic factors influence variation (Chapter 2), and investigate how environmental factors drive this variation (Chapter 3).

\subsection{Overview of chapters}

\subsubsection{Chapter 2: Variation in Westland Petrel (Procellaria westlandica) foraging behaviour: from population to within individual level}

Knowledge on how foraging behaviour varies within a population can tell us a lot about the level of intra-specific competition, environmental conditions and how population will respond to future environmental and anthropogenic threats. In Chapter 2, I used First Passage Time analysis to examine Westland petrel foraging behaviour at the population level, individual level and within individual level. The aim was to describe and categorise foraging strategies and investigate how factors such as year, sex and foraging site influenced foraging variation. I found significant variation at all levels. Most individuals foraged on the "West Coast" within $200 \mathrm{~km}$ of the colony, but some foraged "North" around the Cook Strait and Kaikoura, while others went "South" around Haast and Southland. The petrels also displayed a variety of looping and commuting flight behaviours. Most of the variation was explained by year with individuals in 2015 taking longer trips and travelling further, whereas those in 2011 took the shortest trips and travelled the least of the four years. I also found evidence of sexual segregation, with females foraging further than males. Foraging site explained surprisingly little of the variation due to the high variability at the West Coast foraging site. This suggests that prey availability on the West Coast is highly unpredictable. Lastly, individuals with smaller wing lengths travelled further between foraging bouts suggesting that these long looping trips are being performed by younger/less experienced individuals.

\subsubsection{Chapter 3: Environmental drivers of Westland petrel (Procellaria westlandica) foraging strategies}

In Chapter 3, I investigated whether environmental factors could explain the foraging patterns found in Chapter 2. Specifically, I looked at how environmental factors influenced habitat selection and foraging characteristics such as trip duration, total distance travelled, and the distance travelled between foraging bouts. When looking at habitat selection at the population level, bathymetric slope was the most important factor at all three foraging sites. This was followed by chlorophyll-a, but only at the northern and West Coast foraging sites. Within the West Coast foraging site however, chlorophyll-a had a greater influence on individual habitat selection than bathymetric slope.

Petrels at the West Coast site also showed different habitat selection among years. In 2011, they showed no selection for any oceanic variables. In 2015 and 2016, the petrels showed strong selection for steep 
sloping bathymetry around the Hokitika canyon. In 2015, habitat selection on the West Coast was also strongly influenced by chlorophyll-a with concentrations higher than other years. Although chlorophylla did not influence habitat selection in 2016, chlorophyll-a concentrations were much lower than other years. Habitat selection on the West Coast also differed between sexes with males showing the strongest selection for steep sloping areas with low chlorophyll-a concentration whereas females selected areas with high chlorophyll-a concentrations and showed no selection for bathymetric slope.

Trip duration and total distance travelled were negatively correlated with sea surface temperature suggesting that individuals are travelling further to reach colder, more productive, waters (Pinaud et al., 2005). Lastly, the distance travelled between foraging bouts was positively related to windspeed suggesting that some individuals have less flight control at higher windspeeds (Riotte-Lambert \& Weimerskirch, 2013).

\subsection{Discussion}

Overall, my findings show that Westland petrels feed predominantly around sloping bathymetric features such as undersea canyons and continental shelves. These features are associated with strong upwelling and high marine productivity, so it is likely that the petrels target these areas as they provide a reliable source of prey (De Leo et al., 2010; Munroe et al., 2013). Most foraging took place on the West Coast of the South Island within 200km of the colony around the Hokitika canyon. This would suggest that the West Coast offers a stable source of prey for the petrels. However, the high variation in foraging behaviour and habitat selection among individuals on the West Coast suggest that foraging conditions are highly variable, making prey availability unpredictable.

One proposed driver for this variation could be the high sea surface temperatures observed on the West Coast compared to the northern and southern foraging sites (Chapter 3). High sea surface temperatures reduce marine productivity by weakening upwelling and stratifying the water column (Roxy et al., 2016). This can make prey less abundant and more patchily distributed. Over the past 40 years, rising ocean temperatures in the Tasman sea have made productivity on the West Coast highly sporadic (Chiswell \& O'Callaghan, 2021; Chiswell \& Sutton, 2020). This might explain why sea surface temperature was negatively correlated with trip duration and the total distance individuals travelled (Chapter 3) as unpredictable prey availability on the West Coast, caused by high sea surface temperatures, compels some individuals to travel further in search of food.

The differences in habitat selection on the West Coast among years suggest that variation on the West Coast could be also driven by the El Niño-Southern Oscillation (ENSO). In the La Niña year of 2011, individuals showed no selection for any oceanic variables (Chapter 3), took shorter trips, and remained close to the colony (Chapter 2). La Niña years often bring increased storm activity and in 2011 a major storm event caused the mass mortality of seabirds on the West Coast (Miskelly et al., 2012). It is therefore likely that in 2011, Westland petrels were remaining close to the colony to prioritize their own 
survival rather than risk foraging in more productive areas (Nicoll et al., 2017; Weimerskirch \& Prudor, 2019).

In contrast to 2011, individuals in the El Niño year of 2015 took longer trips and travelled further than other years (Chapter 2). While high chlorophyll-a concentrations along the West Coast in 2015 (Chapter 3) would suggest that marine productivity was high, it may also reflect lower zooplankton abundance (and therefore lower prey availability) caused by warmer El Niño waters (Grémillet et al., 2008). Waugh et al (2018) found that Westland petrels had wider diets in 2015 suggesting that individuals may have travelled further to more productive waters and feed on a wider variety of prey. Although this would suggest that El Niño events have a negative impact on the petrels, Waugh et al (2018) also found that fledglings had higher mass and survival rates in 2015 suggesting that although adults travelled further in 2015, they may have been feeding on more nutritious prey (Ancona et al., 2012).

In 2016, chlorophyll-a levels were much lower than other years (Chapter 3). This was likely caused by a lag-effected of a marine heatwave that occurred over the summer of 2015/2016 (Jackson et al., 2018; Oliver et al., 2017). While I found no observable effect on the foraging behaviour of Westland petrels, Waugh et al (2018) found that breeding success was lower in this year suggesting that the lag effect of the marine heatwave may have reduced the availability of deep-sea prey for the petrels.

High sea surface temperatures and highly variable foraging conditions along the West Coast during El Niño/La Niña years likely explains why I found evidence of sexual foraging segregation occurring in Westland petrels (Chapter 2 and 3). Sexual segregation in seabirds often occurs in years of greater environmental stochasticity when, local food supply becomes depleted or more unpredictable (Paiva et al., 2017). It is often the case that one sex outcompetes the other for prime foraging areas (GonzálezSolís et al., 2007; Paiva et al., 2017). For the Westland petrel, males foraged closer to the colony than females (Chapter 2). Differences in habitat selection between males and females also indicated that males were foraging in higher quality areas than females (Chapter 3). These findings suggest that males are outcompeting females for prime foraging spots on the West Coast as a result of limited prey availability, forcing females to forage further away.

\subsection{Implications for population viability}

Unpredictable prey availability on the West coast may explain why only $47 \%$ of Westland petrels breed each year (S. M. Waugh et al., 2015). For many long-lived species, including procellariiformes, individuals will only breed if foraging conditions do not compromise their own survival (Öst et al., 2018). This is because long-lived species have more opportunities to breed than short-lived species and therefore it is more advantageous to breed only when conditions are favourable (Dobson \& Jouventin, 2010). In marbled murrelets, only $13-20 \%$ of individuals attempt to breed each year, and this has been attributed to the degradation of Washington's marine habitat (Lorenz et al., 2017). While breeding propensity (the proportion of individuals that attempt to breed) in Westland petrels is not as low as 
marbled murrelets, it is lower than the closely related black petrel, at $60 \%$, which have a similar population size (Zhang et al., 2020). Despite their low breeding propensity, breeding success in Westland petrels is relatively high (68-71\%) and their population has been increasing since the 1970s (S. M. Waugh et al., 2015; Waugh et al., 2020). This suggests that although foraging conditions on the West Coast are highly variable, breeding individuals are able to forage successfully by utilizing various foraging strategies.

Climate change predictions for the West Coast include rising sea surface temperatures, more frequent marine heatwaves, and the increased frequency and severity of extreme weather events (Chiswell \& O'Callaghan, 2021; Chiswell \& Sutton, 2020; Ummenhofer \& Meehl, 2017). These conditions will make finding prey increasingly difficult for Westland petrels which could impact the survival of breeding individuals and lower breeding propensity further in the population. We may also see more individuals adopt a generalist looping foraging strategy to locate prey, and potentially see a southward shift in the petrels foraging distribution as marine species around the world are predicted to migrate poleward to cooler waters (Hastings et al., 2020; Smith et al., 2019). The foraging behaviour or other winter breeding species such as Fiordland penguins and Southern Buller's albatross indicate that the continental shelf off the Southern end of New Zealand provides a reliable and concentrated source of prey during the winter (Poupart, Waugh, Bost, et al., 2019; Poupart, Waugh, Miskelly, et al., 2019). In this study, I found that a small number of Westland petrels are already exploiting this area so this could potentially become a core foraging area for the petrels in the future. Another area the petrels may exploit in the future is the Subtropical Front located south of New Zealand's mainland (Ramadyan, 2017). This frontal zone is already used by many seabirds and productivity in this area is predicted to increase as sea surface temperatures in the Tasman Sea continue to rise (Chiswell \& Sutton, 2020; Poupart, 2019; Rayner et al., 2008).

The impacts from climate change on the Westland petrels natural prey source may also lead to an increasing reliance on fishery discards, increasing the risk of incidental fishery mortality. While diet studies have shown that they feed predominantly on natural prey, fishery discards make up $63 \%$ of chick diets (A. Freeman, 1998). This suggests that threats from the commercial fishing industry are largely limited to the chick-rearing stage. However, in the past 10 years, Westland petrels have risen from $10^{\text {th }}$ to the $3^{\text {rd }}$ most at-risk seabird from New Zealand commercial fisheries (Richard et al., 2020; Richard et al., 2015). This suggests that the petrels may already be relying more on fishery discards as a result of rising sea surface temperatures and marine heatwaves over the past decade, making natural prey availability on the West Coast unpredictable (Chiswell \& Sutton, 2020). Currently, Westland petrels are most at risk from inshore trawl fisheries and small-vessel surface-longline fisheries due to their close proximity to the colony and high overlap with the petrels core foraging area (Richard et al., 2020). 


\subsection{Recommendation for management}

Given the ongoing impacts from climate change and commercial fisheries on the West Coast (Chiswell \& Sutton, 2020; Richard et al., 2020), conservation management should focus on protecting the Westland petrels core foraging habitat around the Hokitika canyon. Currently, marine protected areas on the West Coast are limited, with only a handful of coastal marine reserves extending no further than $5 \mathrm{~km}$ from the coastline (Department of Conservation, 2012). Furthermore, the current 'Important Bird Area' (sites internationally recognised as important for bird conservation to help focus and facilitate conservation action) identified for the Westland petrels, only covers an area extending $30 \mathrm{~km}$ from the colony (Forest and Bird, 2014). While this may offer some protection for petrels entering and exiting the colony, this offers little protection for them whilst out foraging. I propose that the Hokitika canyon be identified as an 'Important Bird Area' and that pelagic marine protected areas are established to protect the Westland petrels core foraging area. Establishing marine protected areas around the Hokitika canyon would increase the reliability of prey on the West Coast for the Westland petrels which could potentially buffer against the negative impacts from climate change (Roberts et al., 2017). These marine protected areas would also limit the spatial overlap between foraging petrels and commercial fisheries, lowering the risk of incidental fishery mortality.

As well as protecting habitat around the Hokitika canyon, conservation should also focus on better management of West Coast fisheries to reduce the incidental mortality of Westland petrels. Specifically, stronger regulations for West Coast inshore trawl and small-vessel surface-longline fisheries as they pose the greatest threat to Westland petrels (Richard et al., 2020). Better management of these fisheries would include stricter rules on offal discards and implementing bird-scaring technologies such as Tori lines (Frankish et al., 2021; Jiménez et al., 2020). In South Georgia, the implementation of these management strategies saw a significant reduction in fishery mortality for white-chinned petrels (Frankish et al., 2021).

If foraging conditions on the West Coast become increasingly hostile, and extreme weather events continue to destroy parts of the Westland petrels breeding site, future management may need to consider more drastic action to protect this species. Although translocations have provided a viable option for many seabird species such as Chatham albatrosses (Thalassarche eremita, [(Chatham Island Taiko Trust, 2019) and common diving petrels (Pelecanoides urinatrix, (Miskelly et al., 2009), there are many challenges that prevent translocations being a viable option for Westland petrels. Fossil evidence shows that their historical breeding range did not extend much further than their current range suggesting that they require dense native bush hillslopes as suitable breeding habitat (Worthy \& Holdaway, 1993). This means that many of the offshore islands around New Zealand, where seabird translocations already occur, are unsuitable as they mainly consist of treeless scrubland habitat. While much of the West Coast of the South Island does consist of suitable habitat, the presence of invasive 
feral pigs would put any translocated individuals at risk of predation (Waugh \& Wilson, 2017). The dense native bush habitat where they currently breed also makes accessing chicks for translocation challenging without causing large amounts of stress for the chicks. Westland petrels are also one of the largest burrow nesting seabirds (Waugh \& Bartle, 2013), which means that a high amount of investment would have to be put into constructing large artificial burrows at translocation sites. While translocation efforts have been done on the closely related black petrel, these has largely been unsuccessful (Imber et al., 2003).

\subsection{Limitations and Future Research}

Although this study looked at the foraging behaviour of Westland petrels in more detail, it only captures a small snapshot of their lives. I only investigated foraging during the incubation period and most individuals only had one foraging trip recorded. Future studies should therefore focus on the long-term tracking of individual Westland petrels throughout the breeding season. This would give us greater understanding of the foraging strategies individuals utilize, how those strategies may change throughout the breeding season and the impact this has on overall breeding success. It would also help us understand how Westland petrels manage to maintain high chick survival rates despite the highly varied foraging conditions on the West Coast. Long-term tracking of individuals may also inform us on the degree of individual specialisation occurring in the population and whether having a specialized or more generalist foraging strategy is more beneficial for breeding success. Future research should also focus on tracking the foraging behaviour of non-breeding individuals to better understand why breeding propensity is so low in Westland petrels. Lastly, considering the increasing threat from commercial fisheries, further analysis on the diets of Westland petrels is required to identify whether individuals are relying more on fishery discards as a source of prey. 


\section{References}

Adame, M. F., Fry, B., Gamboa, J. N., \& Herrera-Silveira, J. A. (2015). Nutrient subsidies delivered by seabirds to mangrove islands. Marine Ecology Progress Series, 525, 15-24.

https://doi.org/10.3354/meps11197

Ancona, S., Calixto-Albarrán, I., \& Drummond, H. (2012). Effect of El Niño on the diet of a specialist seabird, Sula nebouxii, in the warm eastern tropical Pacific. Marine Ecology Progress Series, 462, 261-271.

Ancona, S., Sánchez-Colón, S., Rodríguez, C., \& Drummond, H. (2011). El Niño in the Warm Tropics: local sea temperature predicts breeding parameters and growth of blue-footed boobies. Journal of Animal Ecology, 80(4), 799-808.

Anderson, O., Small, C., Croxall, J., Dunn, E., Sullivan, B., Yates, O., \& Black, A. (2011). Global seabird bycatch in longline fisheries. Endangered Species Research, 14(2), 91-106. https://doi.org/10.3354/esr00347

Armengol, L., Calbet, A., Franchy, G., Rodríguez-Santos, A., \& Hernández-León, S. (2019). Planktonic food web structure and trophic transfer efficiency along a productivity gradient in the tropical and subtropical Atlantic Ocean. Scientific reports, 9(1), 1-19.

Bailey, H., Lyubchich, V., Wingfield, J., Fandel, A., Garrod, A., \& Rice, A. (2019). Empirical evidence that large marine predator foraging behavior is consistent with area-restricted search theory. Ecology, 100(8), e02743.

Baker, B., Cunningham, R., \& Hedley, G. (2011). Data collection of demographic, distributional and trophic information on the Westland petrel to allow estimation of effects of fishing on population viability. Report prepared for The Ministry of Fisheries PRO2006-01J, 42, 1-24.

Barnosky, A. D., Matzke, N., Tomiya, S., Wogan, G. O. U., Swartz, B., Quental, T. B., . . Ferrer, E. A. (2011). Has the Earth's sixth mass extinction already arrived? Nature, 471(7336), 51-57. https://doi.org/10.1038/nature09678

Bates, D., Maechler, M., Bolker, B., Walker, S., Christensen, R. H. B., Singmann, H., . . Green, P. (2018). Package 'Ime4'. Version, 1(17), 437.

Beck, J., Michael, P. E., Hester, M., Nevins, H. M., Donnelly-Greenan, E., Gibble, C., . . Fitzgerald, S. (2021). Seasonal variation of Pacific Northern Fulmar bycatch: Implications for age and sexspecific mortality. Fisheries Oceanography, 30(3), 253-263.

Beever, E. A., Hall, L. E., Varner, J., Loosen, A. E., Dunham, J. B., Gahl, M. K., . . Lawler, J. J. (2017). Behavioral flexibility as a mechanism for coping with climate change. Frontiers in Ecology and the Environment, 15(6), 299-308.

Bird, F. a. (2014). New Zealand Seabirds: Sites at Sea, Seaward extensions, pelagic areas. W. The Royal Forest \& Bird Protection Society of New Zealand, New Zealand.

BirdLife International. (2018). Procellaria westlandica. The IUCN Red List of Threatened Species. http: / /dx.doi .org/10.2305/IUCN.UK.2017-3 .RLTS.T22698155A119318610.en

Bonnet-Lebrun, A.-S., Phillips, R., Manica, A., \& Rodrigues, A. S. (2018). Quantifying individual specialization using tracking data: a case study on two species of albatrosses. Marine biology, 165(10), 1-15.

Brooke, M. D. L. (2004). The Food Consumption of the World's Seabirds. Proceedings: Biological Sciences, 271, S246-S248.

Burke, C., \& Montevecchi, W. (2009). The foraging decisions of a central place foraging seabird in response to fluctuations in local prey conditions. Journal of Zoology, 278(4), 354-361.

Calenge, C. (2006). The package adehabitat for the R software: tool for the analysis of space and habitat use by animals. Ecological Modelling, 197, 1035.

Carr, P., Trevail, A., Bárrios, S., Clubbe, C., Freeman, R., Koldewey, H. J., . . Nicoll, M. A. (2021). Potential benefits to breeding seabirds of converting abandoned coconut plantations to native habitats after invasive predator eradication. Restoration Ecology, e13386. 
Carroll, G., Cox, M., Harcourt, R., Pitcher, B. J., Slip, D., \& Jonsen, I. (2017). Hierarchical influences of prey distribution on patterns of prey capture by a marine predator. Functional Ecology, 31(9), 1750-1760.

Catry, T., Ramos, J. A., Catry, I., Monticelli, D., \& Granadeiro, J. P. (2013). Inter-annual variability in the breeding performance of six tropical seabird species: influence of life-history traits and relationship with oceanographic parameters. Marine biology, 160(5), 1189-1201.

Ceia, F. R., Phillips, R. A., Ramos, J. A., Cherel, Y., Vieira, R. P., Richard, P., \& Xavier, J. C. (2012). Shortand long-term consistency in the foraging niche of wandering albatrosses. Marine biology, 159(7), 1581-1591.

Ceia, F. R., \& Ramos, J. A. (2015). Individual specialization in the foraging and feeding strategies of seabirds: a review. Marine biology, 162(10), 1923-1938.

Chatham Island Taiko Trust. (2019). Albatross Translocation. In: Chatham Island Taiko Trust. https://www.taiko.org.nz/projects/albatross-translocation.

Chiswell, S. M., \& O'Callaghan, J. M. (2021). Long-term trends in the frequency and magnitude of upwelling along the West Coast of the South Island, New Zealand, and the impact on primary production. New Zealand Journal of Marine and Freshwater Research, 1-22.

Chiswell, S. M., \& Sutton, P. J. (2020). Relationships between long-term ocean warming, marine heat waves and primary production in the New Zealand region. New Zealand Journal of Marine and Freshwater Research, 54(4), 614-635.

Clark, C. W., \& Mangel, M. (1986). The evolutionary advantages of group foraging. Theoretical population biology, 30(1), 45-75.

Clay, T. A., Oppel, S., Lavers, J. L., Phillips, R. A., \& Brooke, M. d. L. (2019). Divergent foraging strategies during incubation of an unusually wide-ranging seabird, the Murphy's petrel. Marine biology, 166(1), 1-14.

Collins, P. M., Green, J. A., Elliott, K. H., Shaw, P. J., Chivers, L., Hatch, S. A., \& Halsey, L. G. (2020). Coping with the commute: behavioural responses to wind conditions in a foraging seabird. Journal of Avian Biology, 51(4).

Congdon, B. C., Krockenberger, A. K., \& Smithers, B. V. (2005). Dual-foraging and co-ordinated provisioning in a tropical Procellariiform, the wedge-tailed shearwater. Marine Ecology Progress Series, 301, 293-301.

Courbin, N., Besnard, A., Péron, C., Saraux, C., Fort, J., Perret, S., . . Grémillet, D. (2018). Short-term prey field lability constrains individual specialisation in resource selection and foraging site fidelity in a marine predator. Ecology letters, 21(7), 1043-1054.

Da Rocha, N., Oppel, S., Prince, S., Matjila, S., Shaanika, T. M., Naomab, C., . . Frans, E. (2021). Reduction in seabird mortality in Namibian fisheries following the introduction of bycatch regulation. Biological Conservation, 253, 108915.

De Leo, F. C., Smith, C. R., Rowden, A. A., Bowden, D. A., \& Clark, M. R. (2010). Submarine canyons: hotspots of benthic biomass and productivity in the deep sea. Proceedings of the Royal Society B: Biological Sciences, 277(1695), 2783-2792.

De Pascalis, F., Imperio, S., Benvenuti, A., Catoni, C., Rubolini, D., \& Cecere, J. G. (2020). Sex-specific foraging behaviour is affected by wind conditions in a sexually size dimorphic seabird. Animal Behaviour, 166, 207-218.

Department of Conservation. (2012). Marine Reserves Application for five sites in the West Coast Tai Poutini Conservancy, in the localities of Kahurangi, Punakaiki, Ōkārito, Ship Creek and Gorge. Department of Conservation Te Papa Atawhai, Hokitika, New Zealand.

Dias, M. P., Martin, R., Pearmain, E. J., Burfield, I. J., Small, C., Phillips, R. A., . . Croxall, J. P. (2019). Threats to seabirds: A global assessment. Biological Conservation, 237, 525-537. https://doi.org/10.1016/j.biocon.2019.06.033

Dobson, F. S., \& Jouventin, P. (2010). The trade-off of reproduction and survival in slow-breeding seabirds.(Report). Canadian Journal of Zoology, 88(9), 889. https://doi.org/10.1139/Z10-054 
Elliott, K. H., Ricklefs, R. E., Gaston, A. J., Hatch, S. A., Speakman, J. R., \& Davoren, G. K. (2013). High flight costs, but low dive costs, in auks support the biomechanical hypothesis for flightlessness in penguins. Proceedings of the National Academy of Sciences, 110(23), 93809384.

Evans, M. R., \& Moustakas, A. (2018). Plasticity in foraging behaviour as a possible response to climate change. Ecological Informatics, 47, 61-66.

Evans, R., Lea, M. A., \& Hindell, M. A. (2021). Predicting the distribution of foraging seabirds during a period of heightened environmental variability. Ecological Applications, e02343.

Fauchald, P., \& Tveraa, T. (2003). Using first-passage time in the analysis of area-restricted search and habitat selection. Ecology, 84(2), 282-288.

Fayet, A. L., Clucas, G. V., Anker-Nilssen, T., Syposz, M., \& Hansen, E. S. (2021). Local prey shortages drive foraging costs and breeding success in a declining seabird, the Atlantic puffin. Journal of Animal Ecology, 90(5), 1152-1164.

Forest and Bird. (2014). New Zealand Seabirds: Sites at Sea, Seaward extensions, pelagic areas. W. The Royal Forest \& Bird Protection Society of New Zealand, New Zealand.

Frankish, C. K., Manica, A., Navarro, J., \& Phillips, R. A. (2021). Movements and diving behaviour of white-chinned petrels: Diurnal variation and implications for bycatch mitigation. Aquatic Conservation: Marine and Freshwater Ecosystems.

Freeman, A. (1998). Diet of Westland Petrels Procellaria westlandica : the Importance of Fisheries Waste During Chick-rearing. Emu, 98(1), 36-43.

Freeman, A., \& Smith, P. (1998). Iso-electric focusing and the identification of fisheries' waste in the diet of Westland petrels ( Procellaria westlandica ). New Zealand journal of marine and freshwater research, 32(2), 177-180.

Freeman, A. N. (1998). Diet of Westland Petrels Procellaria westlandica: The importance of fisheries waste during chick-rearing. Emu, 98(1), 36-43.

Freitas, C., Caldeira, R., Reis, J., \& Dellinger, T. (2018). Foraging behavior of juvenile loggerhead sea turtles in the open ocean: from Lévy exploration to area-restricted search. Marine Ecology Progress Series, 595, 203-215.

Gagliardo, A., Bried, J., Lambardi, P., Luschi, P., Wikelski, M., \& Bonadonna, F. (2013). Oceanic navigation in Cory's shearwaters: evidence for a crucial role of olfactory cues for homing after displacement. Journal of Experimental Biology, 216(15), 2798-2805.

Garthe, S., Schwemmer, P., Paiva, V. H., Corman, A.-M., Fock, H. O., Voigt, C. C., \& Adler, S. (2016). Terrestrial and marine foraging strategies of an opportunistic seabird species breeding in the Wadden Sea. PloS one, 11(8), e0159630.

Gianuca, D., Votier, S. C., Pardo, D., Wood, A. G., Sherley, R. B., Ireland, L., . . Forcada, J. (2019). Sexspecific effects of fisheries and climate on the demography of sexually dimorphic seabirds. Journal of Animal Ecology, 88(9), 1366-1378.

Gilmour, M. E., Castillo-Guerrero, J. A., Fleishman, A. B., Hernández-Vázquez, S., Young, H. S., \& Shaffer, S. A. (2018). Plasticity of foraging behaviors in response to diverse environmental conditions. Ecosphere, 9(7), e02301.

González-Solís, J., Croxall, J., \& Afanasyev, V. (2007). Offshore spatial segregation in giant petrels Macronectes spp.: differences between species, sexes and seasons. Aquatic Conservation: Marine and Freshwater Ecosystems, 17(S1), S22-S36.

González-Solís, J., Croxall, J. P., \& Wood, A. G. (2000). Sexual dimorphism and sexual segregation in foraging strategies of northern giant petrels, Macronectes halli, during incubation. Oikos, 90(2), 390-398.

Gormezano, L. J., \& Rockwell, R. F. (2013). What to eat now? Shifts in polar bear diet during the icefree season in western Hudson Bay. Ecology and evolution, 3(10), 3509-3523.

Grémillet, D., Lewis, S., Drapeau, L., van Der Lingen, C. D., Huggett, J. A., Coetzee, J. C., . . Ryan, P. G. (2008). Spatial match-mismatch in the Benguela upwelling zone: should we expect 
chlorophyll and sea-surface temperature to predict marine predator distributions? Journal of Applied Ecology, 45(2), 610-621.

Hamann, M., Grémillet, D., Ryan, P. G., Bonadonna, F., van Der Lingen, C. D., \& Pichegru, L. (2012). A hard-knock life: the foraging ecology of Cape cormorants amidst shifting prey resources and industrial fishing pressure. African Journal of Marine Science, 34(2), 233-240. https://doi.org/10.2989/1814232X.2012.709960

Harrell, F. (2019). Package 'hmisc'. CRAN2018, 2019, 235-236.

Hass, T., Hyman, J., \& Semmens, B. (2012). Climate change, heightened hurricane activity, and extinction risk for an endangered tropical seabird, the black-capped petrel Pterodroma hasitata. Marine Ecology Progress Series, 454, 251-261. https://doi.org/10.3354/meps09723

Hastings, R. A., Rutterford, L. A., Freer, J. J., Collins, R. A., Simpson, S. D., \& Genner, M. J. (2020). Climate change drives poleward increases and equatorward declines in marine species. Current Biology, 30(8), 1572-1577. e1572.

Hedd, A., Montevecchi, W. A., Phillips, R. A., \& Fifield, D. A. (2014). Seasonal sexual segregation by monomorphic sooty shearwaters Puffinus griseus reflects different reproductive roles during the pre-laying period. PLoS One, 9(1), e85572.

Hijmans, R. J., Van Etten, J., Cheng, J., Mattiuzzi, M., Sumner, M., Greenberg, J. A., . . Shortridge, A. (2015). Package 'raster'. R package, 734.

Imber, M. J., McFadden, I., Bell, E. A., \& Scofield, R. P. (2003). Post-fledging migration, age of first return and recruitment, and results of inter-colony translocation of black petrels (Procellaria parkinsoni). Notornis, 50(4), 183-190.

IUCN. (2021). The IUCN Red List of Threatened Species. Version 2021. In.

Jackson, J. M., Johnson, G. C., Dosser, H. V., \& Ross, T. (2018). Warming from recent marine heatwave lingers in deep British Columbia fjord. Geophysical Research Letters, 45(18), 97579764.

Jiménez, S., Domingo, A., Winker, H., Parker, D., Gianuca, D., Neves, T., . . Kerwath, S. (2020). Towards mitigation of seabird bycatch: large-scale effectiveness of night setting and Tori lines across multiple pelagic longline fleets. Biological Conservation, 247, 108642.

Kowalczyk, N. D., Reina, R. D., Preston, T. J., \& Chiaradia, A. (2015). Environmental variability drives shifts in the foraging behaviour and reproductive success of an inshore seabird. Oecologia, 178(4), 967-979.

Lande, R. (1998). Anthropogenic, ecological and genetic factors in extinction and conservation. Researches on Population Ecology, 40(3), 259-269. https://doi.org/10.1007/BF02763457

Laurel, B. J., Hunsicker, M. E., Ciannelli, L., Hurst, T. P., Duffy-Anderson, J., O'Malley, R., \& Behrenfeld, M. (2021). Regional warming exacerbates match/mismatch vulnerability for cod larvae in Alaska. Progress in Oceanography, 193, 102555.

Le Roux, A., Cherry, M. I., Gygax, L., \& Manser, M. B. (2009). Vigilance behaviour and fitness consequences: comparing a solitary foraging and an obligate group-foraging mammal. Behavioral Ecology and Sociobiology, 63(8), 1097-1107.

Lees, K. J., Guerin, A. J., \& Masden, E. A. (2016). Using kernel density estimation to explore habitat use by seabirds at a marine renewable wave energy test facility. Marine Policy, 63, 35-44.

Lewis, S., Benvenuti, S., Dall-Antonia, L., Griffiths, R., Money, L., Sherratt, T., . . Hamer, K. (2002). Sex-specific foraging behaviour in a monomorphic seabird. Proceedings of the Royal Society of London. Series B: Biological Sciences, 269(1501), 1687-1693.

Lewis, S., Schreiber, E. A., Daunt, F., Schenk, G. A., Orr, K., Adams, A., . . Hamer, K. C. (2005). Sexspecific foraging behaviour in tropical boobies: does size matter? Ibis, 147(2), 408-414.

Lezama-Ochoa, N., Pennino, M. G., Hall, M. A., Lopez, J., \& Murua, H. (2020). Using a Bayesian modelling approach (INLA-SPDE) to predict the occurrence of the Spinetail Devil Ray (Mobular mobular). Scientific reports, 10(1), 1-11.

Lindgren, F., \& Rue, H. (2015). Bayesian spatial modelling with R-INLA. Journal of statistical software, $63(1), 1-25$. 
Loots, C., Koubbi, P., \& Duhamel, G. (2007). Habitat modelling of Electrona antarctica (Myctophidae, Pisces) in Kerguelen by generalized additive models and geographic information systems. Polar Biology, 30(8), 951-959.

Lorenz, T. J., Raphael, M. G., Bloxton, T. D., \& Cunningham, P. G. (2017). Low breeding propensity and wide-ranging movements by marbled murrelets in Washington. The Journal of Wildlife Management, 81(2), 306-321.

Louzao, M., Navarro, J., Forero, M. G., Igual, J. M., Genovart, M., Hobson, K. A., \& Oro, D. (2011). Exploiting the closest productive area: geographical segregation of foraging grounds in a critically endangered seabird. Marine Ecology Progress Series, 429, 291-301.

Louzao, M., Wiegand, T., Bartumeus, F., \& Weimerskirch, H. (2014). Coupling instantaneous energybudget models and behavioural mode analysis to estimate optimal foraging strategy: an example with wandering albatrosses. Movement Ecology, 2(1), 8. https://doi.org/10.1186/2051-3933-2-8

MacArthur, R. H., \& Pianka, E. R. (1966). On optimal use of a patchy environment. The American Naturalist, 100(916), 603-609.

Magalhães, M., Santos, R., \& Hamer, K. (2008). Dual-foraging of Cory's shearwaters in the Azores: feeding locations, behaviour at sea and implications for food provisioning of chicks. Marine Ecology Progress Series, 359, 283-293.

McDuie, F., Weeks, S. J., \& Congdon, B. C. (2018). Oceanographic drivers of near-colony seabird foraging site use in tropical marine systems. Marine Ecology Progress Series, 589, 209-225.

McInnes, A. M., McGeorge, C., Ginsberg, S., Pichegru, L., \& Pistorius, P. A. (2017). Group foraging increases foraging efficiency in a piscivorous diver, the African penguin. Royal Society open science, 4(9), 170918.

Mendez, L., Borsa, P., Cruz, S., de Grissac, S., Hennicke, J., Lallemand, J., . . . Weimerskirch, H. (2017). Geographical variation in the foraging behaviour of the pantropical red-footed booby. Marine Ecology Progress Series, 568, 217-230.

Michaels, P. J., Knappenberger, P. C., \& Davis, R. E. (2006). Sea-surface temperatures and tropical cyclones in the Atlantic basin. Geophysical Research Letters, 33(9).

Miller, M. G., Silva, F. R., Machovsky-Capuska, G. E., \& Congdon, B. C. (2018). Sexual segregation in tropical seabirds: drivers of sex-specific foraging in the brown booby Sula leucogaster. Journal of Ornithology, 159(2), 425-437.

Miskelly, C., Tennyson, A., \& Taylor, G. (2012). The Great Prion Wreck of 2011. Museum of New Zealand Te Papa Tongarewa.

Miskelly, C. M., Taylor, G. A., Gummer, H., \& Williams, R. (2009). Translocations of eight species of burrow-nesting seabirds (genera Pterodroma, Pelecanoides, Pachyptila and Puffinus: Family Procellariidae). Biological conservation, 142(10), 1965-1980.

Mitchell, I., Daunt, F., Frederiksen, M., \& Wade, K. (2020). Impacts of climate change on seabirds, relevant to the coastal and marine environment around the UK.

Mobile Action Technology. (2016). i-gotU GT-120 Manual. http:// www.manualsworld.net/manual/261538/i-gotu/gt-120

Morley, T. I., Fayet, A. L., Jessop, H., Veron, P., Veron, M., Clark, J., \& Wood, M. J. (2016). The seabird wreck in the Bay of Biscay and South-Western Approaches in 2014: A review of reported mortality. Seabird, 29, 22-38.

Moum, J. N., Perlin, A., Nash, J. D., \& McPhaden, M. J. (2013). Seasonal sea surface cooling in the equatorial Pacific cold tongue controlled by ocean mixing. Nature, 500(7460), 64-67.

Munroe, D., Powell, E., Mann, R., Klinck, J., \& Hofmann, E. (2013). Underestimation of primary productivity on continental shelves: evidence from maximum size of extant surfclam (Spisula solidissima) populations. Fisheries Oceanography, 22(3), 220-233.

Nathan, R., Getz, W. M., Revilla, E., Holyoak, M., Kadmon, R., Saltz, D., \& Smouse, P. E. (2008). A movement ecology paradigm for unifying organismal movement research. Proceedings of the National Academy of Sciences, 105(49), 19052-19059. 
Navarro, J., \& González-Solís, J. (2009). Environmental determinants of foraging strategies in Cory's shearwaters Calonectris diomedea. Marine Ecology Progress Series, 378, 259-267.

Nevitt, G. A. (2008). Sensory ecology on the high seas: the odor world of the procellariiform seabirds. Journal of Experimental Biology, 211(11), 1706-1713. https://doi.org/10.1242/ieb.015412

Newell, M., Wanless, S., Harris, M. P., \& Daunt, F. (2015). Effects of an extreme weather event on seabird breeding success at a North Sea colony. Marine Ecology Progress Series, 532, 257268. https://doi.org/10.3354/meps11329

Nicoll, M. A., Nevoux, M., Jones, C. G., Ratcliffe, N., Ruhomaun, K., Tatayah, V., \& Norris, K. (2017). Contrasting effects of tropical cyclones on the annual survival of a pelagic seabird in the Indian Ocean. Global Change Biology, 23(2), 550-565.

Nicolson, A. (2018). The Seabird's Cry: The Lives and Loves of the Planet's Great Ocean Voyagers. Henry Holt and Company.

Ochi, D., Matsumoto, K., Oka, N., Deguchi, T., Sato, K., Satoh, T. P., ... Watanuki, Y. (2016). Dual foraging strategy and chick growth of Streaked Shearwater Calonectris leucomelas at two colonies in different oceanographic environments. Ornithological Science, 15(2), 213-225.

Oliver, E. C., Benthuysen, J. A., Bindoff, N. L., Hobday, A. J., Holbrook, N. J., Mundy, C. N., \& PerkinsKirkpatrick, S. E. (2017). The unprecedented 2015/16 Tasman Sea marine heatwave. Nature communications, 8(1), 1-12.

Oliver, E. C., Benthuysen, J. A., Darmaraki, S., Donat, M. G., Hobday, A. J., Holbrook, N. J., ... Sen Gupta, A. (2021). Marine heatwaves. Annual Review of Marine Science, 13, 313-342.

Oliver, E. C., Donat, M. G., Burrows, M. T., Moore, P. J., Smale, D. A., Alexander, L. V., . . Hobday, A. J. (2018). Longer and more frequent marine heatwaves over the past century. Nature communications, 9(1), 1-12.

Owen-Smith, N., Fryxell, J., \& Merrill, E. (2010). Foraging theory upscaled: the behavioural ecology of herbivore movement. Philosophical Transactions of the Royal Society B: Biological Sciences, 365(1550), 2267-2278.

Paiva, V. H., Geraldes, P., Ramírez, I., Garthe, S., \& Ramos, J. A. (2010). How area restricted search of a pelagic seabird changes while performing a dual foraging strategy. Oikos, 119(9), 14231434.

Paiva, V. H., Pereira, J., Ceia, F. R., \& Ramos, J. A. (2017). Environmentally driven sexual segregation in a marine top predator. Scientific reports, 7(1), 1-11.

Parsons, M., Mitchell, I., Butler, A., Ratcliffe, N., Frederiksen, M., Foster, S., \& Reid, J. B. (2008). Seabirds as indicators of the marine environment. ICES Journal of Marine Science, 65(8), 1520-1526. https://doi.org/10.1093/icesims/fsn155

Phillips, L. R., Hindell, M., Hobday, A. J., \& Lea, M.-A. (2019). Variability in at-sea foraging behaviour of little penguins eudyptula minor in response to finescale environmental features. Marine Ecology Progress Series, 627, 141-154.

Phillips, R., Croxall, J., Silk, J., \& Briggs, D. (2007). Foraging ecology of albatrosses and petrels from South Georgia: two decades of insights from tracking technologies. Aquatic Conservation: Marine and Freshwater Ecosystems, 17(S1), S6-S21.

Phillips, R., Silk, J., Phalan, B., Catry, P., \& Croxall, J. (2004). Seasonal sexual segregation in two Thalassarche albatross species: competitive exclusion, reproductive role specialization or foraging niche divergence? Proceedings of the Royal Society of London. Series B: Biological Sciences, 271(1545), 1283-1291.

Phillips, R. A., Lewis, S., González-Solís, J., \& Daunt, F. (2017). Causes and consequences of individual variability and specialization in foraging and migration strategies of seabirds. Marine Ecology Progress Series, 578, 117-150.

Piatt, J., Sydeman, W., \& Wiese, F. (2008). Introduction: seabirds as indicators of marine ecosystems. Marine Ecology Progress Series, 352, 199-204. 
Piatt, J. F., Parrish, J. K., Renner, H. M., Schoen, S. K., Jones, T. T., Arimitsu, M. L., . . Duerr, R. S. (2020). Extreme mortality and reproductive failure of common murres resulting from the northeast Pacific marine heatwave of 2014-2016. PloS one, 15(1), e0226087.

Pierson, J. C., Beissinger, S. R., Bragg, J. G., Coates, D. J., Oostermeijer, J. G. B., Sunnucks, P., . . Young, A. G. (2015). Incorporating evolutionary processes into population viability models. Conservation Biology, 29(3), 755-764. https://doi.org/10.1111/cobi.12431

Pimm, S. L., Jenkins, C. N., Abell, R., Brooks, T. M., Gittleman, J. L., Joppa, L. N., . . Sexton, J. O. (2014). The biodiversity of species and their rates of extinction, distribution, and protection. Science (New York, N.Y.), 344(6187), 1246752-1246752. https://doi.org/10.1126/science.1246752

Pinaud, D., Cherel, Y., \& Weimerskirch, H. (2005). Effect of environmental variability on habitat selection, diet, provisioning behaviour and chick growth in yellow-nosed albatrosses. Marine Ecology Progress Series, 298, 295-304.

Pollonara, E., Luschi, P., Guilford, T., Wikelski, M., Bonadonna, F., \& Gagliardo, A. (2015). Olfaction and topography, but not magnetic cues, control navigation in a pelagic seabird: displacements with shearwaters in the Mediterranean Sea. Scientific reports, 5(1), 1-10.

Poupart, T. A., Waugh, S. M., Bost, C. A., Kato, A., Miskelly, C. M., Rogers, K. M., \& Arnould, J. P. (2019). Foraging ecology of a winter breeder, the Fiordland penguin. Marine Ecology Progress Series, 614, 183-197.

Poupart, T. A., Waugh, S. M., Kato, A., \& Arnould, J. P. (2020). Foraging niche overlap during chickrearing in the sexually dimorphic Westland petrel. Royal Society open science, 7(11), 191511.

Poupart, T. A., Waugh, S. M., Miskelly, C. M., Kato, A., Angel, L. P., Rogers, K. M., \& Arnould, J. P. (2019). Fine-scale foraging behaviour of southern Buller's albatross, the only Thalassarche that provisions chicks through winter. Marine Ecology Progress Series, 625, 163-179.

Poupart, T. e. (2019). Foraging ecology of winter-breeding seabirds in New Zealand Université de La Rochelle; Deakin university (Geelong, Australie)].

QGIS Development Team. (2020). QGIS Geographic Information System. Open Source Geospatial Foundation.

R Core Team. (2020). R: A language and environment for statistical computing [Computer software manual]. Vienna, Austria.

Ramadyan, F. (2017). Spatial and temporal variability of phytoplankton productivity in the subtropical front around New Zealand University of Otago].

Rayner, M., Hauber, M., Clout, M., Seldon, D., Van Dijken, S., Bury, S., \& Phillips, R. (2008). Foraging ecology of the Cook's petrel Pterodroma cookii during the austral breeding season: a comparison of its two populations. Marine Ecology Progress Series, 370, 271-284.

Rayner, M. J., Phillips, R. A., Hauber, M. E., \& Landers, T. J. (2011). Dynamics of Seasonal Movements by a Trans-Pacific Migrant, the Westland Petrel. The Condor, 113, 71-79.

Reed, T. E., Harris, M. P., \& Wanless, S. (2015). Skipped breeding in common guillemots in a changing climate: restraint or constraint? Frontiers in Ecology and Evolution, 3, 1.

Regular, P. M., Hedd, A., \& Montevecchi, W. A. (2013). Must marine predators always follow scaling laws? Memory guides the foraging decisions of a pursuit-diving seabird. Animal Behaviour, 86(3), 545-552.

Regular, P. M., Hedd, A., Montevecchi, W. A., Robertson, G. J., Storey, A. E., \& Walsh, C. J. (2014). Why timing is everything: Energetic costs and reproductive consequences of resource mismatch for a chick-rearing seabird. Ecosphere, 5(12), 1-13.

Renner, I. W., Elith, J., Baddeley, A., Fithian, W., Hastie, T., Phillips, S. J., ... Warton, D. I. (2015). Point process models for presence-only analysis. Methods in Ecology and Evolution, 6(4), 366-379.

Renwick, J. (2012). New Zealand national climate summary 2011: A year of extremes. NIWA.

Reyes-González, J. M., De Felipe, F., Morera-Pujol, V., Soriano-Redondo, A., Navarro-Herrero, L., Zango, L., . . . González-Solís, J. (2021). Sexual segregation in the foraging behaviour of a 
slightly dimorphic seabird: Influence of the environment and fishery activity. Journal of Animal Ecology, 90(5), 1109-1121.

Richard, Y., Abraham, E. R., \& Berkenbusch, K. (2020). Assessment of the risk of commercial fisheries to New Zealand seabirds, 2006-07 to 2016-17. Fisheries New Zealand, Tini a Tangaroa.

Richard, Y., Abraham, E. R., \& Filippi, D. (2015). Assessment of the risk of commercial fisheries to New Zealand seabirds, 2006-07 to 2012-13. Ministry for Primary Industries, Manatū Ahu Matua.

Richardson, P. L., Wakefield, E. D., \& Phillips, R. A. (2018). Flight speed and performance of the wandering albatross with respect to wind. Movement ecology, 6(1), 1-15.

Ricklefs, R. E. (1990). Seabird Life Histories and the Marine Environment: Some Speculations. Colonial Waterbirds, 13(1), 1-6. https://doi.org/10.2307/1521414

Riotte-Lambert, L., \& Weimerskirch, H. (2013). Do naive juvenile seabirds forage differently from adults? Proceedings of the Royal Society B: Biological Sciences, 280(1768), 20131434.

Roberts, C. M., O'Leary, B. C., McCauley, D. J., Cury, P. M., Duarte, C. M., Lubchenco, J., . . Wilson, R. W. (2017). Marine reserves can mitigate and promote adaptation to climate change. Proceedings of the National Academy of Sciences, 114(24), 6167-6175.

Roxy, M. K., Modi, A., Murtugudde, R., Valsala, V., Panickal, S., Prasanna Kumar, S., . . Lévy, M. (2016). A reduction in marine primary productivity driven by rapid warming over the tropical Indian Ocean. Geophysical Research Letters, 43(2), 826-833.

Sachs, G. (2016). In-flight measurement of upwind dynamic soaring in albatrosses. Progress in Oceanography, 142, 47-57.

Saraux, C., Robinson-Laverick, S. M., Le Maho, Y., Ropert-Coudert, Y., \& Chiaradia, A. (2011). Plasticity in foraging strategies of inshore birds: how little penguins maintain body reserves while feeding offspring. Ecology, 92(10), 1909-1916.

Sarmento, R., Brito, D., Ladle, R. J., Leal Da Rosa, G., \& Efe, M. A. (2014). Invasive House (Rattus Rattus) and Brown Rats (Rattus Norvegicus) Threaten the Viability of Red-Billed Tropicbird (Phaethon Aethereus) in Abrolhos National Park, Brazil. Tropical Conservation Science, 7(4), 614-627. https://doi.org/10.1177/194008291400700403

Schoener, T. W. (1971). Theory of feeding strategies. Annual review of ecology and systematics, 2(1), 369-404.

Shaffer, M. L. (1981). Minimum population sizes for species conservation. BioScience, 31, 131.

Shaffer, S. A., Tremblay, Y., Weimerskirch, H., Scott, D., Thompson, D. R., Sagar, P. M., . . Costa, D. P. (2006). Migratory Shearwaters Integrate Oceanic Resources across the Pacific Ocean in an Endless Summer. Proceedings of the National Academy of Sciences of the United States of America, 103(34), 12799-12802. https://doi.org/10.1073/pnas.0603715103

Shealer, D. A. (2002). Foraging behavior and food of seabirds. Biology of marine birds, 137-177.

Smale, D. A., Wernberg, T., Oliver, E. C., Thomsen, M., Harvey, B. P., Straub, S. C., . . Donat, M. G. (2019). Marine heatwaves threaten global biodiversity and the provision of ecosystem services. Nature Climate Change, 9(4), 306-312.

Smith, K. A., Dowling, C. E., \& Brown, J. (2019). Simmered then boiled: Multi-decadal poleward shift in distribution by a temperate fish accelerates during marine heatwave. Frontiers in Marine Science, 6, 407.

Soanes, L., Green, J., Bolton, M., Milligan, G., Mukhida, F., \& Halsey, L. (2021). Linking foraging and breeding strategies in tropical seabirds. Journal of Avian Biology.

Sommerfeld, J., Kato, A., Ropert-Coudert, Y., Garthe, S., \& Hindell, M. A. (2013). Foraging parameters influencing the detection and interpretation of area-restricted search behaviour in marine predators: a case study with the masked booby. PloS one, 8(5), e63742.

Spatz, D. R., Newton, K. M., Heinz, R., Tershy, B., Holmes, N. D., Butchart, S. H. M., \& Croll, D. A. (2014). The Biogeography of Globally Threatened Seabirds and Island Conservation Opportunities.(Report). 28(5), 1282. https://doi.org/10.1111/cobi.12279

Spear, L. B., \& Ainley, D. G. (1997a). Flight behaviour of seabirds in relation to wind direction and wing morphology. Ibis, 139(2), 221-233. 
Spear, L. B., \& Ainley, D. G. (1997b). Flight speed of seabirds in relation to wind speed and direction. Ibis, 139(2), 234-251.

Stephens, D., \& Krebs, J. (1986). Foraging Theory, Ser. Monographs in Behavior and Ecology. Princeton, NJ: Princeton University Press.

Stevens, C. L., O'Callaghan, J. M., Chiswell, S. M., \& Hadfield, M. G. (2019). Physical oceanography of New Zealand/Aotearoa shelf seas-a review. New Zealand Journal of Marine and Freshwater Research, 1-40.

Stewart, A. B., \& Dudash, M. R. (2018). Foraging strategies of generalist and specialist Old World nectar bats in response to temporally variable floral resources. Biotropica, 50(1), 98-105.

Stidworthy, M. F., \& Denk, D. (2018). Sphenisciformes, Gaviiformes, Podicipediformes, Procellariiformes, and Pelecaniformes. In Pathology of Wildlife and Zoo Animals (pp. 653686). Elsevier.

Sydeman, W. J., Thompson, S. A., \& Kitaysky, A. (2012). Seabirds and climate change: roadmap for the future. Marine Ecology Progress Series, 454, 107-117.

Terraube, J., Arroyo, B., Madders, M., \& Mougeot, F. (2011). Diet specialisation and foraging efficiency under fluctuating vole abundance: a comparison between generalist and specialist avian predators. Oikos, 120(2), 234-244.

Terraube, J., Villers, A., Ruffino, L., Iso-livari, L., Henttonen, H., Oksanen, T., \& Korpimäki, E. (2015). Coping with fast climate change in northern ecosystems: Mechanisms underlying the population-level response of a specialist avian predator. Ecography, 38(7), 690-699.

Tessier, E., \& Bost, C.-A. (2020). Behavioural adjustments during foraging in two diving seabirds: king and macaroni penguins. Marine Biology, 167(9), 138. https://doi.org/10.1007/s00227-02003711-z

Thiers, L., Delord, K., Barbraud, C., Phillips, R., Pinaud, D., \& Weimerskirch, H. (2014). Foraging zones of the two sibling species of giant petrels in the Indian Ocean throughout the annual cycle: implication for their conservation. Marine Ecology Progress Series, 499, 233-248. https://doi.org/10.3354/meps10620

Tyson, C., Kirk, H., Fayet, A., Van Loon, E., Shoji, A., Dean, B., . . Guilford, T. (2017). Coordinated provisioning in a dual-foraging pelagic seabird. Animal behaviour, 132, 73-79.

Ummenhofer, C. C., \& Meehl, G. A. (2017). Extreme weather and climate events with ecological relevance: a review. Philosophical Transactions of the Royal Society B: Biological Sciences, 372(1723), 20160135.

Ventura, F., Granadeiro, J. P., Padget, O., \& Catry, P. (2020). Gadfly petrels use knowledge of the windscape, not memorized foraging patches, to optimize foraging trips on ocean-wide scales. Proceedings of the Royal Society B, 287(1918), 20191775.

Vilchis, L. I., Ballance, L. T., \& Fiedler, P. C. (2006). Pelagic habitat of seabirds in the eastern tropical Pacific: effects of foraging ecology on habitat selection. Marine Ecology Progress Series, 315, 279-292.

Votier, S. C., \& Sherley, R. B. (2017). Seabirds. Current Biology, 27(11), R448-R450. https://doi.org/10.1016/j.cub.2017.01.042

Waggitt, J. J., Cazenave, P. W., Howarth, L. M., Evans, P. G., van der Kooij, J., \& Hiddink, J. G. (2018). Combined measurements of prey availability explain habitat selection in foraging seabirds. Biology letters, 14(8), 20180348.

Wakefield, E. D., Phillips, R. A., \& Matthiopoulos, J. (2009). Quantifying habitat use and preferences of pelagic seabirds using individual movement data: a review. Marine Ecology Progress Series, 391, 165-182.

Warham, J. (1977). Wing loadings, wing shapes, and flight capabilities of Procellariiformes. New Zealand Journal of Zoology, 4(1), 73-83.

Waugh, S., Poupart, T., \& Wilson, K. (2015). Storm damage to Westland petrel colonies in 2014 from cyclone Ita. Notornis, 62(3), 165-168. 
Waugh, S., \& Wilson, K. (2017). Threats and threat status of the Westland Petrel (Procellaria westlandica). Marine Ornithology, 45(2), 195-203.

Waugh, S. M., Barbraud, C., Adams, L., Freeman, A. N. D., Wilson, K.-J., Wood, G., . . Baker, G. B. (2015). Modeling the demography and population dynamics of a subtropical seabird, and the influence of environmental factors. The Condor, 117(2), 147-164.

https://doi.org/10.1650/CONDOR-14-141.1

Waugh, S. M., Barbraud, C., Delord, K., Simister, K. L., Baker, G. B., Hedley, G. K., . . Rands, D. R. (2020). Trends in density, abundance, and response to storm damage for Westland Petrels Procellaria westlandica, 2007-2019. Marine Ornithology, 48, 273-281.

Waugh, S. M., \& Bartle, J. A. (2013). Westland petrel. In Miskelly, C.M. (ed.). In: New Zealand Birds Online. www.nzbirdsonline.org.nz.

Waugh, S. M., Griffiths, J. W., Poupart, T. A., Filippi, D. P., Rogers, K., \& Arnould, J. Y. (2018). Environmental factors and fisheries influence the foraging patterns of a subtropical seabird, the Westland Petrel (Procellaria westlandica), in the Tasman Sea. The Condor: Ornithological Applications, 120(2), 371-387.

Webb, L. A., \& Harvey, J. T. (2015). Diet of a piscivorous seabird reveals spatiotemporal variation in abundance of forage fishes in the Monterey Bay region. Journal of Marine Systems, 146, 5971.

Weimerskirch, H. (2007). Are seabirds foraging for unpredictable resources? Deep Sea Research Part II: Topical Studies in Oceanography, 54(3-4), 211-223.

Weimerskirch, H., Delord, K., Guitteaud, A., Phillips, R. A., \& Pinet, P. (2015). Extreme variation in migration strategies between and within wandering albatross populations during their sabbatical year and their fitness consequences. Scientific reports, 5(1), 1-7.

Weimerskirch, H., Guionnet, T., Martin, J., Shaffer, S. A., \& Costa, D. (2000). Fast and fuel efficient? Optimal use of wind by flying albatrosses. Proceedings of the Royal Society of London. Series B: Biological Sciences, 267(1455), 1869-1874.

Weimerskirch, H., Louzao, M., de Grissac, S., \& Delord, K. (2012). Changes in wind pattern alter albatross distribution and life-history traits. science, 335(6065), 211-214.

Weimerskirch, H., \& Prudor, A. (2019). Cyclone avoidance behaviour by foraging seabirds. Scientific reports, 9(1), 1-9.

Weimerskirch, H., \& Robertson, G. (1994). Satellite tracking of light-mantled sooty albatrosses. Polar Biology, 14(2), 123-126.

Weimerskirch, H., Salamolard, M., Sarrazin, F., \& Jouventin, P. (1993). Foraging strategy of wandering albatrosses through the breeding season: a study using satellite telemetry. The Auk, 110(2), 325-342.

West Coast Regional Council. (2020). West Coast region: Water Quantity. LAWA: Land Air Water Aotearoa.

Wilkinson, B. P., Satgé, Y. G., Lamb, J. S., \& Jodice, P. G. (2019). Tropical cyclones alter short-term activity patterns of a coastal seabird. Movement ecology, 7(1), 1-11.

Wingfield, J. C., Hau, M., Boersma, P. D., Romero, L. M., Hillgarth, N., Ramenofsky, M., ... Walker, B. (2018). Effects of El Niño and La Niña Southern Oscillation events on the adrenocortical responses to stress in birds of the Galapagos Islands. General and comparative endocrinology, 259, 20-33.

Wojczulanis-Jakubas, K., Jakubas, D., Karnovsky, N. J., \& Walkusz, W. (2010). Foraging strategy of little auks under divergent conditions on feeding grounds. Polar Research, 29(1), 22-29.

Worthy, T. H., \& Holdaway, R. N. (1993). Quaternary fossil faunas from caves in the Punakaiki area, West Coast, South Island, New Zealand. Journal of the Royal Society of New Zealand, 23(2), 147-254.

Zango, L., Reyes-González, J. M., Militão, T., Zajková, Z., Álvarez-Alonso, E., Ramos, R., \& GonzálezSolís, J. (2019). Year-round individual specialization in the feeding ecology of a long-lived seabird. Scientific reports, 9(1), 1-12. 
Zarn, A. M., Valle, C. A., Brasso, R., Fetzner, W. D., \& Emslie, S. D. (2020). Stable isotope and mercury analyses of the Galápagos Islands seabird community. Marine Ornithology, 48, 71-80.

Zhang, J., Bell, E., \& Roberts, J. (2020). Demographic Assessment of Black Petrels (Procellaria parkinsoni) at Great Barrier Island (Aotea Island).

Zotier, R. (1990). Breeding ecology of a subantarctic winter breeder: the grey petrel Procellaria cinerea on Kerguelen Islands. Emu-Austral Ornithology, 90(3), 180-184.

Öst, M., Lindén, A., Karell, P., Ramula, S., \& Kilpi, M. (2018). To breed or not to breed: drivers of intermittent breeding in a seabird under increasing predation risk and male bias. Oecologia, 188(1), 129-138. https://doi.org/10.1007/s00442-018-4176-5 


\section{Appendix}

S1: Results of GLMM, testing the effects of phenotypic characteristics on Westland petrel foraging characteristics. * represents level of significance $(*=0.05, * *=0.01, * * *=0.001)$.

\begin{tabular}{|c|c|c|c|c|c|}
\hline & Estimate & std.Error & $\mathrm{df}$ & t value & $\operatorname{Pr}(>|t|)$ \\
\hline \multicolumn{6}{|c|}{ sqrt(Trip Duration) } \\
\hline (Intercept) & 38.73 & 34.18 & 11.61 & 1.13 & 0.28 \\
\hline Culmen Length & 0.07 & 0.49 & 15.50 & 0.15 & 0.88 \\
\hline Culmen Depth & -0.10 & 0.65 & 18.27 & -0.16 & 0.88 \\
\hline Culmen width & -0.56 & 0.56 & 17.65 & -1.01 & 0.33 \\
\hline Tarsus & 0.43 & 0.57 & 13.98 & 0.75 & 0.46 \\
\hline Wing & -0.13 & 0.11 & 13.66 & -1.17 & 0.26 \\
\hline \multicolumn{6}{|c|}{$\log$ (Max Distance from Colony) } \\
\hline (Intercept) & 3429.46 & 1880.20 & 10.53 & 1.82 & 0.10 \\
\hline Culmen Length & -16.15 & 26.99 & 15.01 & -0.60 & 0.56 \\
\hline Culmen Depth & 47.19 & 36.30 & 18.14 & 1.30 & 0.21 \\
\hline Culmen width & -40.22 & 31.13 & 17.41 & -1.29 & 0.21 \\
\hline Tarsus & -6.42 & 31.32 & 12.72 & -0.21 & 0.84 \\
\hline Wing & -4.64 & 5.93 & 12.62 & -0.78 & 0.45 \\
\hline \multicolumn{6}{|c|}{ sqrt(Total Distance Travelled) } \\
\hline (Intercept) & 5969000 & 5639000 & 9.34 & 1.06 & 0.32 \\
\hline Culmen Length & -6028 & 83400 & 16.26 & -0.07 & 0.94 \\
\hline Culmen Depth & 50220 & 113900 & 22.66 & 0.44 & 0.66 \\
\hline Culmen width & -184700 & 97350 & 20.75 & -1.90 & 0.07 \\
\hline Tarsus & 111400 & 94930 & 10.25 & 1.17 & 0.27 \\
\hline Wing & -22420 & 18030 & 11.21 & -1.24 & 0.24 \\
\hline \multicolumn{6}{|l|}{ Travelling Speed } \\
\hline (Intercept) & 27.17 & 36.77 & 7.22 & 0.74 & 0.48 \\
\hline Culmen Length & -0.75 & 0.56 & 14.43 & -1.34 & 0.20 \\
\hline Culmen Depth & 0.64 & 0.77 & 18.89 & 0.83 & 0.42 \\
\hline Culmen width & -0.60 & 0.66 & 17.68 & -0.92 & 0.37 \\
\hline Tarsus & 0.92 & 0.62 & 6.72 & 1.49 & 0.18 \\
\hline Wing & -0.07 & 0.12 & 8.48 & -0.60 & 0.56 \\
\hline \multicolumn{6}{|l|}{ \%Foraging } \\
\hline (Intercept) & 0.56 & 1.61 & 8.76 & 0.35 & 0.74 \\
\hline Culmen Length & -0.03 & 0.02 & 14.61 & -1.13 & 0.28 \\
\hline Culmen Depth & 0.04 & 0.03 & 18.46 & 1.21 & 0.24 \\
\hline Culmen width & 0.03 & 0.03 & 17.49 & 1.22 & 0.24 \\
\hline Tarsus & -0.01 & 0.03 & 9.87 & -0.27 & 0.79 \\
\hline Wing & 0.00 & 0.01 & 10.62 & 0.13 & 0.90 \\
\hline \multicolumn{6}{|c|}{ log(Foraging Distance) } \\
\hline (Intercept) & 1528.83 & 825.79 & 10.67 & 1.85 & 0.09 . \\
\hline Culmen Length & -16.14 & 11.39 & 12.77 & -1.42 & 0.18 \\
\hline Culmen Depth & -8.48 & 14.91 & 14.68 & -0.57 & 0.58 \\
\hline Culmen width & -14.20 & 12.86 & 14.30 & -1.11 & 0.29 \\
\hline Tarsus & 2.41 & 13.34 & 12.83 & 0.18 & 0.86 \\
\hline Wing & -0.64 & 2.54 & 12.20 & -0.25 & 0.81 \\
\hline \multicolumn{6}{|c|}{ log(Foraging duration) } \\
\hline (Intercept) & 10.51 & 8.12 & 10.96 & 1.30 & 0.22 \\
\hline Culmen Length & -0.03 & 0.10 & 10.22 & -0.29 & 0.77 \\
\hline Culmen Depth & 0.24 & 0.15 & 13.08 & 1.67 & 0.12 \\
\hline Culmen width & 0.07 & 0.13 & 16.69 & 0.52 & 0.61 \\
\hline Tarsus & 0.05 & 0.12 & 8.60 & 0.44 & 0.67 \\
\hline Wing & -0.04 & 0.02 & 9.92 & -1.62 & 0.14 \\
\hline \multicolumn{6}{|c|}{ log(Dist trav between foraging) } \\
\hline (Intercept) & 18.82 & 7.54 & 16.28 & 2.50 & $0.02 *$ \\
\hline Culmen Length & 0.10 & 0.10 & 17.00 & 1.07 & 0.30 \\
\hline Culmen Depth & -0.03 & 0.14 & 17.85 & -0.21 & 0.83 \\
\hline Culmen width & -0.26 & 0.13 & 26.00 & -2.01 & 0.05 . \\
\hline Tarsus & 0.13 & 0.11 & 11.13 & 1.23 & 0.25 \\
\hline Wing & -0.05 & 0.02 & 13.78 & -2.38 & 0.03 \\
\hline
\end{tabular}


S2: Details of environmental data used in chapter 3.

\begin{tabular}{lllll}
\hline Oceanographic variable & Abbreviation & \multirow{2}{*}{ Unit } & $\begin{array}{l}\text { Spatial/temporal } \\
\text { resolution }\end{array}$ & Product \\
\hline Seafloor Depth & Depth & $\mathrm{m}$ & $250 \mathrm{~m} /-$ & New Zealand Regional Bathymetry (2016) \\
Seafloor Slope & Slope & $\circ$ & $250 \mathrm{~m} /-$ & Derived from Depth \\
Chlorophyll-a & Chl-a & $\mathrm{mg} \mathrm{m}^{-3}$ & $4 \mathrm{~km} /$ daily & OCEANCOLOUR_GLO_CHL_L4_REP_OBSERVATIONS_009_082 \\
Sea surface temperature & SST & ${ }^{\circ} \mathrm{C}$ & $0.05^{\circ} /$ daily & SST_GLO_SST_L4_REP_OBSERVATIONS_010_011 \\
Windspeed & Wind_S & $\mathrm{ms}^{-1}$ & $0.25^{\circ} / 6$ hourly & WIND_GLO_WIND_L4_REP_OBSERVATIONS_012_006 \\
Wind direction & Wind_D & $\circ$ & $0.25^{\circ} / 6$ hourly & WIND_GLO_WIND_L4_REP_OBSERVATIONS_012_006
\end{tabular}


S3: Correlation matrix of environmental variables. Correlogram shows the size (circle size) and direction (colour) of correlation. $\mathrm{R}$ and $\mathrm{P}$-values are displayed below.

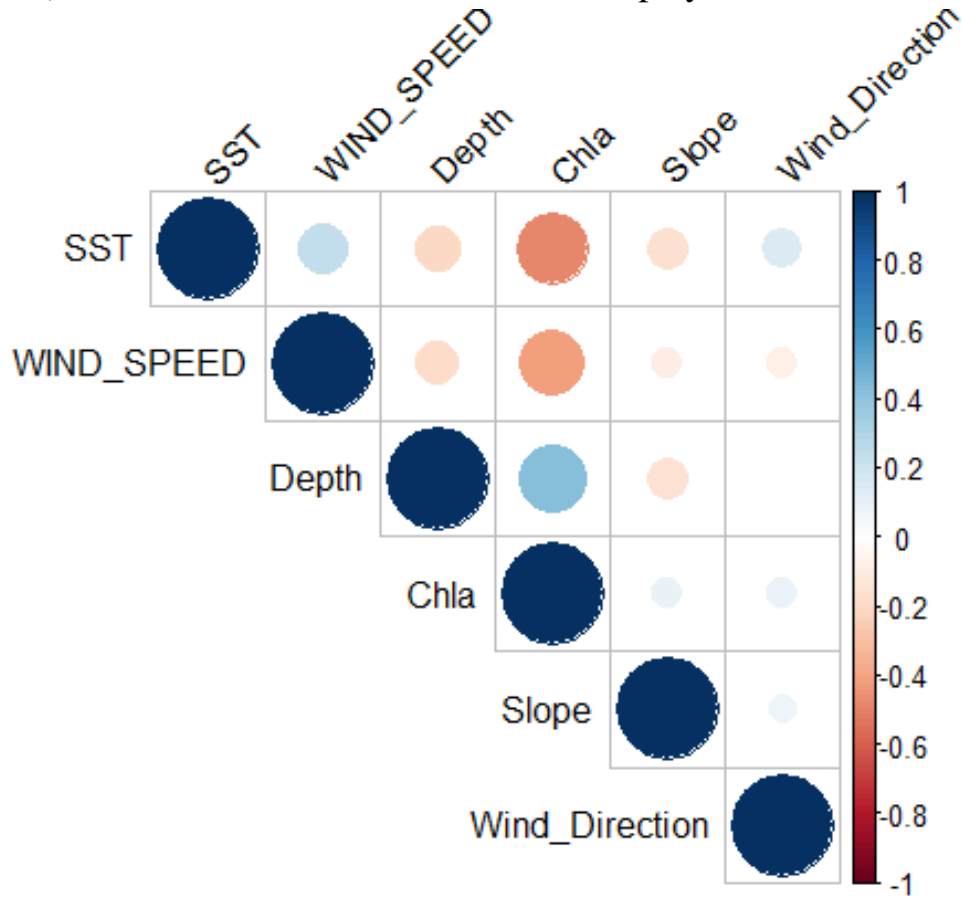

R-value

\begin{tabular}{|l|l|r|r|r|r|r|}
\hline & \multicolumn{1}{|l|}{ STope } & Depth & \multicolumn{1}{l|}{ Ch1-a } & \multicolumn{1}{l|}{ SST } & Wind_S & Wind_D \\
\hline Slope & 1.00 & -0.16 & 0.09 & -0.16 & -0.09 & 0.08 \\
\hline Depth & & 1.00 & 0.42 & -0.21 & -0.19 & -0.01 \\
\hline Ch1-a & & & 1.00 & -0.49 & -0.42 & 0.09 \\
\hline SST & & & & 1.00 & 0.24 & 0.15 \\
\hline Wind_S & & & & & 1.00 & -0.09 \\
\hline Wind_D & & & & & & 1.00 \\
\hline
\end{tabular}

P-values

\begin{tabular}{|c|c|c|c|c|c|c|}
\hline & Slope & Depth & chl-a & SST & Wind_S & Wind_D \\
\hline Slope & 0 & 0 & 0 & 0 & 0 & 0 \\
\hline Depth & & 0 & 0 & 0 & 0 & 0.3672 \\
\hline chl-a & & & 0 & 0 & 0 & 0 \\
\hline SST & & & & 0 & 0 & 0 \\
\hline Wind_S & & & & & 0 & 0 \\
\hline Wind_D & & & & & & 0 \\
\hline
\end{tabular}


S4: Tukey post-hoc outputs from the GLM comparing environmental characteristics among foraging sites. * represents level of significance (significance $(*=0.05, * *=0.01, * * *=0.001)$.

\begin{tabular}{c:cccc} 
& Estimate & std.Error & z value & p-value \\
\hline \hline Chl-a & & & & \\
South*North & -0.031 & 0.106 & -0.294 & 0.952 \\
WestCoast*North & -0.035 & 0.078 & -0.449 & 0.892 \\
WestCoast*South & -0.004 & 0.082 & -0.046 & 0.999 \\
\hline Windspeed & & & & \\
South*North & -0.049 & 1.529 & -0.032 & 0.999 \\
WestCoast*North & 0.152 & 1.123 & 0.136 & 0.99 \\
WestCoast*South & 0.201 & 1.191 & 0.169 & 0.984 \\
\hline Bathymetric Slope & & &
\end{tabular}

\begin{tabular}{r:cccc} 
Bathymetric Slope & & & & \\
South*North & 0.030 & 0.009 & 3.333 & $0.002 * *$ \\
WestCoast*North & -0.031 & 0.007 & -4.764 & $<0.001 * * *$ \\
WestCoast*South & -0.061 & 0.007 & -8.775 & $<0.001 * * *$ \\
\hline Seafloor Depth & & & & \\
South*North & 458.4 & 133.7 & 3.43 & $0.002 * *$ \\
WestCoast*North & 72.2 & 98.2 & 0.735 & 0.7364 \\
WestCoast*South & -386.1 & 104.1 & -3.71 & $<0.001 * * *$ \\
\hline SST & & & & \\
South*North & -0.160 & 0.411 & -0.39 & 0.917 \\
WestCoast*North & 0.659 & 0.302 & 2.183 & 0.071. \\
WestCoast*South & 0.819 & 0.320 & 2.56 & $0.027 * *$ \\
\hline Wind direction & & & & \\
South*North & -11.782 & 37.313 & -0.316 & 0.945 \\
WestCoast*North & -4.901 & 27.416 & -0.179 & 0.982 \\
WestCoast*South & 6.881 & 29.059 & 0.237 & 0.969
\end{tabular}

